\section{D) Check for updates}

Cite this: Nat. Prod. Rep., 2019, 36, 593

\title{
Metabolic functions of the human gut microbiota: the role of metalloenzymes
}

\author{
Lauren J. Rajakovich (iD and Emily P. Balskus (D)*
}

Covering: up to the end of 2017

The human body is composed of an equal number of human and microbial cells. While the microbial community inhabiting the human gastrointestinal tract plays an essential role in host health, these organisms have also been connected to various diseases. Yet, the gut microbial functions that modulate host biology are not well established. In this review, we describe metabolic functions of the human gut microbiota that involve metalloenzymes. These activities enable gut microbial colonization, mediate interactions with the host, and impact human health and disease. We highlight cases in which enzyme characterization has advanced our understanding of the gut microbiota and examples that illustrate the diverse ways in which metalloenzymes facilitate both essential and unique functions of this community. Finally, we analyze Human Microbiome Project sequencing datasets to assess the distribution of a prominent family of metalloenzymes in human-associated microbial communities, guiding future enzyme characterization efforts.

Received 14th August 2018

DOI: $10.1039 / \mathrm{c} 8 \mathrm{np} 00074 \mathrm{c}$

rsc.li/npr

our gut from infancy and plays a critical role in the development

1 Introduction

2 Commensal colonization of the human gut: fitness and adaptation

2.1 Glycan sulfation

2.2 Glycan fucosylation

3 Colonization resistance to pathogenic microbes

4 Biosynthesis of essential nutrients

4.1 Vitamin biosynthesis

4.2 Queuosine biosynthesis

5 Production of host immune-modulatory metabolites

6 Gut microbial metabolism linked to human disease

6.1 Trimethylamine production

6.2 $p$-Cresol production

6.3 Ammonia production

6.4 Hydrogen sulfide production

7 Microbial metabolism of xenobiotics

8 Metalloenzyme abundance in human microbiomes

9 Conclusions

10 Conflicts of interest

11 Acknowledgements

12 References

\section{Introduction}

The human gastrointestinal (GI) tract harbors a unique and complex microbial ecosystem consisting of trillions of bacteria, fungi, archaea, and viruses. This microbial community inhabits

Department of Chemistry and Chemical Biology, Harvard University, USA. E-mail: balskus@chemistry.harvard.edu and maintenance of healthy human physiology. It aids in developing the innate and adaptive immune systems, ${ }^{1,2}$ provides nutrients and vitamins, ${ }^{3}$ and protects against pathogen invasion. ${ }^{4}$ Counter to its vital role in normal physiology, the gut microbiota has also been linked to a wide range of human diseases. ${ }^{5}$ Unsurprisingly, many of these conditions are localized to the gastrointestinal tract, including colorectal cancer $^{6}$ and inflammatory bowel diseases (IBD) ${ }^{7}$ like Crohn's disease and ulcerative colitis. However, the gut microbiota has also been connected with systemic diseases, such as obesity and diabetes, ${ }^{8}$ and with maladies of distal organs, including neurological and cardiovascular disorders., ${ }^{9,10}$

The intriguing relationship between the gut microbiota and its host elicits fundamental questions about the composition of this community in both health and disease states, the gut microbial functions that influence host biology, and ultimately, the ways that this knowledge can be leveraged to improve human health. Over the last decade and a half, the application of next-generation sequencing has significantly advanced the field toward addressing the first point. ${ }^{11}$ Taxonomic profiling of gut microbial communities has shown that only two bacterial phyla, Bacteroidetes and Firmicutes, typically dominate this habitat in healthy western populations..$^{12,13}$ However, the bacteria within these two phyla that constitute the community have been found to vary greatly in healthy populations depending on geography, age, and environmental factors. $^{14,15}$ These discoveries have dispelled the concept of a core community of gut bacteria that are characteristic of a healthy person. Instead, the focus has shifted toward defining 
conserved microbial functions that promote host health or affect disease susceptibility. ${ }^{16}$

The metabolic potential of the gut microbiota greatly surpasses that of the host as its genetic content exceeds that of the human genome 150 -fold. ${ }^{17,18}$ Consequently, gut microbes produce a vast set of small molecules that are often chemically distinct from those generated by host metabolism. ${ }^{19}$ The nature of these metabolites and their abundance can vary substantially between individuals depending on the composition of their gut microbiota and dietary intake. ${ }^{20}$ In many cases, metabolites produced by the host and the gut microbiota are exchanged and can be co-metabolized to generate molecules that can have unique consequences in the context of the human body. ${ }^{21}$ Indeed, many microbially-produced metabolites have been strongly correlated with human disease. ${ }^{22}$ Thus, the chemical output of microbial metabolism is becoming recognized as a critical component of human health and disease. However, we currently lack a molecular understanding of gut microbial metabolic activities. Bacteria from this habitat are often difficult to cultivate in the laboratory. In addition, bacteria of the same genus and even from the same species can have substantially divergent metabolic capabilities. Therefore, taxonomic profiling, which at present is limited to genus level assignments, is insufficient to provide an accurate assessment or prediction of the metabolic functions of the gut microbiota.

The identification of specific organisms, genes, and enzymes responsible for metabolic functions of interest will improve our understanding of the metabolic potential of the gut microbiota and its role in host health and disease. Metagenomic, metatranscriptomic and metaproteomic approaches are currently used to profile the gut microbiota on a community level. Ideally, specific genes, transcripts, or proteins could be used as indicators in complex meta'omic data to predict the presence of a metabolic function and potentially serve as a personalized read-out of health status. Microbial enzymes could even be direct targets for therapeutics. ${ }^{23,24}$ However, the present challenge to leverage this type of analysis or manipulate gut microbial functions is that only $\sim 50 \%$ of genes from human stool metagenomes can be assigned a broad functional annotation and less than half of that $50 \%$ can be given more descriptive annotations. ${ }^{25}$ This gap in knowledge limits our understanding of the metabolic functions of the gut microbiota and the molecular basis of the diseases linked to this community. This vast area of unexplored biochemical space creates a need, as well as great opportunity, for biochemists and chemical biologists to contribute to this exciting field.

Metalloenzymes are an important class of enzymes for all domains of life. In enzyme catalysis, metallocofactors enable unique molecular rearrangements and transformations of relatively chemically inert molecules. In particular, anaerobic microbes often use metalloenzymes to promote radical catalysis, which presents challenges in aerobic environments due to the reactivity of dioxygen with organic radical intermediates. ${ }^{26}$ In the anoxic environment of the human colon, anaerobic bacteria deploy metalloenzymes to perform many interesting metabolic functions. These metal-dependent transformations can enable gut microbes to access nutrients or energy from alternative substrates or to generate molecules that can have important consequences for the host. This review describes unique metabolic functions of the human gut microbiota that involve metalloenzymes. Rather than providing a comprehensive account of all extant metalloenzymes employed by gut microbes for housekeeping functions, we will focus on enzymatic transformations that enable gut microbes to interact with their environment, pathogens, ingested compounds (dietary molecules and xenobiotics), and the human host. Finally, we evaluate the prevalence and distribution of the major families of metalloenzymes across the healthy human microbiota, with the goal of inspiring further investigation into characterized and

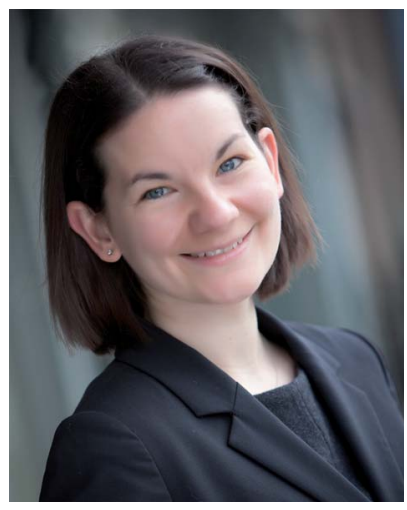

Emily Balskus received her BA from Williams College and her $P h D$ in synthetic organic chemistry from Harvard University, where she worked with Eric Jacobsen. Her postdoctoral studies at Harvard Medical School with Christopher $T$. Walsh focused on deciphering the biosynthesis of cyanobacterial sunscreens. She began her independent career at Harvard University in 2011 and is now a Professor of Chemistry and Chemical Biology. Her research program explores the intersection of organic chemistry, biochemistry, and microbiology, with a major focus on understanding metabolic activities of the human microbiota and their contributions to host health and disease. 
uncharacterized microbial enzymes that play important roles in human biology.

\section{Commensal colonization of the human gut: fitness and adaptation}

The dense population of microbes in the human gut creates a highly competitive environment for nutrient resources. Consequently, commensal organisms utilize a variety of energy sources for colonization and survival in this ecological niche. Carbohydrates are rich energy sources that gut microbes obtain from the diet, the colonic mucosal layer, and epithelial cell debris. ${ }^{27}$ The dietary carbohydrates that microbes access are complex polysaccharides typically derived from plant components that the human host is unable to digest. ${ }^{28}$ Whereas the availability of these exogenous carbohydrates depends on host intake, the mucosal layer of the GI tract provides a constant and accessible endogenous supply of glycans for microbial consumption. This mucosal lining is a matrix primarily composed of glycoproteins (e.g., mucins) that serves as a barrier between the colonic epithelial cells and the microbes that reside in the lumen. ${ }^{29}$ Commensal bacteria, notably strains of Bacteroides, Akkermansia, Ruminococcus and Bifidobacteria, are known to utilize mucins as energy sources, ${ }^{30}$ which contributes to their population stability in the community. Additionally, there is evidence for cooperative degradation of mucin polysaccharides by multiple bacteria, suggesting a role for this metabolism in ecology structure in the gut. ${ }^{31,32}$ However, an over-abundance of mucin-degraders has been noted in patients with inflammatory bowel diseases, suggesting that microbes can compromise this protective layer and induce an immune response..$^{30}$ Enteric pathogens have also evolved to take advantage of this mucusderived resource to breakdown this protective barrier and enable infection. ${ }^{33}$

Gut microbes produce specialized enzymes for reducing both host and dietary polysaccharides into smaller units for energy. ${ }^{34}$ For example, Bacteroides thetaiotaomicron (B. theta) is one of the most prevalent and prominent members of the gut microbiota in average healthy adult humans (found in $46 \%$ of individuals from the HMP cohort at a mean abundance of $0.6 \%)^{13,35}$ and excels at carbohydrate metabolism. ${ }^{36-38}$ Nearly $20 \%$ of its genome is dedicated to degradation of these macromolecules, ${ }^{37}$ allowing $B$. theta to access carbohydrates from various sources depending on their availability. Transcriptional responses to available carbohydrates in mice colonized with $B$. theta revealed the ability of this bacterium to prioritize transient dietary resources when available and forage alternative resources (e.g., mucin) when ingested polysaccharides have been depleted. ${ }^{39}$ This expanded metabolic repertoire may explain why $B$. theta is a prominent colonizer of the healthy human gut. Indeed, deletion of only a small subset of the carbohydrate metabolism genes impaired the ability of B. theta to persist in the gut of a mouse model and to be transmitted vertically to offspring. ${ }^{37}$

The carbohydrate active enzymes of gut microbes act upon polysaccharides that are diverse in monosaccharide composition, linkages, and modifications..$^{30,32,40}$ Metalloenzymes in particular help with the degradation of polysaccharides containing two common modifications: (i) sulfation and (ii) fucosylation. These modifications are especially abundant on glycans that make up the mucus layer of the GI tract.

\subsection{Glycan sulfation}

Glycosaminoglycans, such as chondroitin and heparin, and mucin sugars like galactose and $N$-acetylglucosamine found in the gut mucosa are commonly modified with sulfate groups. ${ }^{40-43}$ Removal of this modification is a prerequisite for further utilization of the mucus-derived monosaccharides and is postulated to be the rate-limiting step in mucin breakdown. ${ }^{44-46}$ Gut microbes possess exo- and endo-sulfatases that desulfate both simple and complex carbohydrates (Fig. 1a). ${ }^{47-51}$ While sulfatase activity plays an integral role in nutrient acquisition and bacterial colonization, there is accumulating evidence connecting it with intestinal inflammation. Sulfatase genes were shown to be essential for inducing $B$. theta triggered colitis in a susceptible mouse model, ${ }^{52}$ and increased sulfatase activity was detected in fecal samples of patients with ulcerative colitis. ${ }^{45,53}$ Thus, the potential role of this microbial activity in development of disease phenotypes suggests it could represent a target for therapeutics.

Sulfatases are ubiquitous throughout all domains of life and can be delineated into three main groups: the Zn-dependent alkylsulfatases, the Fe-dependent dioxygenase sulfatases, and the formylglycine-dependent sulfatases. ${ }^{54,55}$ The latter class constitutes the largest group, and its members are frequently encoded in the genomes of gut microbes ${ }^{48,55}$ These sulfatases employ a unique post-translational $\mathrm{C} \boldsymbol{\alpha}$-formylglycine (fGly) modification that is critical for activity (Fig. 1b)..$^{56}$ The hydrated gem-diol form of the fGly cofactor (Fig. 1b) has been observed in crystal structures of both eukaryotic and prokaryotic homo$\operatorname{logs},{ }^{57,58}$ implicating it as the catalytically relevant form. The proposed mechanism involves nucleophilic attack of a deprotonated alcohol of the gem-diol onto the sulfur atom of the sulfate monoester, eliminating the attached sugar and forming a sulfated-enzyme intermediate..$^{59,60}$ Deprotonation of the second hydroxyl group would then promote release of sulfate from this tetrahedral intermediate, regenerating the aldehyde cofactor.

The catalytic fGly residue originates from either an active site cysteine (in eukaryotes ${ }^{56,61}$ and prokaryotes ${ }^{62-64}$ ) or serine (in prokaryotes ${ }^{63,65,66}$ ) residue that is post-translationally modified by a separate maturase enzyme (Fig. 1b). The type of maturase found in eukaryotes and some prokaryotes, termed formylglycine-generating enzyme (FGE), is dioxygen-dependent and operates through an acid-base mechanism without the use of a cofactor. ${ }^{61,67,68}$ In prokaryotes, two other types of maturases have been identified, ${ }^{64,66,69,70}$ the best studied of which are the bacterial anaerobic sulfatase-maturating enzymes (anSMEs). The anSMEs are commonly found in the anaerobic bacteria that inhabit the human gut. This class of maturase is oxygensensitive and uses radical chemistry to generate the fGly 


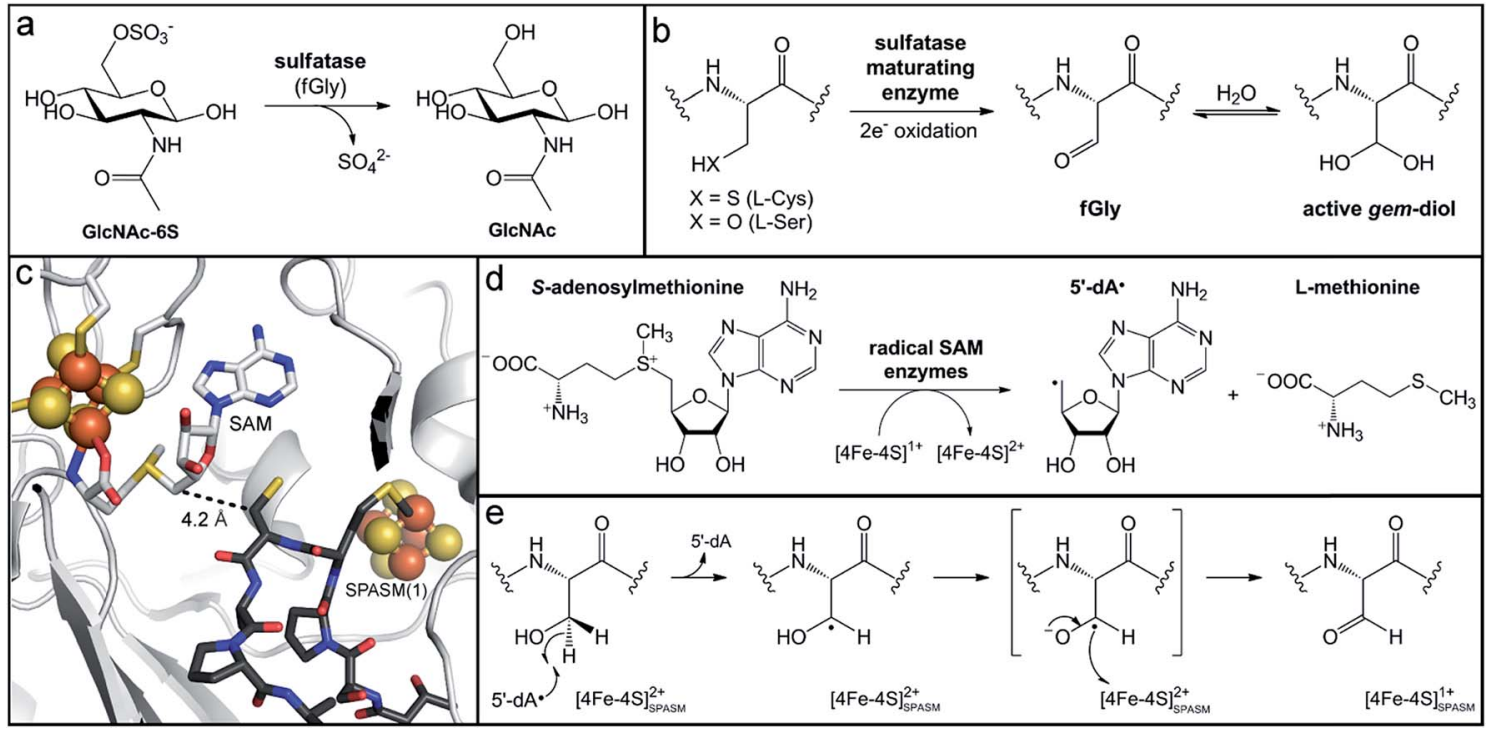

Fig. 1 Maturation of gut microbial sulfatases by the radical SAM anSMEs. (a) Sulfate removal from an N-acetyl-glucosamine-6-sulfate substrate by sulfatases harboring an formylglycine (fGly) cofactor. (b) Post-translational modification of a sulfatase L-serine or L-cysteine residue to an fGly residue that is hydrated to the gem-diol active form. (c) Depiction of the anaerobic sulfatase maturating enzyme (PDB accession code: 4K38) with SAM coordinating the radical SAM cluster and a peptide substrate analogue (dark grey sticks) bound in the active site. (d) Reductive cleavage of $S$-adenosylmethionine (SAM) by the radical SAM $[4 \mathrm{Fe}-4 \mathrm{~S}]^{1+}$ cluster to generate $5^{\prime}$-deoxyadenosine radical $\left(5^{\prime} \mathrm{dA} \cdot\right)$ and $\mathrm{L}-\mathrm{methionine}$. (e) Proposed mechanism for fGly generation by anSMEs.

cofactor. ${ }^{64,69,71}$ AnSMEs belong to the large superfamily of radical $S$-adenosylmethionine (SAM) enzymes, which harbor an essential $[4 \mathrm{Fe}-4 \mathrm{~S}]$ cluster within a $\beta$-barrel structural domain. ${ }^{72}$ Three iron ions of the cluster are ligated by cysteine residues in a strictly conserved $\mathrm{CX}_{3} \mathrm{CX}_{2} \mathrm{C}$ sequence motif, and the fourth iron ion is coordinated by the enzyme co-substrate, SAM (Fig. 1c). ${ }^{72}$ The canonical function of this metallocofactor is to reductively cleave the $5^{\prime}-\mathrm{C}-\mathrm{S}^{+}$bond of SAM (Fig. 1d) to generate the potent one-electron oxidant, $5^{\prime}$-deoxyadenosyl radical $\left(5^{\prime}\right.$ $\mathrm{dA} \cdot$ ), which then initiates subsequent radical chemistry. ${ }^{72-75}$ In the anSMEs, the $5^{\prime}-\mathrm{dA} \cdot$ abstracts the pro- $S$ - $\mathrm{C}_{\beta}$-hydrogen ${ }^{76,77}$ of the target sulfatase Cys/Ser residue located in close proximity to the radical SAM cluster (Fig. 1c), generating a $\mathrm{C}_{\beta}$-centered radical (Fig. 1e). Deprotonation of the residue's thiol or alcohol group is proposed to result in a transient radical anion intermediate that is oxidized to the (thio)aldehyde (Fig. 1e). In the case of cysteine modification, hydrolysis of the thioaldehyde would yield the final fGly functional group.

The anSMEs are members of a subclass of the radical SAM superfamily comprised of proteins that have a C-terminal "SPASM" (subtilosin, PQQ, anSME, mycofactocin) domain. ${ }^{78}$ SPASM domains possess additional cysteine-rich sequence motifs, which coordinate at least one auxiliary [2Fe-2S] or [4Fe$4 \mathrm{~S}$ ] cluster. ${ }^{78}$ The postulated roles of these clusters differ from the canonical function of the radical SAM iron-sulfur cluster because they are not known to catalyze cleavage of SAM. Instead they are purported to mediate electron transfer during catalysis and/or aid in substrate positioning and activation. In the case of the anSMEs, Mössbauer-spectroscopic characterization and crystal structures of both Cys- and Ser-type anSMEs determined that the SPASM domain harbors two additional [4Fe-4S] clusters. ${ }^{77,79,80}$ Their positions in the protein structure, one close to the radical SAM cluster (Fig. 1c) and the other near the protein surface, ${ }^{\mathbf{8 0}}$ suggest that they constitute an electron transfer relay pathway to mediate the final oxidation of the radical anion intermediate to the product (Fig. 1e). This relay ultimately shuttles the electron to acceptors in solution that can reduce the oxidized radical SAM $[4 \mathrm{Fe}-4 \mathrm{~S}]^{2+}$ cluster to enable multiple turnovers, as is observed in vitro. ${ }^{77,79}$

The crystal structure of the anSME AtsB in the presence of a peptide substrate analogue (Fig. 1c) demonstrated the mode of binding of the sulfatase polypeptide, ${ }^{80}$ and suggested a possible rationale for substrate promiscuity. The majority of substrate peptide contacts to the anSME protein are established through the peptide backbone, instead of the residue side chains. ${ }^{\mathbf{8 0}}$ Though the sequence immediately following the target Cys/Ser has a distinct pattern $[(\mathrm{C} / \mathrm{S}) \mathrm{X}(\mathrm{P} / \mathrm{A}) \mathrm{XR}]{ }^{81}$ this mode of interaction would enable recognition of diverse peptide sequences for maturation. This promiscuity appears to be biologically important as analysis of bacterial genomes often reveals numerous sulfatases, but only a few or just a single anSME. ${ }^{\mathbf{2}}$ Indeed, in $B$. theta, mutation of the single anSME present in its genome dramatically reduced the ability of the organism to utilize sulfated mucin and glycosaminoglycan carbohydrates as energy sources for growth in vitro. ${ }^{82}$ This deficiency manifested in vivo as reduced fitness to persist or colonize in the gut of a germ-free mouse when introduced in competition with or after colonization of the wild-type strain, respectively. ${ }^{82}$ Thus, disruption of this single, metallocofactor-containing maturase enzyme dramatically altered the metabolic capabilities of this organism that allow it to thrive in the gut environment. 


\subsection{Glycan fucosylation}

Mucin glycans are often terminally decorated with the simple sugar monomers L-fucose and sialic acid. ${ }^{30}$ These host-derived glycan modifications are critical mediators of host-microbe interactions, influencing the composition of the intestinal microflora by enriching microbes capable of hydrolyzing and consuming these sugars. ${ }^{83}$ Interestingly, the genomes of $\sim 20 \%$ of the human population encode for a non-functional fucosyltransferase (Fut2) that normally adds terminal L-fucose molecules to glycans, ${ }^{\mathbf{8 4}}$ and this genotype has been associated with decreased microbiota diversity and a higher risk for Crohn's disease ${ }^{85-87}$ Conversely, gut bacteria can influence host mucin fucosylation patterns for their own benefit. The commensal microflora, or even a single bacterium (e.g., B. theta), has been observed to stimulate host glycan fucosylation during enterocyte differentiation $^{\mathbf{8 8 , 8 9}}$ and in response to pathogen invasion. ${ }^{\mathbf{9 0}}$ This interaction allows gut bacteria to maintain a sufficient nutrient supply. For example, metabolism of L-fucose gives
B. theta a growth advantage in a competitive environment ${ }^{89}$ and L-fucose scavenged by Bacteroides fragilis is used for construction of their own polysaccharide cellular components and confers a fitness advantage in vivo. ${ }^{91}$ However, the simple sugars released by glycosidases that are secreted from commensal organisms can alternatively be co-opted by pathogenic organisms when the gut microbiota has been compromised..$^{92}$ Thus, although L-fucose metabolism is critical in shaping and maintaining the commensal microbial community, it can also facilitate expansion of enteric pathogens.

The L-fucose sugars released from polysaccharides can have multiple fates depending on the degrading organism and the environmental conditions. One of the pathways, termed the "fucose utilization" ( fuc) pathway, starts with steps similar to those of glycolysis, involving aldol cleavage to yield lactaldehyde and dihydroxyacetone phosphate. ${ }^{93}$ The lactaldehyde product is then reduced to $(S)$-1,2-propanediol (Fig. 2a), ${ }^{93}$ which can be further metabolized either oxidatively or reductively. In the oxidative pathway, known as the "propanediol utilization" ( $p d u)$

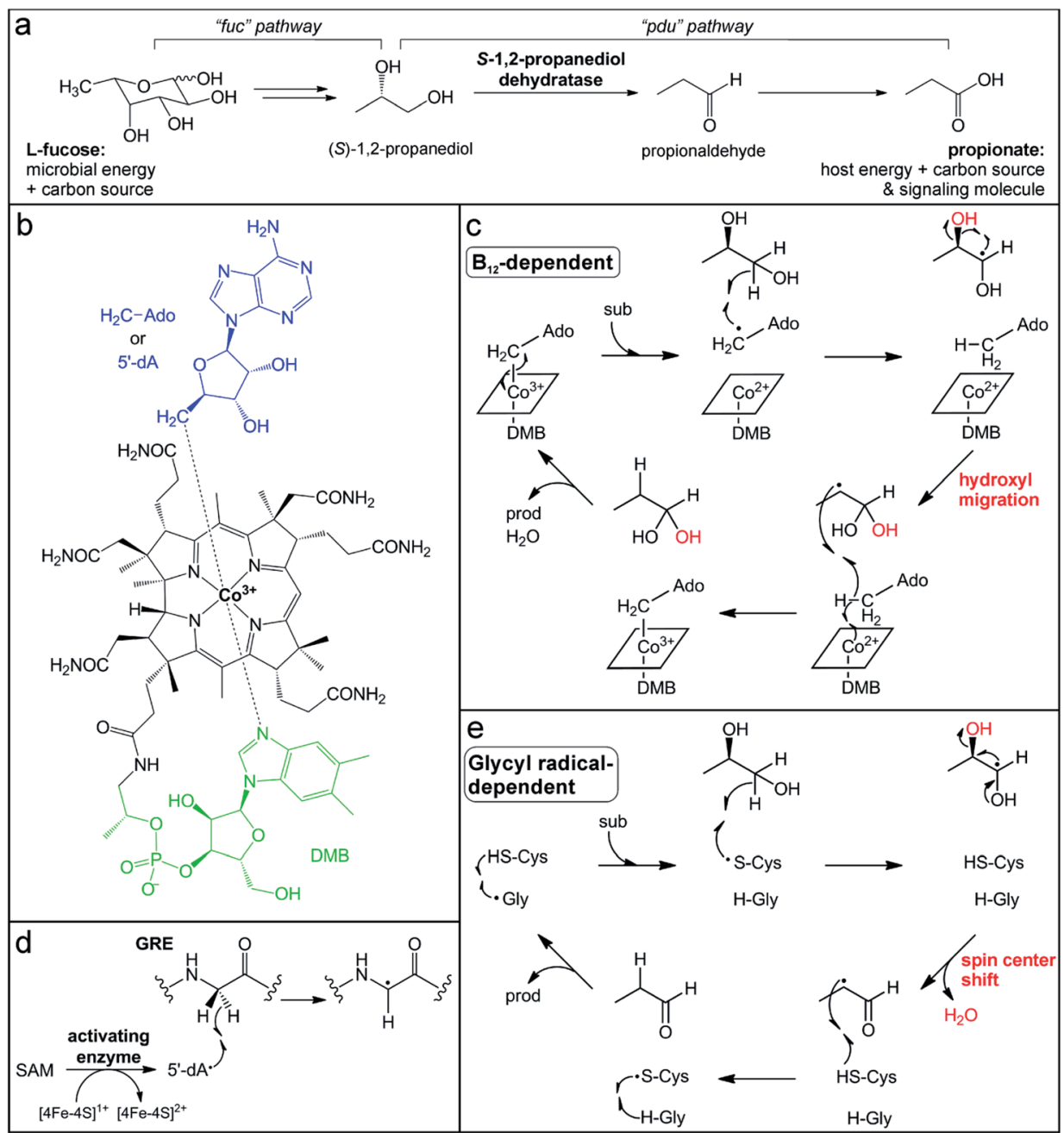

Fig. 2 Participation of $\mathrm{B}_{12}$-dependent and glycyl radical-dependent enzymes in gut microbial L-fucose metabolism. (a) Propionate generation via the L-fucose and (S)-1,2-propanediol utilization pathways (fuc and pdu, respectively). (b) Structure of adenosylcobalamin in the "base-on" form. (c) Proposed mechanism for (S)-1,2-propanediol dehydration catalyzed by the $\mathrm{B}_{12}$-dependent enzyme PduC invoking a hydroxyl migration step. (d) Glycyl radical installation by the radical SAM activating enzyme. (e) Proposed mechanism for (S)-1,2-propanediol dehydration catalyzed by the GRE dehydratase involving a spin center shift. 
pathway, $(S)$-1,2-propanediol is converted via the intermediate propionaldehyde to the short-chain fatty acid propionate (Fig. 2a). ${ }^{94}$ Short-chain fatty acids are common products of gut microbial fermentation of carbohydrates and amino acids and have been noted for their beneficial effects on host biology. ${ }^{95-98}$ Most notably, they can serve as an energy source for colonic epithelial cells, contributing $\sim 10 \%$ of the human daily caloric requirement. ${ }^{99}$ In addition, short-chain fatty acids can serve as health-promoting signaling molecules in host cells. Propionate, in particular, has been connected with beneficial health effects, such as lowering lipid biosynthesis and serum cholesterol levels, and reducing carcinogenesis. ${ }^{\mathbf{1 0 0}}$

The penultimate step in the metabolism of $\mathrm{L}$-fucose to propionate is the dehydration of $(S)$-1,2-propanediol to propionaldehyde (Fig. 2a). This reaction is catalyzed by two different microbial enzymes that each requires a metallocofactor for either enzyme activation or catalysis. The $\mathrm{B}_{12}$-dependent $(S)$-1,2propanediol dehydratase (PduC) has been extensively characterized since its identification over 50 years ago. ${ }^{\text {101-104 }}$ PduC exists as a dimer of heterotrimeric subunits in an $\alpha_{2} \beta_{2} \gamma_{2}$ stoichiometry with the vitamin $\mathrm{B}_{12}$ (cobalamin) cofactor located at the $\alpha \beta$ interface of each monomer. ${ }^{105}$ The cobalamin cofactor consists of a tetrapyrrole corrin ring structure, which provides four equatorial nitrogen ligands to coordinate a cobalt ion at the center (Fig. 2b). ${ }^{\mathbf{1 0 3 , 1 0 6 - 1 0 8}}$ Spectroscopic ${ }^{\mathbf{1 0 9 , 1 1 0}}$ and structural $^{105,111,112}$ characterization determined that a 5,6-dimethylbenzimidazole (DMB) moiety extending from the corrin ring coordinates the cobalt ion in the lower axial position in "baseon" form and a $5^{\prime}$-deoxyadenosine molecule occupies the upper axial position (Fig. 2b). In the resting state, the cobalt ion of the cofactor is in the $3+$ oxidation state with a $\mathrm{Co}-\mathrm{C}$ coordination bond to the $5^{\prime}$-deoxyadenosine (adenosylcobalamin).

The conserved first step in the mechanism of adensoylcobalamin enzymes is homolytic cleavage of this $\mathrm{Co}-\mathrm{C}$ bond to generate a $\mathrm{Co}^{2+}$ center and $5^{\prime}$-dA $\cdot($ Fig. $2 \mathrm{c}),{ }^{104}$ the same radical oxidant generated by radical SAM enzymes. Many factors trigger activation of the Co-C bond, including cofactor and substrate binding to the enzyme active site, as well as kinetic coupling to the subsequent hydrogen atom abstraction step. ${ }^{\mathbf{1 1 3 , 1 1 4}}$ In $(S)-1,2-$ propanediol dehydratase, two different metal ions, a $\mathrm{K}^{+}$ion and a $\mathrm{Ca}^{2+}$ ion, are thought to contribute to activation of the $\mathrm{Co}-\mathrm{C}$ bond. An essential $\mathrm{K}^{+}$ion binds in the protein active site near the adenine ring, inducing a protein conformational change and resulting in $\mathrm{Co}-\mathrm{C}$ bond cleavage even in the absence of substrate. ${ }^{\mathbf{1 1 1 , 1 1 2 , 1 1 5}}$ The substrate coordinates a $\mathrm{Ca}^{2+}$ ion via its two hydroxyl groups, thereby increasing its effective size and resulting in a larger energetic release upon binding, ${ }^{\mathbf{1 1 1}, \mathbf{1 1 2 , 1 1 6}}$ which could balance the energetic cost of $\mathrm{Co}-\mathrm{C}$ bond cleavage. ${ }^{117}$

When the Co-C bond cleavage event occurs in the presence of substrate, the resultant $5^{\prime}-\mathrm{dA} \cdot$ abstracts a hydrogen atom from the $\mathrm{C} 1$ position of $(S)$-1,2-propanediol to generate an $\alpha$-hydroxyalkyl substrate radical (Fig. 2c). ${ }^{118}$ Based on the crystal structure, this $\mathrm{C}-\mathrm{H}$ bond cleavage would necessitate rotation about the glycosidic bond to bring the $5^{\prime}$-dA radical in close proximity to the target carbon. ${ }^{\mathbf{1 0 4 , 1 1 2 , 1 1 9}}$ The substrate-based radical then undergoes hydroxyl group migration from the
C2 position to generate a $\mathrm{C} 1$ gem-diol intermediate with a C2-centered radical (Fig. 2c). ${ }^{120}$ This migration is mediated by acidic and basic residues in the active site, as well as the aforementioned $\mathrm{Ca}^{2+}$ ion that interacts with the two hydroxyl groups of the substrate. ${ }^{\mathbf{1 1 1}, \mathbf{1 1 2}, \mathbf{1 1 6}}$ This mechanism is consistent with the observed retention of the ${ }^{18} \mathrm{O}$-label in the product when using a C2- ${ }^{18} \mathrm{O}$-isotopically labeled substrate. ${ }^{120,121}$ The C2-centered substrate radical then abstracts a hydrogen atom from the same $5^{\prime}$-deoxyadenosine molecule that initiated chemistry, ${ }^{122,123}$ regenerating the $5^{\prime}-\mathrm{dA} \cdot$ that can reform the Co-C bond with concomitant oxidation of $\mathrm{Co}^{2+}$ to $\mathrm{Co}^{3+}$ (Fig. 2c). Finally, dehydration of the $\mathrm{C} 1$ gem-diol intermediate yields the final propionaldehyde product.

Recently, another enzyme from a different superfamily was discovered to catalyze the same $(S)$-1,2-propanediol dehydration reaction. ${ }^{\mathbf{1 2 4 , 1 2 5}}$ Transcriptional analysis of the gut microbe Roseburia inulinivorans grown on L-fucose as a carbon source noted the absence of a $\mathrm{B}_{12}$-dependent $(S)$-1,2-propanediol dehydratase, PduC. ${ }^{\mathbf{1 2 6}}$ Instead, a member of the glycyl radical enzyme (GRE) superfamily was observed in a gene cluster that was up-regulated during L-fucose growth. ${ }^{\mathbf{1 2 6}}$ GREs utilize an active site glycyl radical to initiate radical chemistry. ${ }^{127}$ This radical is installed post-translationally by a dedicated partner activating enzyme (GRE-AE) that belongs to the radical SAM superfamily. ${ }^{128}$ The canonical $[4 \mathrm{Fe}-4 \mathrm{~S}]^{1+}$ cluster in the activating enzyme reductively cleaves SAM to generate the $5^{\prime}$-dA - oxidant, which abstracts a hydrogen atom from the active site glycine in the partner GRE protein (Fig. 2d). ${ }^{\mathbf{1 2 7 , 1 2 8}}$ The glycyl radical is then thought to react with a nearby conserved and essential cysteine residue to generate a thiyl radical that acts on the substrate. ${ }^{127,129}$ In the $(S)$-1,2-propanediol dehydration reaction, the thiyl radical is proposed to abstract a hydrogen atom from the $\mathrm{C} 1$ position of the substrate (Fig. $2 \mathrm{e}$ ), ${ }^{\mathbf{1 2 4}}$ in a step analogous to the $\mathrm{C}-\mathrm{H}$ bond cleavage by the $5^{\prime}-\mathrm{dA} \cdot$ in the $\mathrm{B}_{12}$-dependent enzyme. However, the mechanisms of the GRE and the $\mathrm{B}_{12}$ dependent dehydratases are thought to diverge from this point. Instead of hydroxyl group migration, the resultant C1-based radical intermediate in the GRE mechanism is postulated to undergo a spin center shift to the $\mathrm{C} 2$ position. In this mechanism (Fig. 2e) supported by computational studies, ${ }^{\mathbf{1 2 6 , 1 2 7}}$ deprotonation of the $\mathrm{C} 1$ hydroxyl group initiates elimination of the C2 hydroxyl group with concomitant formation of the C1 aldehyde and radical migration (Fig. 2e). ${ }^{\mathbf{1 3 0 , 1 3 1}}$ This elimination mechanism is consistent with the observed loss of the ${ }^{18} \mathrm{O}$-label in the product when using a $\mathrm{C} 2-{ }^{18} \mathrm{O}$-isotopically labeled substrate. ${ }^{121}$ Hydrogen atom abstraction by the $\mathrm{C} 2$ alkyl radical from the catalytic cysteine thiol regenerates the thiyl radical and forms the propionaldehyde product. At the end of each cycle, the radical migrates back to the initial conserved glycine residue.

These two enzymes represent a striking example of convergent enzyme evolution. They carry out identical dehydration reactions of (S)-1,2-propanediol, yet have different mechanisms to generate the initial radical and stabilize different substratebased radical intermediates during catalysis. One feature they share is the ability to recycle or store the radical oxidant that activates the substrate, enabling catalytic turnover. However, 
the protein-based radicals of GREs and the metallocofactor of their activating enzymes are extremely sensitive to oxidation and enzyme inactivation by dioxygen or reactive oxygen species. ${ }^{\mathbf{1 2 2 , 1 2 8 , 1 2 9}}$ Consequently, expression of the GRE $(S)-1,2-$ propanediol dehydratase and fermentation of $(S)$-1,2-propanediol are induced in low-oxygenic or anaerobic conditions in the gut environment. ${ }^{\mathbf{1 2 6}}$ In contrast, the $\mathrm{B}_{12}$-dependent enzyme is less vulnerable to oxidation, ${ }^{94}$ which may allow for gut microbes possessing this enzyme to utilize L-fucose under conditions of host intestinal inflammation when oxygen levels are higher. ${ }^{132,133}$ Interestingly, the $\mathrm{B}_{12}$-dependent dehydratases are primarily found in opportunistic enteric pathogens, including Salmonella and Klebsiella, perhaps enabling their expansion in the inflamed gut. ${ }^{134}$ Indeed, the expression of the $\mathrm{B}_{12}$-dependent enzyme in Salmonella enterica serovars Typhimurium confers a fitness advantage and is considered a genetic determinant of pathogenicity. ${ }^{\mathbf{1 3 5}}$ Conversely, the GREs have been identified more often in commensal organisms of the Clostridia class. ${ }^{\mathbf{1 2 4 , 1 2 5}}$ This observation suggests the possibility of targeting the pathogen-associated $\mathrm{B}_{12}$-dependent dehydratases to impair their ability to utilize L-fucose, without disrupting L-fucose metabolism by commensal organisms.

\section{Colonization resistance to pathogenic microbes}

The commensal gut microbiota acts through multiple mechanisms to protect the host from the outgrowth of pathogens, a phenomenon referred to as colonization resistance. ${ }^{\mathbf{1 3 6 , 1 3 7}} \mathrm{Gut}$ microbes prepare the host to detect and combat invasive harmful microorganisms by training and aiding in the development of the innate and adaptive immune systems. ${ }^{138}$ The importance of this interaction is highlighted by the increased susceptibility of germ-free mice to enteric pathogen infections. ${ }^{138}$ In addition, commensal microbes indirectly aid their host by creating a competitive ecosystem in which space and resources are limited, preventing colonization or expansion of pathogenic bacteria. Disruption or abolishment of the gut microbial community due to diet, disease, or antibiotic treatment can make these niches available to other microorganisms, resulting in overgrowth of opportunistic pathogens already residing in the GI tract and/or increased susceptibility to pathogenic invaders. ${ }^{\mathbf{1 3 9 - 1 4 1}}$ Due to this phenomenon, restoring the commensal microbial population through fecal microbiota transplantation has proven to be an effective mechanism to treat Clostridium difficile infection. ${ }^{\mathbf{1 4 2 , 1 4 3}}$ Finally, commensal microbes can directly antagonize microbial pathogens or competitors through the production of toxins and antibiotics.

One large class of antibiotics produced by gut microbes is the bacteriocins, which are ribosomally synthesized and posttranslationally modified peptides (RiPPs). ${ }^{\text {144-147 }}$ These natural products are encoded by a precursor gene that is ribosomally translated to yield a short peptide, typically consisting of 20-100 amino acids. ${ }^{\mathbf{1 4 4}}$ This precursor peptide consists of a core sequence and a short leader sequence that is cleaved following post-translational modifications of the core peptide to yield the final mature natural product. ${ }^{\mathbf{1 4 6}}$ These modifications result in unique structural features that serve to classify the bacteriocin RiPPs into smaller subgroups, which have been comprehensively reviewed. ${ }^{\mathbf{1 4 4}}$ Bioinformatic analyses of human-associated microbial genomes and metagenomes showed that they encode an array of bacteriocins representing all structural subclasses. ${ }^{\mathbf{1 4 8 - 1 5 2}}$ While many putative RiPP gene clusters mapped to bacteria in the GI tract, ${ }^{\mathbf{1 5 1 , 1 5 2}}$ an even higher abundance were identified from microbes residing in other sites of the human body, with the majority in the oral and vaginal cavities. ${ }^{152}$ Collectively, these analyses underscore the competitive microbial ecological niches on and in the human body and suggest that they could be untapped reservoirs of natural product antibiotics.

Sactipeptides (sacti- = sulfur-to-alpha-carbon), also known as sactibiotics, are a growing family of bacteriocins with a defining thioether peptide linkage that is installed by a metalloenzyme. ${ }^{\mathbf{1 4 4}}$ Inhabitants of the human gut produce sactipeptides that exhibit antibiotic activity against enteric pathogens. These peptides are thought to act by creating pores in the bacterial membrane, causing an influx of ions that leads to membrane depolarization and cell death. ${ }^{153,154}$ Subtilosin A, produced by strains of Bacillus subtilis, was the first sactipeptide to be identified and characterized (Fig. 3a). ${ }^{\mathbf{1 5 5 - 1 5 7}}$ Its biosynthetic gene cluster has been detected in stool metagenomic samples, as well as the genomes of microbes from various habitats. ${ }^{151,152}$ Subtilosin A demonstrates relatively broad bacteriocidal activity against Gram-positive pathogenic bacteria implicated in bacterial vaginosis, food poisoning, and hospital infections, including Gardnerella vaginalis, Listeria monocytogenes, Enterococcus faecium, and Staphylococcus aureus. ${ }^{\mathbf{1 5 3 , 1 5 8 , 1 5 9}}$ Other sactipeptides have been isolated exclusively from gut microbes, such as thuricin $\mathrm{CD}^{\mathbf{1 5 4 , 1 6 0 - 1 6 2}}$ (Fig. 3a) and thurincin $\mathrm{H}^{\mathbf{1 6 3 , 1 6 4}}$ (Fig. 3a) that are produced by strains of Bacillus thuringiensis, and ruminococcin $\mathrm{C}$ made by the commensal bacterium Ruminococcus gnavus. ${ }^{165-167}$ The latter demonstrates narrow antibiotic activity toward Clostridium perfringes, ${ }^{168}$ a bacterium that causes food-borne illnesses. The thuricin $\mathrm{CD}$ product is a peptide heterodimer $(\operatorname{Trn} \alpha \beta)$ that displays antibiotic activity against the infectious gut pathogen $C$. difficile. ${ }^{\mathbf{1 6 0 , 1 6 1}}$ Importantly, whereas other broad spectrum antibiotics commonly used in C. difficile treatment cause major disruption to the rest of the gut microflora, thuricin CD does not alter the community composition due to its narrow spectrum activity, yet is equally as effective against $C$. difficile. ${ }^{\mathbf{1 6 1}}$ The use of these narrow-spectrum antibiotics against enteric pathogens could improve outcomes and mitigate adverse effects, including infection reoccurrence, caused by destroying the resident commensal gut microbiota.

The unique thioether structural motif common to all sactipeptides arises from a $\mathrm{C}-\mathrm{S}$ bond-forming reaction between the thiol group of a cysteine residue and the $\alpha$-carbon of a variable amino acid residue in the peptide. ${ }^{\mathbf{1 4 4}}$ While thioether bonds are also found in lantibiotics (another subclass of bacteriocin RiPPs), those linkages are formed from conjugate addition between a cysteine thiol and a dehydroalanine or dehydrobutyrine residue, which is mediated by enzymes that employ acid-base chemistry. ${ }^{144}$ In contrast, generation of the thioether 


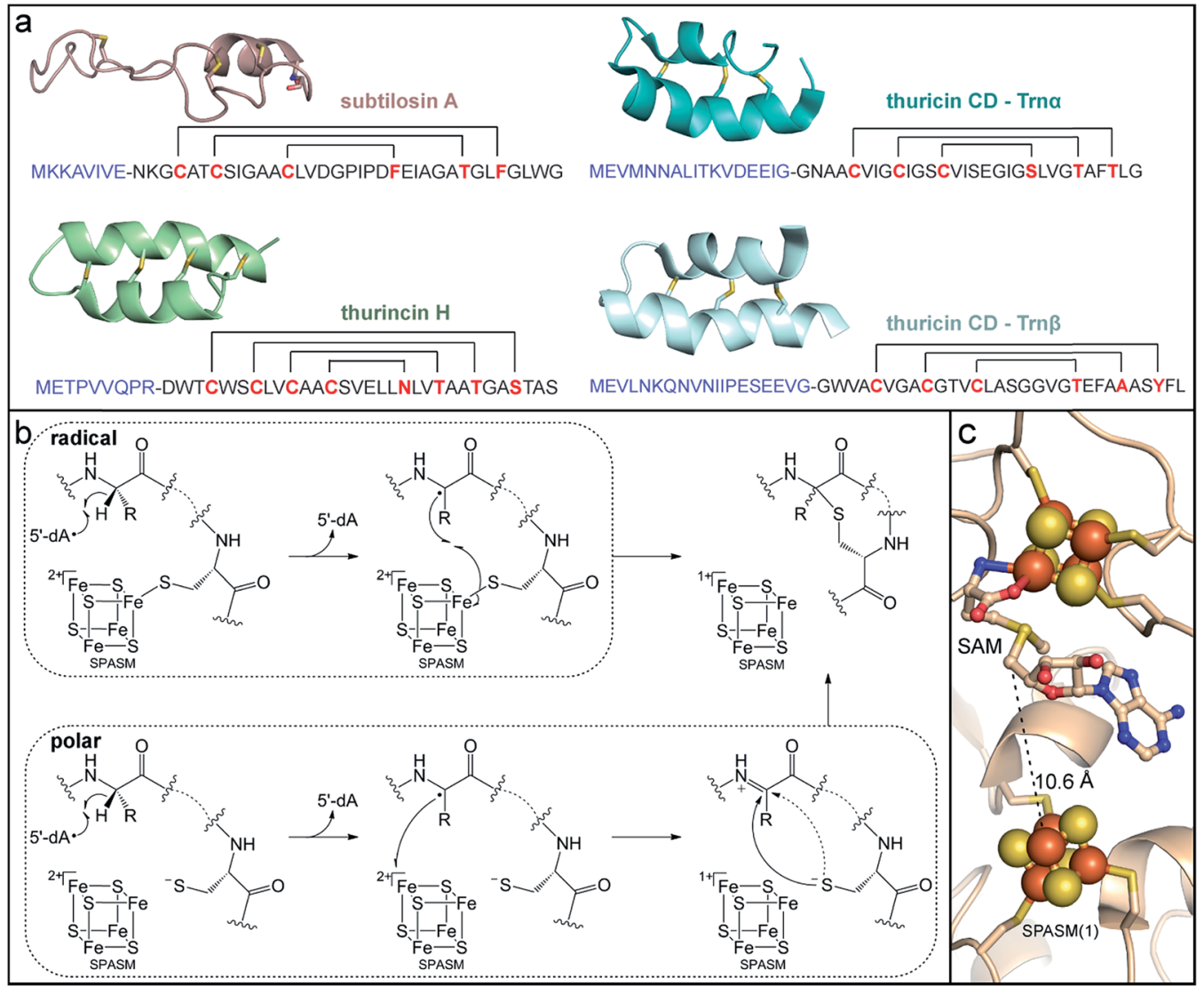

Fig. 3 Sactipeptide RiPP natural products synthesized by commensal gut microbes contain metalloenzyme-installed thioether linkages. (a) Structures of sactipeptides produced by human-associated bacteria [PDB accession codes: subtilosin A, 1PXQ; thurincin H, 2LBZ; thuricin CD, 2L9X and 2LAO]. Leader sequences are shown in blue and brackets indicate thioether linkages. (b) Mechanistic proposals for thioether bond formation invoking an iron-sulfur cluster activated thiol (radical scheme) or a ketoimine intermediate (polar scheme). (c) The CteB (PDB accession code: 5WGG) active site depicting one of the SPASM domain auxiliary clusters located in close proximity to the SAM substrate bound to the radical SAM cluster.

linkages in sactipeptides requires radical chemistry to enable hydrogen atom abstraction from the amino acid $\alpha$-carbon. Sactipeptide biosynthetic gene clusters invariantly include a gene encoding for a radical SAM enzyme, leading to its suspected involvement in thioether-bond formation. ${ }^{169}$ The first thioether bond forming radical SAM maturase to be characterized was AlbA, the enzyme that modifies the sactipeptide subtilosin A. ${ }^{170}$ This single enzyme catalyzes the crosslinking of three different cysteine residues with the respective $\alpha$-carbons of one threonine and two phenylalanine residues in the subtilosin A precursor peptide (Fig. 3a). Sactipeptides commonly have multiple thioether crosslinks with either stereochemical configuration. Thus, the mechanism of $\mathrm{C}-\mathrm{S}$ bond formation by radical SAM sactipeptide maturases and the basis for their regio- and stereoselectivity have been points of intrigue.

AlbA and the other identified sactipeptide maturases are members of the aforementioned SPASM-domain subgroup of radical SAM enzymes. AlbA harbors one extra [ $4 \mathrm{Fe}-4 \mathrm{~S}]$ cluster in its SPASM domain, ${ }^{170}$ whereas other recently described maturases harbor two auxiliary [4Fe-4S] clusters. ${ }^{171,172}$ As expected, the radical SAM $[4 \mathrm{Fe}-4 \mathrm{~S}]$ cluster alone is competent and sufficient for reductive SAM cleavage to generate the $5^{\prime}$-dA. intermediate. ${ }^{170,171}$ This oxidant is proposed to perform the initial hydrogen atom abstraction from the $\alpha$-carbon of the target amino acid. Conversely, the SPASM [ $4 \mathrm{Fe}-4 \mathrm{~S}]$ cluster is not essential for SAM cleavage, but is required for thioether bond formation. ${ }^{170} \mathrm{~A}$ recent crystal structure of the sactipeptide radical SAM maturase CteB revealed that, unexpectedly, only three of the four iron ions in the SPASM cluster were ligated with cysteine residues, while the fourth site remained open. ${ }^{172}$ This unsaturated coordination sphere contrasts with the full cysteine coordination observed for the SPASM domain clusters in the anSMEs, which act as electron transfer mediators, perhaps suggesting another role for this cluster.

An additional structure of CteB solved in the presence of a truncated peptide substrate provided potential insights into the role of the SPASM cluster and its open coordination site in thioether-bond formation. ${ }^{172}$ In this structure, a cysteine from the peptide substrate (albeit not the thioether bond-forming cysteine) coordinates the open site of the SPASM auxiliary cluster, which is located $<11 \AA$ from the $5^{\prime}$-position of SAM (Fig. 2c). ${ }^{172}$ Prior to this structure, such a direct interaction had been postulated based on perturbations in the UV/visible absorption spectrum of the SPASM [4Fe-4S] cluster in AlbA in 
the presence of the peptide substrate. ${ }^{\mathbf{1 7 0}}$ The authors proposed that the SPASM cluster could act as an electron acceptor and a Lewis acid to activate the coordinated thiol for oxidative coupling to the carbon-centered radical (Fig. $3 \mathrm{~b}$ ). ${ }^{170}$ There are mechanistic precedents for iron ion activation of a coordinated sulfur atom for oxidation and $\mathrm{C}-\mathrm{S}$ bond formation. In the enzyme isopenicillin- $N$-synthase (IPNS), the cysteine thiol of the substrate tripeptide directly coordinates a mononuclear non-heme $\mathrm{Fe}^{3+}$ ion. ${ }^{173}$ This sulfur undergoes attack by a carboncentered radical to form a $\mathrm{C}-\mathrm{S}$ bond with concomitant oneelectron reduction of the iron ion. ${ }^{173,174}$ In the case of the sulfur-inserting radical SAM enzyme BioB (described in detail in a later section), the activated sulfur atom is a sulfide bridge of an auxiliary [2Fe-2S] cluster. In this mechanism, a substratebased alkyl radical attacks the bridging sulfide and reduces one of the $\mathrm{Fe}^{3+}$ ions through inner-sphere electron transfer (Fig. 5b). ${ }^{175,176}$ Extending this rationale to the sactipeptide maturases, radical coupling of the $\alpha$-carbon radical to the ironcoordinated cysteine thiol would yield the thioether linkage with concomitant loss of an electron through inner-sphere electron transfer to the $[4 \mathrm{Fe}-4 \mathrm{~S}]^{2+}$ SPASM cluster (Fig. $3 \mathrm{~b}$ ).

An alternative mechanism has been put forth that invokes a distinct oxidation event preceding $\mathrm{C}-\mathrm{S}$ bond formation via polar chemistry. ${ }^{171}$ In this mechanism (Fig. $3 \mathrm{~b}$ ), the $\alpha$-carbon-centered radical first undergoes one-electron oxidation, presumably via electron transfer to the SPASM $[4 \mathrm{Fe}-4 \mathrm{~S}]^{2+}$ cluster, to form a ketoimine intermediate. This electrophilic intermediate is then attacked by the deprotonated cysteine thiol to form the $\mathrm{C}-\mathrm{S}$ bond. ${ }^{171}$ In this case, the observed cysteine coordination to the SPASM domain auxiliary cluster could be rationalized by a role in substrate positioning. The core sequences of sactipeptides often contain many cysteine residues, which either form crosslinks in a processive fashion or remain unmodified. Coordination of the additional, unmodified cysteines to the SPASM domain cluster could be serving to lock the substrate into the proper configuration such that both the target carbon and cysteine are positioned close to the radical SAM cluster.

Importantly, both of these mechanistic hypotheses satisfy the observation of both $\mathrm{D}^{-}$- and L-stereochemistry for the thioether bonds in sactipeptide natural products. In some cases, a single peptide has both $\mathrm{D}^{-}$and L-linkages that are all installed by the action of the same maturase, as observed for subtilosin A. ${ }^{156,157,170}$ As the precursor peptides contain only L-amino acids, the lack of stereoretention at the $\alpha$-carbon could support the formation of a ketoimine intermediate, which could be attacked on either planar face by the deprotonated thiol. Alternatively, this outcome could also arise from the planar character of the carbon-centered radical, which is stabilized by the captodative effect. Indeed, epimerization of amino acids in RiPP peptides is known to be promoted by radical SAM enzymes. ${ }^{177}$ These epimerases are proposed to generate a similar $\mathrm{C} \alpha$-radical substrate intermediate that is quenched by a hydrogen atom from a protein residue on the opposite face to invert the $\mathrm{C} \alpha$ stereocenter, yielding a D-amino acid. ${ }^{177}$ Further structural and spectroscopic characterization of the auxiliary SPASM cluster in sactipeptide maturases in the presence of native peptide substrates will help to resolve these two mechanistic proposals and the precise role(s) of the SPASM clusters.
Regardless of the operant mechanism, both hypotheses imply precise positioning of the reacting cysteine residue with respect to the activated $\alpha$-carbon to ensure the stereoselective outcome of each respective crosslink. The stereochemistry and location of the thioether crosslinks are expected to greatly impact the peptide structure due to its small size and therefore influence its bioactivity. The antibiotic activity of these sactipeptides, and, in particular, the promise of thuricin $\mathrm{CD}$ as a therapeutic agent against $C$. difficile infection, warrants further investigation into their structural properties and the enzymes responsible for thioether installation.

\section{Biosynthesis of essential nutrients}

Whereas the human body requires substantial nutrient uptake through the diet, microbes can often be more self-sufficient through de novo biosynthesis of essential small molecules. For example, many microbes can make vitamins, cofactors, and small molecules that the human host cannot synthesize. In many cases, it is unclear if the host can take advantage of the biochemical expertise of its microbes or if the host actively selects for microbes with beneficial capabilities. The extent of symbiosis between gut microbes and the human host is interesting to contemplate with respect to our co-evolutionary history. It is also an active area of exploration in the development of probiotics to supplement the nutritional needs of the human host.

\subsection{Vitamin biosynthesis}

Vitamins are small molecules essential to basic cellular function and metabolism, from energy conversion to macromolecule biosynthesis. Despite their indispensability, humans do not have the ability to synthesize most vitamins de novo. Instead, these molecules are acquired through the diet and from gut microbial production. The potential role of the gut microbiota in vitamin provision has been recognized for decades. ${ }^{178-183}$ However, the exact contribution of gut microbes to the total pool of vitamins available to the host has not been reliably quantified. In addition, it is not well-established whether bacteria actively export vitamins for host uptake, if vitamins are accessed by the host as a result of microbial cell death, or if certain vitamins are even available to the host. In some cases, specific colonic transporters have been identified to support the notion that certain vitamins (e.g. folate and thiamine) are absorbed by the host. ${ }^{\mathbf{1 8 4 , 1 8 5}}$ Mechanisms of acquisition are also important to consider in terms of vitamin exchange between gut microbes. In the case of vitamin $\mathrm{B}_{12}$, intermicrobial exchange has been identified as playing a key role in shaping the composition of the microbiota. ${ }^{\mathbf{1 8 6 , 1 8 7}}$ Conversely, the availability of microbially-produced vitamin $B_{12}$ to the host is still being debated. ${ }^{3}$

De novo pathways for vitamin and cofactor biosynthesis in microbes involve a variety of unusual and chemically challenging transformations, many of which are catalyzed by members of the radical SAM enzyme superfamily. ${ }^{\mathbf{1 8 8}}$ For example, the futalosine biosynthetic pathway for vitamin $K_{2}$ 


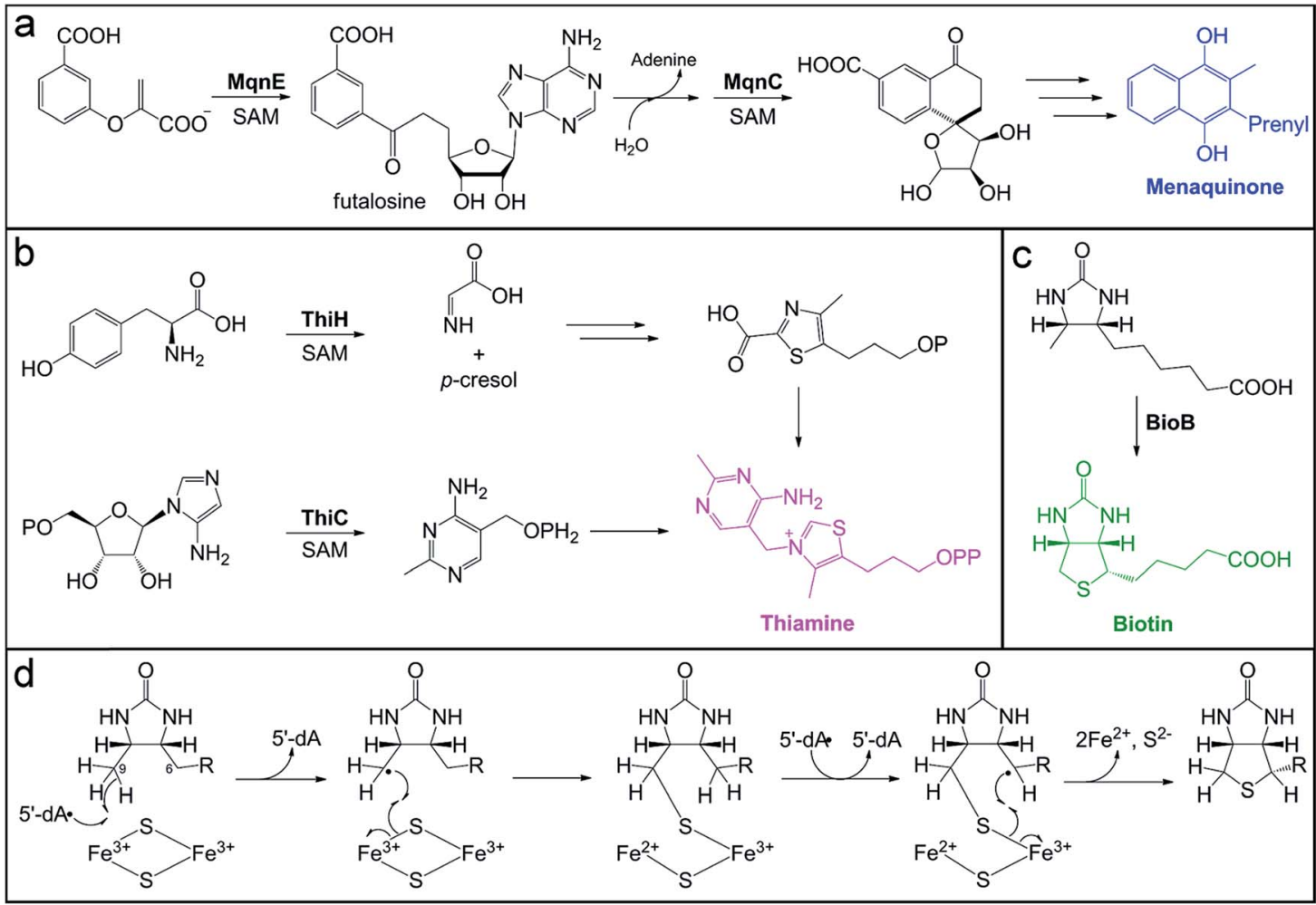

Fig. 4 Microbial pathways for vitamin biosynthesis that involve radical SAM enzymes. (a) Futalosine biosynthetic pathway for vitamin $\mathrm{K}$ (menaquinone) production, highlighting the transformations catalyzed by the radical SAM enzymes, MqnE and MqnC. (b) Biosynthesis of thiamine from the pyrimidine and thiazole precursors, highlighting the reactions catalyzed by radical SAM enzymes, ThiC and ThiH, in each branch of the pathway. (c) Final step of sulfur installation in biotin biosynthesis, catalyzed by the radical SAM enzyme BioB. (d) Proposed mechanism for BioB sulfur insertion using the auxiliary [2Fe-2S] cluster as the sulfur source.

(menaquinone) and the biosynthesis of vitamin $\mathrm{B}_{1}$ (thiamine) require the action of radical SAM enzymes that catalyze $\mathrm{C}-\mathrm{C}$ bond-forming reactions (Fig. 4). We direct the reader to a recent review for more information on the mechanisms of these enzymes, including ThiC, which catalyzes the complex rearrangement of 5-aminoimidazole ribonucleotide to form the pyrimidine moiety of thiamine. ${ }^{189} \mathrm{~A}$ second thiamine biosynthetic enzyme, tyrosine lyase (ThiH), catalyzes an elimination reaction that shares mechanistic similarities with the transformations catalyzed by radical SAM enzymes HydG, CofH, and NosL. ${ }^{190-192}$ In the proposed mechanism of ThiH, the $5^{\prime}$-dA. oxidant abstracts a hydrogen atom from the amine of $\mathrm{L}$-tyrosine to generate a nitrogen-centered radical. ${ }^{188}$ The $\mathrm{C}_{\alpha}-\mathrm{C}_{\beta}$ bond then undergoes $\beta$-scission to yield a one-electron oxidized $p$-cresol intermediate that gets reduced and protonated, while the dehydroglycine co-product feeds into thiazole biosynthesis (Fig. 4b).

Thiamine acts as an enzyme cofactor in essential pathways, such as branched-chain amino acid and carbohydrate metabolism, as well as in non-coenzymatic roles. ${ }^{193,194}$ Thiamine deficiency with systemic and neurological symptoms often occurs in infants and young children from tropical and impoverished regions. ${ }^{194}$ The diet is a major source of this vitamin, but a recent study using Drosophila as a model system ${ }^{195}$ has provided evidence for the long postulated role of the gut microbiota ${ }^{196}$ in provision of this nutrient to the host. In this model, axenic offspring that were unable to develop on a thiamine-deficient diet were rescued by introduction of a microbiota and even a single organism, Acetobacter pomorum. ${ }^{195}$ Indeed, human colonocytes express a thiamine pyrophosphatespecific transport that would allow for uptake of this vitamin by the host. ${ }^{184,197-199}$ Interestingly, variants in this gene have been identified as susceptibility markers for ulcerative colitis in Northern Indian populations, which are known to exhibit thiamine deficiency. ${ }^{200,201}$ This connection between thiamine uptake and ulcerative colitis remains to be explored further.

Another example of a radical SAM enzyme that participates in vitamin biosynthesis is one of the founding superfamily members, biotin synthase (BioB). BioB is responsible for the incorporation of a sulfur atom in the thiophane ring of the cofactor biotin (Fig. 4c) and belongs to a subgroup of radical SAM enzymes that all perform sulfur insertion reactions. ${ }^{202,203}$ Each of these enzymes possesses additional auxiliary [4Fe-4S] or [2Fe-2S] cluster(s) that serve as sacrificial donors of one or two sulfur atom(s) that are incorporated into the final product. ${ }^{202}$ The auxiliary cluster in $\mathrm{BioB}$ is a $[2 \mathrm{Fe}-2 \mathrm{~S}]$ cluster ligated by three cysteine residues and an unusual arginine residue. ${ }^{204-206}$ The mechanism of BioB (Fig. 4d) initiates with generation of a $5^{\prime}-\mathrm{dA} \cdot$ at the radical SAM $[4 \mathrm{Fe}-4 \mathrm{~S}]$ cluster and subsequent abstraction of a hydrogen atom from the C9 position of the desthiobiotin substrate. ${ }^{207}$ The substrate-based radical then attacks a bridging sulfide of the auxiliary $[2 \mathrm{Fe}-$ 
$2 \mathrm{~S}]^{2+}$ cluster, forming the first $\mathrm{C}-\mathrm{S}$ bond with concomitant inner-sphere electron transfer to an $\mathrm{Fe}^{3+}$ ion of the cluster. ${ }^{175}$ This reaction yields a chemically competent 9-mercaptodethiobiotin intermediate species ${ }^{\mathbf{2 0 8}}$ that remains cross-linked to the $\mathrm{Fe}^{3+}$ ion of the $[2 \mathrm{Fe}-2 \mathrm{~S}]^{1+}$ cluster. ${ }^{176} \mathrm{BioB}$ then catalyzes another SAM cleavage event, generating a second $5^{\prime}$-dA $\cdot$ equivalent that abstracts a hydrogen atom from the $\mathrm{C} 6$ position of the substrate. ${ }^{207}$ The resultant substrate alkyl radical undergoes a similar reaction with the cross-linked sulfur to cyclize the substrate, which also reduces the second $\mathrm{Fe}^{3+}$ ion of the cluster to $\mathrm{Fe}^{2+}$.

Upon reduction and loss of sulfur to the product, the auxiliary cluster degrades, resulting in an inactive enzyme in vitro. ${ }^{209,210}$ However, evidence of catalytic activity in vivo ${ }^{211}$ suggested that additional components might enable cluster reassembly to allow for multiple turnovers in the cell. A recent report reconciled the issue of cluster degradation in vitro through study of another sulfur inserting enzyme, lipoyl synthase (LipA). Scaffold proteins NfuA and IscU, associated with iron-sulfur cluster biogenesis, were demonstrated to reassemble and insert a new auxiliary cluster into lipoyl synthase, rendering it capable of multiple turnovers in vitro. ${ }^{212}$ This type of cluster repair mechanism could very well extend to other sulfur inserting enzymes, like BioB, to enable their catalytic activity in vivo.

Biotin is an essential cofactor for carboxylase enzymes in pathways such as fatty acid biosynthesis, branched-chain amino acid catabolism, and gluconeogenesis. ${ }^{213}$ Deficiency of this vitamin in humans causes alopecia and skin dermatitis. ${ }^{\mathbf{2 1 4}}$ A recent study using murine models demonstrated the impact of the gut microbiota on systemic host biotin levels and the display of alopecia phenotypes. ${ }^{215}$ A shift in gut microbiota composition consisting of a bloom of Lactobacillus murinus, a biotin auxotroph, was identified as the cause of low biotin levels in the host. ${ }^{215}$ This example represents an interesting case in which the gut microbiota is actively depleting the vitamin pool available to the host, an aspect of vitamin homeostasis that has not been adequately explored with respect to the gut microbiota.

\subsection{Queuosine biosynthesis}

In addition to vitamins and cofactors, gut microbes can synthesize other small molecule products that are incorporated into host macromolecules. One such metabolite is queuine, a modified 7-deazapurine nucleobase that is found in tRNA molecules of all eukaryotic and bacterial organisms. ${ }^{216-219}$ It substitutes for guanine exclusively at the "wobble" position-34 of the $5^{\prime}$-GUN-3' anticodon that is found in aspartyl-, tyrosyl-, histidinyl-, and asparginyl-tRNAs. ${ }^{216,218}$ Although the function of the queuine nucleoside (queuosine) has not been definitively established, its ubiquity in living organisms implies a critical biological role. Indeed, its absence in tRNA has been implicated in numerous, but ill-defined physiological phenomena, including cell proliferation and differentiation, cancer progression, and neurological abnormalities. ${ }^{220-223}$ Interestingly, mammals lack the biosynthetic machinery to make queuine de novo. The queuine base is scavenged by host cells and transferred into the guanine-34 position of tRNAs. ${ }^{224,225} \mathrm{~A}$ major source of queuine is the diet, but early experiments showed that conventional mice maintained on a queuinedeficient diet still possessed this modified base in their tRNA. ${ }^{226}$ Conversely, queuosine was not detected in tRNA from germ-free mice fed a queuine-deficient diet, ${ }^{226,227}$ implicating gut microbes as a significant source of this micronutrient. Queuosine biosynthesis has been well-characterized in the model organisms Escherichia coli and B. subtilis; however, the distribution of this biosynthetic pathway in gut microbes has not been evaluated.

Although the structure of queuosine had been known for decades, ${ }^{228,229}$ the complete pathway for its de novo biosynthesis in bacteria (Fig. 5a) has only been recently established. ${ }^{223,230}$ The pathway begins with conversion of GTP to 7,8-dihydroneopterin-3'-triphosphate by a GTP cyclohydrolase, analogous to the first steps in folate and biopterin biosynthesis. The unique 7-deazaguanine ring is synthesized from this intermediate through the action of the enzymes QueD and QueE, the latter of which is a radical SAM enzyme. The ATPdependent enzyme QueC transforms the carboxyl group of the 7-deazaguanine to a nitrile in the PreQ $_{0}$ intermediate. The NADH-dependent enzyme QueF then reduces the nitrile to an aminomethyl group, generating the PreQ $_{1}$ intermediate. The enzyme tRNA guanine transglycosylase (TGT) then inserts the $\mathrm{PreQ}_{1}$ intermediate into the target tRNA, replacing guanine at position 34. The final two enzymes act on the PreQ $_{1}-$ tRNA complex to yield the queuosine-tRNA final product. The SAMdependent enzyme QueA catalyzes transfer and isomerization of the ribose group from SAM to the aminomethyl of PreQ $_{1}$ to form epoxyqueuosine-tRNA. Lastly, the enzyme QueG reduces the epoxide to generate the cyclopentene ring of queuosine.

The enzyme responsible for this final transformation remained elusive for many years, even following the elucidation of the rest of the pathway. It was finally discovered by screening a strain library of $E$. coli single gene knockout mutants for the accumulation of epoxyqueuosine and the absence of queuosine in isolated tRNA nucleotides. ${ }^{231}$ The protein identified, QueG, shares sequence homology to reductive dehalogenases, which utilize a cobalamin (vitamin $\mathrm{B}_{12}$ ) cofactor and multiple ironsulfur clusters for catalysis. These enzymes belong to the class III group of cobalamin-dependent enzymes, which to date remain grossly under-characterized despite the amazing chemistry attributed to the few known members. ${ }^{232}$ Cofactor analysis of QueG by EPR spectroscopy and structural characterization confirmed the presence of a cobalamin cofactor with square-pyramidal geometry, existing in the "free-base" configuration (i.e., no lower axial ligand) with an upper axial water ligand. ${ }^{233-235}$ However, in the presence of substrate, this water ligand is displaced (Fig. 5c). ${ }^{235}$ The lack of an upper ligand is unique to enzymes of this class, in contrast to the other classes of cobalamin-dependent enzymes which have either a 5'-deoxyadenosyl or methyl axial ligand, and is proposed to have a key function in their mode of action. ${ }^{232,236}$

In the case of QueG, the "open-Cbl" form is predicted to enable formation of a covalent substrate adduct intermediate 
during catalysis. ${ }^{224,225}$ The proposed mechanism for QueG ${ }^{234,235}$ (Fig. 5b) ${ }^{230,231}$ begins with nucleophilic attack by the reduced $\mathrm{Co}^{1+}$ on the substrate epoxide to form a $\mathrm{Co}^{3+}-\mathrm{C}$ adduct and open the epoxide ring, which is facilitated by protonation of the oxygen atom. Single electron reduction of the alkyl- $\mathrm{Co}^{3+}$ species induces homolytic cleavage of the metal-carbon bond, formation of the alkene, and concomitant elimination of the hydroxyl group. Reduction of the resultant $\mathrm{Co}^{2+}$ center to regenerate the $\mathrm{Co}^{1+}$ state for another turnover is mediated by two $[4 \mathrm{Fe}-4 \mathrm{~S}]$ clusters positioned between the protein surface and the cobalamin cofactor (Fig. 5c). ${ }^{\mathbf{2 3 4 , 2 3 5}}$ These clusters were

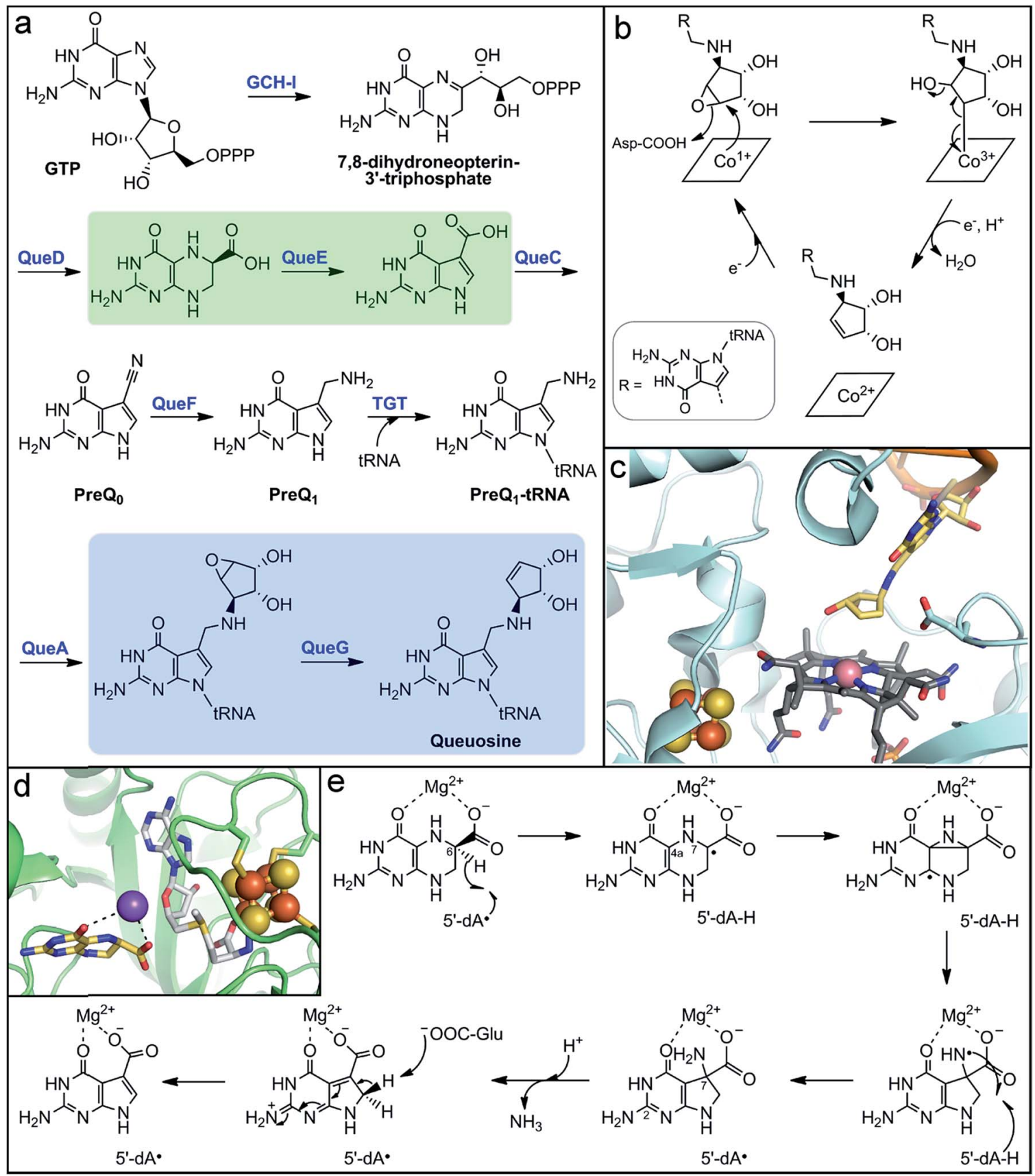

Fig. 5 Microbial biosynthesis of the alternative tRNA base, queuosine, involves two metalloenzymes. (a) Complete biosynthetic pathway for queuosine production with the reactions catalyzed by metalloenzymes highlighted in green and blue boxes. (b) Mechanistic proposal for the final step in queuosine biosynthesis catalyzed by the Cbl-dependent epoxyqueuosine reductase, QueG. (c) Active site depiction of product-bound QueG (PDB accession code 5DOB) showing the open-form cobalamin (grey sticks) with the central cobalt ion (pink sphere), the two proximal [4Fe-4S] clusters (orange and yellow spheres), and the queuosine base (yellow sticks) of the bound tRNA mimic. (d) Active site depiction of substrate-bound QueE (PDB accession code 4NJH) showing the radical SAM cluster (orange and yellow spheres) with the co-substrate SAM (light grey sticks) bound and the substrate (yellow sticks) coordinating the essential $\mathrm{Mg}^{2+}$ ion (purple sphere). (e) Proposed mechanism for 7-deazapurine synthesis by the radical SAM enzyme, QueE. 
determined to have sufficiently low reduction potential to reduce the low redox potential $\mathrm{Co}^{2+/ 1+}$ couple. ${ }^{235}$

Further insight into the mechanisms of substrate recognition and binding, as well as support for the proposed catalytic mechanism, were obtained from structural comparison of substrate-free QueG and a co-crystal structure with a short oligonucleotide tRNA mimic containing the queuosine product. ${ }^{235}$ QueG is composed of three structural domains: the N-terminal Cbl-binding domain, a ferredoxin-like fold that harbors the iron-sulfur clusters, and a triple HEAT-repeat domain that interacts with the tRNA substrate. The cyclopentenediol ring of the queuosine product is observed in the structure directly above the cobalamin cofactor with the target carbon at a distance of $\sim 4 \AA$ (Fig. 5c), ${ }^{235}$ supporting the proposal of a metal-carbon adduct intermediate at the open axial position. In addition, a conserved aspartate residue is positioned in the active site approximately $3 \AA$ from the double bound of the product cyclopentene (Fig. 5c), suggesting it could aid in substrate positioning through interaction with the epoxide oxygen and could serve as a catalytic acid. The unique mechanism of QueG formulated based on structural, mechanistic, and spectroscopic studies highlights the key role of the potent nucleophilic $\mathrm{Co}^{1+}$ reactant species. This reactivity could be exploited in the design of inhibitors for use as experimental tools to probe the role of queuosine in host biology.

Another metalloenzyme involved in the biosynthesis of this alternative nucleobase is the radical SAM enzyme QueE. This enzyme and its homologs catalyze an unusual pterin ring contraction/rearrangement reaction that generates the 7-deazapurine ring found in the tRNA bases queuosine and archeosine (found exclusively in archaea), as well as a number of natural products. ${ }^{230,237}$ The structure of QueE consists of a minimal TIM barrel fold that harbors the radical SAM [4Fe-4S] cluster via either the traditional $\mathrm{CX}_{3} \mathrm{CX}_{2} \mathrm{C}$ or an atypical $\mathrm{CX}_{14} \mathrm{CX}_{2} \mathrm{C}$ sequence motif. ${ }^{238}$ The 6-carboxy-5,6,7,8tetrahydropterin substrate is bound in close proximity to the radical SAM cluster and is stabilized through coordination of an essential $\mathrm{Mg}^{2+}$ ion via its 4- and 6-carboxylate oxygen atoms (Fig. 5d). ${ }^{238,239}$ In the proposed mechanism (Fig. 5e), the $5^{\prime}-\mathrm{dA} \cdot$ oxidant generated from reductive SAM cleavage initiates the reaction through abstraction of the substrate C6 hydrogen atom. ${ }^{239}$ The resulting substrate radical then rearranges to form a strained aziridine intermediate or transition state, which is supported by computational studies. ${ }^{240}$ This mechanism is reminiscent of the migration reactions catalyzed by radical SAM aminomutases. Alternatively, the pyrazine ring could open through $\beta$-scission of the N7-C4a bond to form an imine intermediate. In the next step, formation of the 5 -membered deazapyrrole ring is proposed to yield an exocyclic amine with a nitrogen-centered radical. This amine-based radical is quenched by hydrogen abstraction from the original $5^{\prime}$-dA molecule to regenerate the $5^{\prime}-\mathrm{dA} \cdot$, which rationalizes the observed catalytic nature of SAM in QueE catalysis. ${ }^{239}$ Deprotonation of either the $\mathrm{C} 2$ pyrimidine exocyclic amine or the pyrrole nitrogen by a basic amino acid residue ${ }^{238}$ promotes elimination of ammonia from the C7-gem-aminocarboxylate pyrrole intermediate. Finally, a basic residue abstracts the pro-
$R$-proton from the activated C8 position to rearomatize the final pyrrolopyrimide structure. ${ }^{\mathbf{2 3 8 , 2 3 9}}$

Although the physiological role of queuine remains enigmatic, preliminary findings suggest it may regulate cell proliferation. ${ }^{\mathbf{2 2 0 2 4 1}}$ Queuosine has been reported to influence mitotic signaling pathways that rely on protein phosphorylation patterns. ${ }^{242}$ In cancer cells, protein tyrosine phosphorylation levels are abnormally high and tRNA molecules are hypomodified with queuosine. ${ }^{243}$ Exogenous queuine administration reverses both of these phenotypes in cancer cells, ${ }^{242,243}$ suggesting that queuine plays a role in regulation of tyrosine kinases that are critical in cell proliferation processes. However, these studies have not been able to differentiate the potential effects of the free queuine base from the queuosine-containing tRNA. The connection between queuine, cell proliferation, and cancer malignancy warrants further investigation.

\section{Production of host immune- modulatory metabolites}

The gut microbiota is a critical component in human immune system development and maintenance. Gut microbes produce small molecules that can modulate the immune response of the host. In particular, fermentation products of tryptophan metabolism, including indole-3-aldehyde, indole-3-acetic acid, indolelactic acid, indolepropionic acid, and indoleacrylic acid, promote fortification of the intestinal epithelial barrier and influence immune cell differentiation and function. Their ability to act as ligands for pregnane $\mathrm{X}$ receptor (PXR) and arylhydrocarbon receptor $(\mathrm{AhR})^{\mathbf{2 4 4 - 2 4 7}}$ has been suggested as the mechanism by which these metabolites protect against chemically-induced colitis in mice. Specifically, indoleacrylic acid was shown to stimulate IL-10 production, suppressing production of TNF and IL-6, and up-regulate expression of antioxidant pathways through NRF2 activation. ${ }^{248}$ In contrast, some metabolites derived from aromatic amino acid fermentation can also be further transformed by gut microbes to diseaseassociated molecules (see following section).

The acrylate and propionate derivatives of tryptophan are produced via a reductive fermentation pathway consisting of a promiscuous set of enzymes encoded by the aromatic amino acid metabolism gene operon, fldAIBC. ${ }^{249}$ In this pathway (Fig. 6), the aromatic amino acid first undergoes transamination to form the 2-oxo-acid, which is reduced via an $\mathrm{NADH}$-dependent enzyme to the corresponding 2-hydroxy-acid. A CoA-ligase (FldA) appends CoA via a thioester linkage to activate the 2-hydroxy-acid, which is a prerequisite for the next enzymatic transformation. ${ }^{250}$ The 2-hydroxyacyl-CoA molecule is then dehydrated (FldIBC) to the acrylate-CoA and reduced in the final step to the fully saturated derivative. ${ }^{249}$ While most of these steps can be achieved through acid-base chemistry, the dehydration of a 2-hydroxy-acid is chemically challenging due to the high $\mathrm{p} K_{\mathrm{a}}$ of the protons at the $\beta$-carbon. ${ }^{251,252}$ Instead of acid-base chemistry, 2-hydroxyacyl-CoA dehydratases utilize reductive radical chemistry to perform this reaction, with the CoA thioester playing a key role in stabilizing reaction 


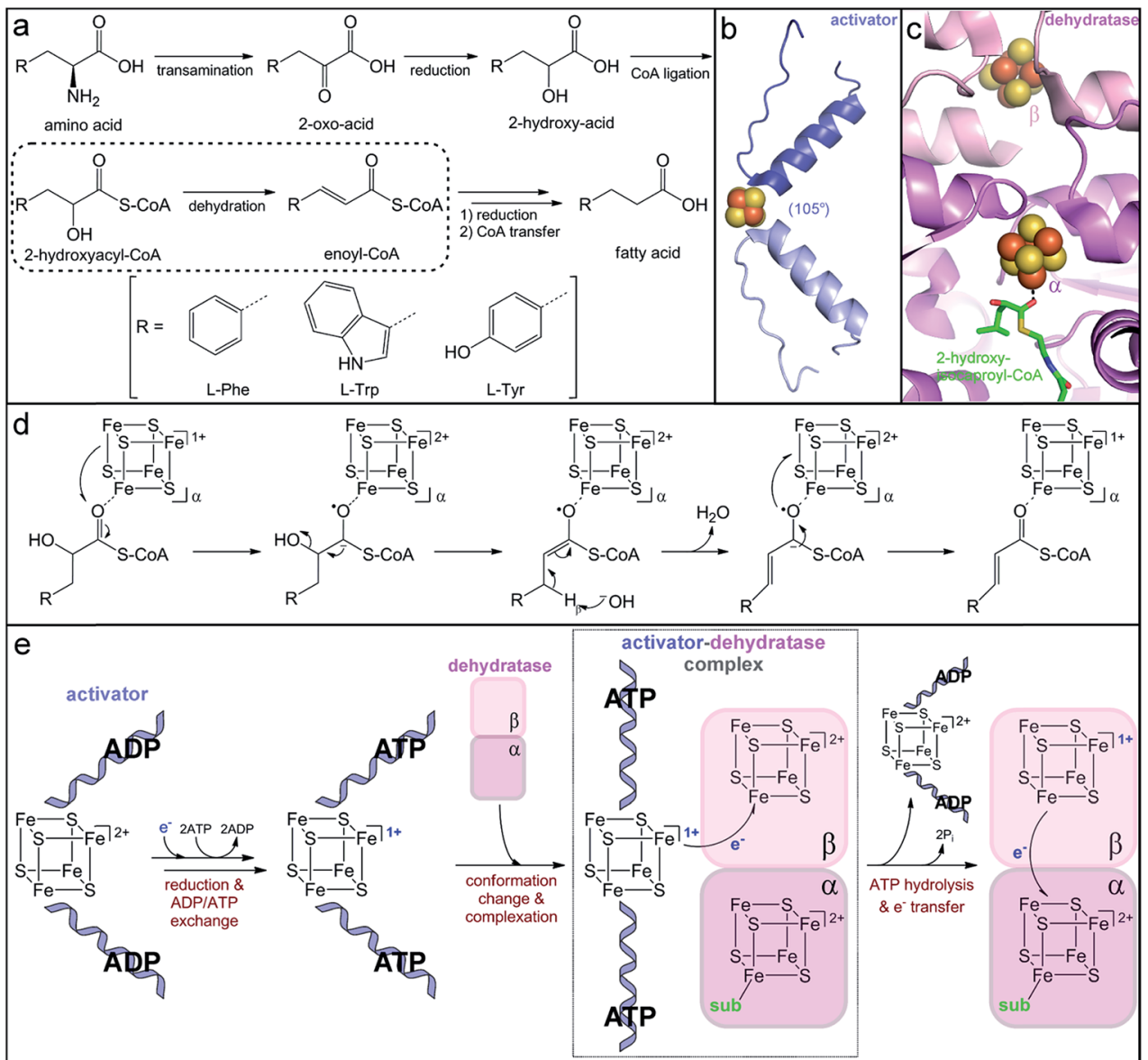

Fig. 6 Production of immune-modulatory indole derivatives by gut-associated Clostridia. (a) Reductive amino acid fermentation pathway involving dehydration of a 2-hydroxy-acid. (b) Homodimer interface of the dehydratase activator (2-hydroxyisocaproyl-CoA dehydratase activator, PDB accession code: 4EHT) highlighting the helix-cluster-helix motif in the ADP-bound $105^{\circ}$ angle conformation. (c) Heterodimer interface of the dehydratase component (2-hydroxyisocaproyl-CoA dehydratase, PDB accession code: 3O3N) depicting the [4Fe-4S] clusters in each subunit and the direct substrate coordination to the $\alpha$-cluster. (d) Umpolung charge reversal mechanism of 2-hydroxyacyl-CoA dehydration. (e) Proposed ATP-dependent electron transfer mechanism of dehydratase activation.

intermediates. The proposed mechanism of the 2-hydroxyacyl-

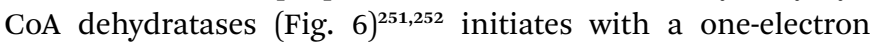
reduction of the substrate to generate a ketyl radical anion. Next, the carbanion eliminates the hydroxyl group to form an enoxy radical intermediate. The $\mathrm{p} K_{\mathrm{a}}(\sim 14)$ of the $\beta$-proton of this intermediate is markedly lower than that of the 2-hydroxy-acid (by $>25 \mathrm{pK}$ units), ${ }^{253}$ facilitating its deprotonation to yield another ketyl radical anion that undergoes one-electron oxidation to form the final enoyl-CoA product.

The critical single electron transfer that initiates dehydratase catalysis is promoted by an essential partner activating enzyme, a $[4 \mathrm{Fe}-4 \mathrm{~S}]$ cluster-dependent electron transfer protein with ATPase activity. ${ }^{249,254}$ Structural characterization of homologs that activate other 2-hydroxyacyl-CoA dehydratases has provided insight into the conserved mechanism of activation (Fig. 6e). The activating partner exists as a homodimer with a single ATP/ADP bound per monomeric subunit and a [4Fe-4S] cluster at the interface of the dimer (Fig. $6 \mathrm{~b}$ ). ${ }^{255,256}$ The cluster is highly solvent exposed and thus extremely sensitive to oxidation; ${ }^{249}$ it is ligated by two cysteine residues contributed by a helix of each monomer to form an interesting helix-cluster- helix structural motif (Fig. 6b) ${ }^{255,256}$ In the ADP-bound form, the helix-cluster-helix has an angle of $105^{\circ}$ (Fig. 6b), ${ }^{255,256}$ which inspired the epithet for these "Archerase" enzymes. ${ }^{252}$ Reduction of the cluster and substitution of the ADP molecules for ATP is proposed to induce a conformational change to form a $180^{\circ}$ angle at the helix-cluster-helix dimer juncture that promotes complex formation with the dehydratase (Fig. 6e) ${ }^{256,257}$ ATP hydrolysis then drives the electron transfer from the $[4 \mathrm{Fe}-4 \mathrm{~S}]^{1+}$ cluster of the activating partner to an oxidized $[4 \mathrm{Fe}-4 \mathrm{~S}]]^{2+}$ cluster in the dehydratase (Fig. 6e). ${ }^{254,256,257}$ This dehydratase cluster then transfers the electron via a second [4Fe-4S] cluster to ultimately reduce the substrate (Fig. 6e).

This mechanism of enzyme activation has been largely devised based on analogy to the activation of the nitrogenfixation metalloenzyme, nitrogenase. ${ }^{254,258}$ Although the activating partners of 2-hydroxyacyl-CoA dehydratases and nitrogenases both have the helix-cluster-helix structural motif, their structures do not otherwise share apparent homology. ${ }^{259}$ The nitrogenase activator is most similar to the family of G-proteins, while the dehydratase activator resembles the ASKHA (acetate and sugar kinases, heat shock protein 70 and actin) proteins, ${ }^{259}$ 
implying that they independently evolved similar ATPdependent strategies to promote one-electron reduction. As expected from their analogous roles in electron transfer, the [4Fe-4S] clusters of the dehydratase and the nitrogenase activator proteins share distinctive electronic properties. Spectroscopic characterization of the $[4 \mathrm{Fe}-4 \mathrm{~S}]^{1+}$ cluster in the phenyllactyl-CoA dehydratase activator (FldI) revealed that it has an unusual $S=3 / 2$ ground state. ${ }^{249}$ Studies of the homologous 2-hydroxyglutaryl-CoA dehydratase activator demonstrated that, when treated with the strong reductant titanium(III) citrate, the $[4 \mathrm{Fe}-4 \mathrm{~S}]^{1+}$ cluster can be further reduced to the superreduced $[4 \mathrm{Fe}-4 \mathrm{~S}]^{0}$ oxidation state. ${ }^{260}$ To our knowledge, the nitrogenase and dehydratase activators are the only examples of superreduced clusters in biology. However, at least in the case of the dehydratase activator protein, only the more traditional $[4 \mathrm{Fe}-4 \mathrm{~S}]^{2+/ 1+}$ redox couple is likely to be biologically relevant for electron transfer, as the superreduced cluster cannot activate the 2-hydroxyglutaryl-CoA dehydratase in vitro. ${ }^{260}$

After one-electron reduction by the activating protein, the dehydratase is catalytically active and capable of thousands of turnovers through storage of the reducing equivalent in its own iron-sulfur clusters. ${ }^{249,261}$ The crystal structure of the 2-hydroxyisocaproyl-CoA dehydratase provided insight into the electron transfer cycle during catalysis. The dehydratase is a heterodimer composed of two structurally similar subunits that share low sequence homology. ${ }^{262}$ Each subunit harbors a $[4 \mathrm{Fe}-4 \mathrm{~S}]$ cluster positioned at the interface of the $\alpha \beta$ dimer (Fig. 6c). ${ }^{262}$ The $\beta$-subunit cluster is ligated by three protein cysteine residues and another thiolate ligand and is believed to be the initial acceptor of the electron provided by the activating protein. ${ }^{262}$ The $\alpha$-subunit cluster has three cysteine ligands and an open coordination site that is occupied by a water molecule in the absence of substrate. ${ }^{\mathbf{2 6 2}}$ Upon substrate binding, this water ligand is displaced by the carbonyl oxygen of the substrate thioester (Fig. 6c), ${ }^{262}$ indicating that the $\alpha$-subunit harbors the catalytic active site. The direct, monodentate coordination of the substrate to the iron-sulfur cluster enables facile innersphere electron transfer and stabilization of the ketyl radical anion intermediate. Interestingly, neither dehydratase cluster can be reduced by any tested chemical reductants, ${ }^{263}$ suggesting that they have very low reduction potentials. Either the reduction potential of the activator cluster is lowered upon complex formation due to the large postulated $105^{\circ}$ to $180^{\circ}$ conformational change and likely desolvation of the cluster ${ }^{256}$ or the reduction potentials of the dehydratase clusters are altered upon complexation and/or as a result of desolvation observed upon substrate binding. ${ }^{262}$ Once the dehydratase is reduced, the electron can continuously cycle between the two dehydratase clusters and the substrate. Overall, this elaborate and elegant mechanism of ATP-dependent electron transfer to a CoAactivated substrate is used to achieve a charge reversal (Umpolung effect) for water elimination from an unactivated 2hydroxy-acid substrate.

Reductive aromatic amino acid metabolism has only been demonstrated for a handful of gut bacteria, all belonging to the phylum Firmicutes, but it has important implications for human health and disease. The fldAIBC gene operon responsible for this metabolism was shown to be less prevalent and less abundant in metagenomes of patients with inflammatory bowel diseases (both Crohn's and ulcerative colitis) compared to healthy populations. ${ }^{\mathbf{2 4 4 , 2 4 8}}$ As expected, the abundance of the gene operon correlated with observed levels of tryptophan metabolites in biological samples of these patients, ${ }^{248}$ suggesting that the lack of this operon could be a good genetic marker for inflammatory disease. Interestingly, reduction of tryptophan metabolism is correlated with reduced mucin degradation, specifically of L-fucosylated glycans. ${ }^{248}$ In the healthy gut, the host presents fucosylated mucins, which promote colonization of fucose-degrading microbes that are known to produce tryptophan-derived metabolites with immune suppression activity. The host immune response to these microbial metabolites then results in increased mucin fucosylation. This cometabolism thus perpetuates a positive feedback cycle between the gut microbiota and the host to suppress inflammation. Conversely in IBD, the observed reduction of these beneficial microbes could reflect disruption of this cycle as either a cause or a consequence of host inflammation and could present a target for microbiota-based therapeutics.

\section{Gut microbial metabolism linked to human disease}

The metabolism of gut microbes is centered around nutrient and energy extraction for their own benefit. These functions can be detrimental to the host by consuming metabolites that it may need. In addition, because of the physical proximity between microbes and their host, the host is exposed to microbial metabolic waste products. These compounds can vary in distribution and abundance depending on the composition of the individual's gut microbiota. Importantly, many microbial metabolites have been associated with risk for disease development in the host. In addition, unique metabolic functions can allow for pathogenic bacteria or pathobionts to colonize or expand in the GI tract, resulting in host infection.

\subsection{Trimethylamine production}

The quaternary amine choline is an essential nutrient for humans and major dietary component of red meat, eggs, dairy, and soy. Gut microbes metabolize this diet-derived molecule under anaerobic conditions to generate acetaldehyde and trimethylamine (TMA) (Fig. 7a). ${ }^{\mathbf{2 6 4 , 2 6 5}}$ Whereas acetaldehyde can be utilized by the microbe as a source of carbon and energy, TMA is not consumed by the producing organism. Instead, it is absorbed by host cells and circulated in the bloodstream to the liver where it is converted by a host flavin monooxygenase (FMO3) to trimethylamine $N$-oxide (TMAO) (Fig. 7a). ${ }^{266}$ This final metabolite plays a causative role in the development of atherosclerosis and cardiac disease in mice, ${ }^{267-269}$ and has been associated with numerous other diseases, including diabetes, kidney disease, and non-alcoholic fatty liver disease. ${ }^{270-272}$ Thus, TMAO production is currently viewed as a therapeutic target. A priori, the FMO3 enzyme presents as an attractive candidate for 


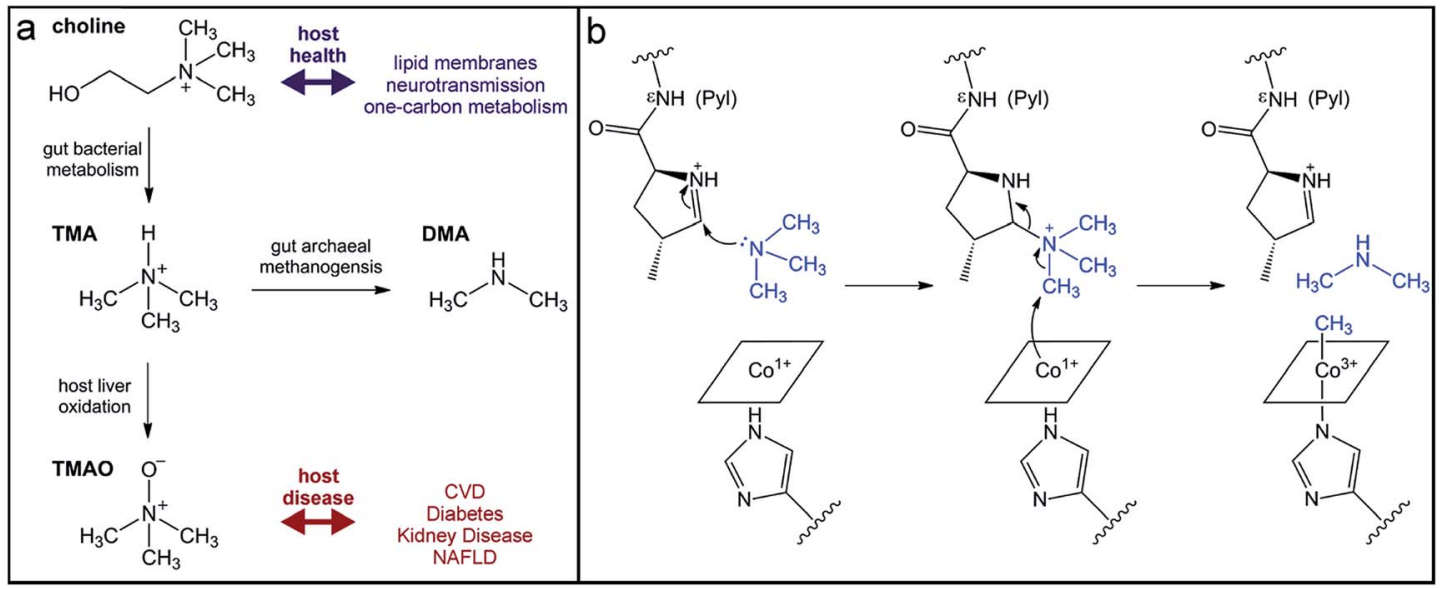

Fig. 7 Production of the TMAO precursor TMA results from gut microbial metabolism. (a) Choline metabolism by gut microbes produce trimethylamine that can be oxidized by the host liver enzyme FMO3 or demethylated by human-associated archaea for methanogenesis. (b) Mechanism for TMA demethylation by archaeal pyrrolysine (Pyl)-containing, coronoid-dependent methyltransferases.

inhibition; however, individuals with genetic mutations in the fmo3 gene have the disease trimethylaminuria that results in accumulation and excretion of TMA causing an undesired fishy malodor. ${ }^{273}$ Conversely, targeting the microbial component of this pathway could have additional benefits beyond decreased TMAO production. Choline plays essential roles in biology as a methyl donor, a precursor to the neurotransmitter acetylcholine, and a component of lipid biomolecules. The depletion of available choline due to gut microbial choline metabolism has been recently shown to have other effects on host physiology. ${ }^{274}$ The decreased abundance of choline in a mouse model of metabolic disease led to altered lipid metabolism and one-carbon metabolism that manifested as changes in DNA methylation. ${ }^{274}$ This host-microbial metabolic pathway is a clear example by which the microbial transformation of a dietary molecule can promote disease and thus represents a specific target for manipulation of the gut microbiota to influence host health.

The enzyme responsible for anaerobic microbial choline metabolism, choline TMA-lyase (CutC), was recently identified through a genome mining approach and is widely distributed in gut microbial genomes and human gut metagenomes. ${ }^{275-277}$ CutC is another member of the GRE family, but prior to its characterization, $\mathrm{C}-\mathrm{N}$ bond cleavage was not a known transformation for these enzymes. As with all GREs, a partner radical SAM activating enzyme generates the catalytic glycyl radical on CutC. ${ }^{275}$ The mechanism of $\mathrm{C}-\mathrm{N}$ bond cleavage is proposed to initiate with hydrogen atom abstraction by the thiyl radical from the $\mathrm{C} 1$ position of choline to generate an $\alpha$-hydroxyalkyl radical intermediate. Deprotonation of the hydroxyl group and formation of a transient ketyl radical intermediate is then proposed to promote heterolytic cleavage of the $\mathrm{C}-\mathrm{N}$ bond to directly eliminate TMA. This proposal is supported by the substrate-bound crystal structure of CutC. ${ }^{278}$ The substrate is positioned in the active site pocket with a gauche conformation that is imposed by $\mathrm{CH}-\mathrm{O}$ hydrogen bonding interactions between the partial positively charged, polarized $N$-methyl groups and the oxygen atoms of active site residues. ${ }^{278}$
This conformation allows for hyperconjugation between the p-orbital of the carbon-centered radical and the $\sigma^{*}$ anti-bonding orbital of the $\mathrm{C}-\mathrm{N}$ bond and is expected to facilitate elimination of TMA. ${ }^{278}$ Following this step, the resultant acetaldehyde radical can abstract the hydrogen atom from the active site cysteine to regenerate the thiyl radical.

Instead of uptake and oxidation of TMA by the host, other gut microbes may further metabolize this molecule. Microbes from different environments have been shown to demethylate methylamines, such as TMA, by the action of corrinoiddependent methyltransferases. In the first step, the donor amine forms a covalent bond with a post-translationally modified pyrrolysine residue in the active site (Fig. 7b). ${ }^{279}$ Once activated, the supernucleophilic $\mathrm{Co}^{1+}$ state of the vitamin $\mathrm{B}_{12}$ cofactor attacks the donor methyl group in an $\mathrm{S}_{\mathrm{N}} 2$-like reaction (Fig. 7b), cleaving the $\mathrm{C}-\mathrm{N}$ bond of TMA. ${ }^{279}$ The resultant $\mathrm{CH}_{3}-\mathrm{Co}^{3+}$ cofactor can then be utilized as a methyl donor in one-carbon metabolism. Certain archaea possess $N$-methyltransferases that are able to initiate methanogenesis through the specific demethylation of TMA, dimethylamine, and monomethylamine. ${ }^{280}$ Interestingly, this activity has been demonstrated in human-associated methanogenic archaea and has been proposed as a route to lowering TMA levels and consequently TMAO production by the host. ${ }^{281,282}$ This "archaebiotic" proposal is an intriguing example of targeting a microbiallyproduced metabolite to treat its associated human diseases, such as trimethylaminuria and cardiovascular disease.

\section{$6.2 p$-Cresol production}

In addition to the reductive pathway for amino acid fermentation described above, Clostridia also commonly oxidize aromatic amino acids to their corresponding arylacetate derivatives. Whereas the tryptophan-derived indole-3-acetate produced via this pathway has beneficial properties, the tyrosine-derived metabolite can be further metabolized to molecules linked to human disease. The enteric pathogen C. difficile metabolizes the tyrosine-derived oxidation product 


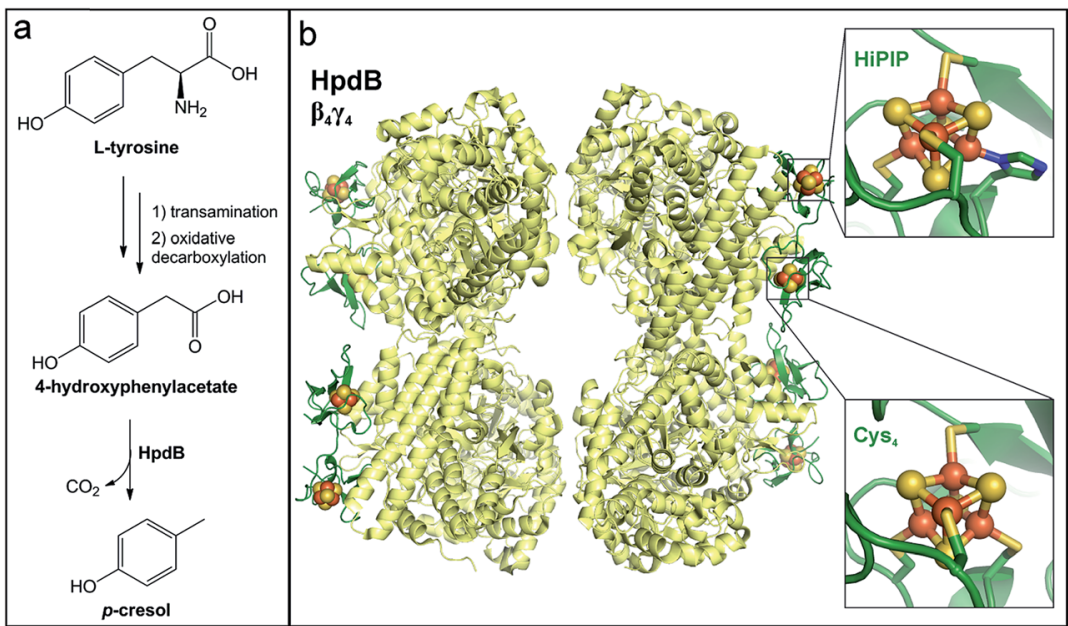

Fig. 8 Generation of $p$-cresol by a gut microbial glycyl radical enzyme. (a) Oxidative metabolic pathway in Clostridia for L-tyrosine conversion to p-cresol via a 4-hydroxyphenylacetate intermediate. (b) Hetero-octameric structure of the glycyl radical enzyme 4-hydroxyphenylacetate decarboxylase (PDB accession code: 2 YAJ) with the $\beta$-subunit shown in yellow and the $\gamma$-subunit shown in dark green. Insets show the two ironsulfur clusters harbored in the $\gamma$-subunit.

$p$-hydroxyphenylacetate to $p$-cresol (Fig. 8a). This metabolite has both antioxidant and antimicrobial properties. ${ }^{283,284}$ Thus, production of $p$-cresol has been proposed as a mechanism for this pathogen to eliminate microbial competition in the gut during invasion. ${ }^{285}$ Importantly, $p$-cresol production appears to be predictive of $C$. difficile virulence. So-called 'hypervirulent' strains of $C$. difficile have been shown to produce higher levels of $p$-cresol in culture and can tolerate higher concentrations of this molecule than less virulent strains. ${ }^{285,286}$ The production of $p$-cresol is an inducible activity in $C$. difficile; however, the mechanisms of regulation have not been elucidated. Comparative genomics of $C$. difficile strains identified an additional transcriptional regulator of phenolic acid metabolism in more virulent strains. ${ }^{287}$ Thus, differential regulation could be a possible explanation for the higher production of and/or tolerance to $p$-cresol exhibited in hypervirulent strains. Beyond the bactericidal effects of $p$-cresol, this metabolite can have other negative consequences on host biology. For example, $p$-cresol can be sulfated or glucuronidated by human enzymes to generate metabolites that have been implicated in chronic kidney disease. ${ }^{288,289}$ In fact, $p$-cresol competes with other substrates, including pharmaceuticals (e.g., acetaminophen), for sulfate conjugation by host enzymes, reducing the host's capacity to detoxify them.

The microbial enzyme that catalyzes production of $p$-cresol, $p$-hydroxyphenylacetate decarboxylase (HpdB), is a member of the GRE family. ${ }^{290}$ While it shares the common mechanistic features of protein-based radical-mediated chemistry that define this family, HpdB belongs to a separate subclass of the GRE family together with the enzyme benzylsuccinate synthase. ${ }^{291}$ These GREs are unique in their requirement for an accessory scaffold protein $(\gamma)$. This small $\gamma$-subunit is composed of two homologous domains that each harbor a [4Fe-4S] cluster (Fig. 8b). ${ }^{291,292}$ The C-terminal domain cluster has complete cysteine ligation, whereas the $\mathrm{N}$-terminal domain contains a HiPIP (high-potential iron-sulfur proteins)-like cluster coordinated by one histidine and three cysteine ligands (Fig. 8b). ${ }^{292}$ Redox titrations revealed only a single reduction potential of $-287 \mathrm{mV}$, suggesting that only one cluster, likely that with full cysteine ligation, is able to redox cycle, whereas the HiPIP cluster might play a structural role. ${ }^{293}$ Although the precise roles of these iron-sulfur clusters in GRE activity remain unclear, the $\gamma$-subunit is essential for decarboxylase activity. ${ }^{294}$ The active form of the HpdB decarboxylase protein ( $\beta$ ) is a $\beta_{4} \gamma_{4}$ hetero-octamer that associates only upon phosphorylation of a serine residue in the $\beta$-subunit. ${ }^{291}$ Conversely, when the serine is dephosphorylated, the $\gamma$-subunits dissociate and the $\beta$-subunits form inactive homodimers. ${ }^{294}$ The active hetero-octamer only has a single glycyl radical equivalent at any given time, ${ }^{294}$ and it is unusually short-lived in the absence of substrate relative to the lifetimes of glycyl radicals in other GREs. ${ }^{291}$ It has been postulated that dissipation of the glycyl radical is facilitated by one-electron reduction via the iron-sulfur cluster(s) in the $\gamma$-subunit. ${ }^{291}$ Glycyl radical quenching could be a regulatory mechanism to limit enzymatic production of the toxic molecule, $p$-cresol.

The radical SAM activating enzyme of the HpdB protein possesses, in addition to the canonical N-terminal radical SAM [4Fe-4S] cluster, extra [4Fe-4S] cluster(s) that are located in a C-terminal ferredoxin-like domain. ${ }^{291}$ With the exceptions of the archetypal GRE-AEs of pyruvate formate-lyase and anaerobic Class III ribonucleotide reductase, many other GRE-AEs possess a homologous ferredoxin-like C-terminal domain with conserved cysteine sequence motifs, suggesting that they also harbor one or more additional iron-sulfur clusters. However, the purpose of these clusters is not well established. In the case of the HpdB activating enzyme, elimination of the domain harboring the auxiliary [4Fe-4S] cluster did not abolish $5^{\prime}$-dA. production and the enzyme was still able to activate the decarboxylase ${ }^{295}$ Yet this truncated variant reduced the stability of the glycyl radical in the decarboxylase enzyme, decreasing its half-life 10 -fold. ${ }^{295}$ The observed radical lability has led to speculation that this domain could protect the glycyl radical 
from solvent during dissociation of the decarboxylase from the activating enzyme. ${ }^{295}$ Yet structural and spectroscopic characterization of GREs in complex with their activating enzymes is lacking to support this hypothesis.

Once activated, the mechanism of HpdB diverges from that of traditional glycyl radical enzymes. In the canonical mechanism, the first step in substrate activation is hydrogen atom abstraction by the active site cysteine-based thiyl radical. This type of mechanism was originally postulated for 4-hydroxyphenylacetate decarboxylation. In this proposal, the phenolic $\mathrm{O}-\mathrm{H}$ bond would be homolytically cleaved, generating an intermediate that acts as an electron sink for subsequent decarboxylation. ${ }^{290}$ However, the structure of the decarboxylase solved in the presence of substrate did not support that hypothesis, as it showed the carboxylate end of 4-hydroxyphenylacetate positioned near the cysteine. ${ }^{292}$ Thus, a mechanism was proposed in which the thiyl radical initiates a concerted proton-coupled electron transfer, abstracting an electron from the substrate carboxylate and a proton from a nearby glutamate residue. The resultant substrate radical undergoes a Kolbe-type decarboxylation, facilitated by parallel orbital alignment of the carboxylate-methylene $\mathrm{C}-\mathrm{C}$ bond with the benzene ring, to generate $\mathrm{CO}_{2}$ and a 4-benzoquinone methide radical anion upon deprotonation of the phenolic hydroxyl. Hydrogen atom abstraction from the catalytic cysteine would yield the $p$-cresol product and regenerate the thiyl radical. Quantum mechanical calculations support this proposed mechanism, ${ }^{296}$ postulating a transition state that is already induced by the protein in substrate binding to promote the Kolbe-type decarboxylation. ${ }^{\mathbf{2 9 2}}$

$p$-Cresol is a metabolite biomarker for autism spectrum disorder. ${ }^{297}$ High urinary levels of $p$-cresol, its sulfatedderivative, and a similar molecule, 4-ethylphenylsulfate, have been detected in young children with autism and are correlated with disorder severity. ${ }^{298}$ A higher abundance of $C$. difficile, in addition to other community shifts in the gut microflora, has been noted in children with autism,${ }^{298}$ which could explain the increased levels of $p$-cresol. However, this metabolic activity has also been attributed to Clostridium sporogenes as well as other gut microbes ${ }^{299,300}$ and has not been extensively profiled across other commensal microbes. Despite the observed accumulation of $p$-cresol in this patient population, its causative effect in autism, if any, has not yet been elucidated. Conversely, administration of 4-ethylphenylsulfate to conventional mice has been shown to induce anxiety phenotypes associated with the disorder. ${ }^{301}$ Interestingly, a single health-promoting bacterium, Bacteroides fragilis, reduced levels of 4-ethylphenylsulfate and other elevated metabolites in a mouse model of autism spectrum disorder. ${ }^{301}$ Both $p$-cresol-sulfate and 4-ethylphenylsulfate are thought to derive from tyrosine and are speculated to have similar bioactivities based on their chemical structures; however, it is worth noting that their enzymatic production likely differs. The Kolbe-type decarboxylation that results in $p$-cresol production relies on the orbital overlap between the $\mathrm{C}-\mathrm{C}$ bond to be cleaved and the $\pi$-system of the benzene ring, as well as resonance stabilization of the 4-benzoquinone methide radical anion intermediate. These molecular features are not conserved when the carbon chain is extended by a methylene group in the putative 4-ethylphenylsulfate precursor, and thus, an alternative enzymatic mechanism is likely used to achieve production of this metabolite. The enzyme(s) responsible for 4-ethylphenylsulfate production have not yet been identified.

\subsection{Ammonia production}

Urea is the major circulating pool and waste-product of nitrogen in humans. ${ }^{302}$ It is primarily generated in the liver, transferred through the kidneys, and excreted in urine. ${ }^{303}$ However, $\sim 20-$ $30 \%$ of this metabolite reaches the intestinal organs, ${ }^{304}$ where it can be used by gut bacteria as a source of nitrogen. Gut microbes capable of metabolizing urea possess the enzyme urease, which hydrolyzes urea to generate two equivalents of ammonia from every molecule of substrate. ${ }^{305}$ Some of the ammonia produced is metabolically assimilated by the ureasepositive microbe or by other gut inhabitants. Interestingly, the introduction of a urease-positive strain of $E$. coli into a mouse model reshaped the gut community composition and exacerbated the colitis phenotype in this model. ${ }^{306}$ The free ammonia that is not microbially assimilated becomes protonated, leading to high concentrations of positively-charged ammonium ions in the host intestine. Some ammonium ions can recirculate to the liver to be reused by hepatic cells. ${ }^{303}$ However, in individuals with liver dysfunction, ammonium ions accumulate throughout the body, leading to a condition termed hyperammonemia that can cause dysfunction of the central nervous system. ${ }^{307,308}$ Under normal physiological conditions, the urea-derived ammonium ions that do not get recirculated to the liver remain in the colon. These ions cause an increase in $\mathrm{pH}$ that helps to offset the acidity arising from short-chain fatty acids produced by gut microbes. While the shift in $\mathrm{pH}$ resulting from urease activity is beneficial in the context of the colon, it also enables the pathogen Helicobacter pylori to colonize in the stomach. The low $\mathrm{pH}$ of the stomach normally precludes bacterial colonization, but the urease activity of $H$. pylori creates a microenvironment with a more neutral $\mathrm{pH}^{309}$ In addition, ammonium ions have been shown to have direct cytotoxic effects on gastric epithelial cells, contributing to the pathology of $H$. pylori infection. ${ }^{310}$ For these reasons, urease is considered a virulence factor of $H$. pylori and other pathogens, and is a primary antigen for the host immune response to $H$. pylori. ${ }^{309,311}$

The decomposition of urea by urease occurs in two steps. The first is enzymatic hydrolysis to produce ammonia and carbamate, followed by non-enzymatic hydrolysis of carbamate in water to yield the second molecule of ammonia and carbonic acid (Fig. 9a). ${ }^{312}$ The enzymatic reaction carried out by urease is facilitated by a rare dinickel cofactor, which acts as a Lewis acid to activate the substrate and water. The dinickel cofactor enhances the electrophilicity of the urea carbonyl and lowers the $\mathrm{p} K_{\mathrm{a}}$ of water, generating the more nucleophilic hydroxide ion. ${ }^{305}$ Urease was the first enzyme to be crystallized, an experiment which confirmed that enzymes are proteins and garnered a Nobel Prize. ${ }^{305}$ Numerous crystal structures have been solved of this enzyme from bacterial and plant sources in its resting state and in the presence of small molecule inhibitors that 


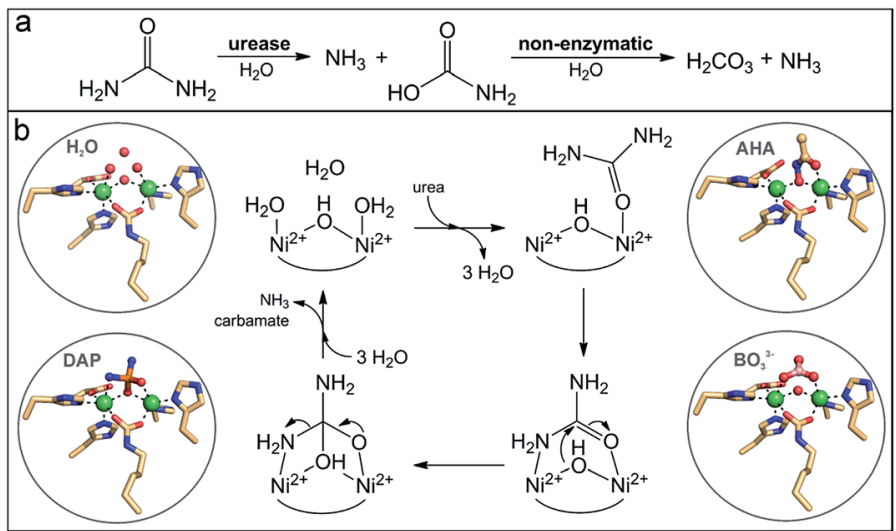

Fig. 9 Microbial urea metabolism catalyzed by the dinickel enzyme urease. (a) Two-step breakdown of urea. (b) Proposed catalytic cycle of urease mediated by its dinickel (green spheres) cofactor. Active site depictions of inhibitor-bound structures that support the mechanism are shown as insets (PDB accession codes: $\mathrm{H}_{2} \mathrm{O}=2 \mathrm{UBP}$, acetohydroxamic acid, $\mathrm{AHA}=4 \mathrm{UBP}, \mathrm{BO}_{3}{ }^{3-}=1 \mathrm{~S} 3 \mathrm{~T}$, diamidophosphate, $\mathrm{DAP}=3 \mathrm{UBP}$ ).

illustrate key features of the proposed mechanism for urea hydrolysis. ${ }^{305}$ The protein exists as a trimer of trimeric subunits $(\alpha \beta \gamma)_{3}$ with the dinickel cofactor in the $\alpha$ subunit, giving three active sites per trimeric complex. ${ }^{313,314}$ The two $\mathrm{Ni}^{2+}$ ions in each active site are located within $\sim 3 \AA$ from one another in a weakly antiferromagnetically-coupled cluster. ${ }^{305,313,314}$ The coupling is achieved through two bridging ligands - a hydroxide and a posttranslationally modified carbamylated lysine residue (Fig. 9b). ${ }^{314}$ The former acts as the nucleophile in urea hydrolysis and the latter is essential for nickel ion binding. ${ }^{315}$ The dinickel cofactor is asymmetrically coordinated with two histidine ligands at the $\mathrm{Ni}^{2+}$ ion in site 1 and two histidine residues and a monodentate aspartate residue ligating the $\mathrm{Ni}^{2+}$ ion in site 2 (Fig. 9b)..$^{313,314}$ In the resting state, the first coordination sphere of both sites includes a water ligand, resulting in a sixcoordinate metal at site 2 and a five-coordinate metal at site 1 (Fig. 9b)..$^{314}$

In the presence of substrate, both water ligands are displaced and urea is proposed to bind directly via its carboxyl oxygen to the open coordination site of the nickel ion in site 1 . This coordination is supported by the structure solved in the presence of the urease inhibitor, acetohydroxamic acid (AHA), ${ }^{316}$ which effectively mimics the bridging hydroxyl group and the urea structure (Fig. 9b). A conformational change is then proposed to induce coordination of the urea amine to the $\mathrm{Ni}^{2+}$ at site 2 , poising the molecule as a $\mu-1,3$-bridging ligand for attack by the bridging hydroxide. This bridging mode is analogous to that observed in the borate-inhibited structure (Fig. 9b). ${ }^{317}$ The structure with the inhibitor diamidophosphate (DAP) (Fig. 9b) (14 $^{314}$ has led to the proposal of a tetrahedral intermediate (or transition state) upon nucleophilic attack of the bridging hydroxide that is stabilized through an extensive hydrogen-bonding network. Finally, protonation of the coordinated amine by a nearby histidine residue is postulated to facilitate its elimination. ${ }^{305}$

Urease is one of just a handful of enzymes that use a nickelcontaining metallocofactor. ${ }^{305,318,319}$ Most metal-dependent hydrolases utilize the non-redox active $\mathrm{Zn}^{2+}$ ion in mono-, diand tri-nuclear clusters for catalysis. However, urease is highly specific for its dinuclear $\mathrm{Ni}^{2+}$ cofactor, as it is inactive with $\mathrm{Zn}^{2+}$ and other divalent metals. ${ }^{320,321}$ Both $\mathrm{Ni}^{2+}$ and $\mathrm{Zn}^{2+}$ have large positive charge density that can facilitate polarization of the hydroxide nucleophile and the substrate. However, the protein active site could favor intrinsic stereoelectronic properties of $\mathrm{Ni}^{2+}$ over $\mathrm{Zn}^{2+}$ ions. ${ }^{305,322}$ The $\mathrm{d}^{8}$ electronic configuration of $\mathrm{Ni}^{2+}$ favors an octahedral coordination sphere, whereas $\mathrm{Zn}^{2+}$ ion complexes in biology typically have tetrahedral geometry. Thus, the active site geometry could rearrange with $\mathrm{Zn}^{2+}$ ions to potentially preclude bridging of the water nucleophile and of the substrate. Conversely, the preference for an octahedral coordination sphere results in open $\mathrm{Ni}^{2+}$ coordination sites occupied by labile water molecules that can be displaced for proper positioning of the activated substrate with respect to the bridging hydroxide ligand to facilitate ureolysis.

The importance of the dinickel cofactor is also underscored by the suite of accessory proteins dedicated to its incorporation into the urease apo-protein. ${ }^{323}$ Four accessory proteins, UreDEFG, are often encoded in the same operon with the urease gene and are minimally essential for urease activity in most bacteria. ${ }^{323,324}$ UreD is postulated to act as a protein scaffold for a multicomponent complex of the apo-urease enzyme with the other accessory proteins. ${ }^{325-327}$ UreF binding to the apo-ureaseUreD complex induces a conformational change that exposes the urease active site, providing access for the nickel ions and $\mathrm{CO}_{2}$ for lysine carbamylation. ${ }^{325,328}$ Lastly, UreG catalyzes GTP hydrolysis that is proposed to drive $\mathrm{Ni}^{2+}$ transfer from the metallochaperone UreE to the urease active site. ${ }^{329}$ Nickel binding sites have been identified in the UreE metallochaperone, ${ }^{330-332}$ as well as UreG and UreF proteins, ${ }^{333,334}$ suggesting a metal shuttling mechanism from UreE via UreG and UreF to the final destination in the urease active site. ${ }^{327}$ The UreDEFG proteins are sufficient to activate urease that is heterologously expressed in E. coli. ${ }^{335}$ However, in some native bacteria, additional proteins can play essential roles in urease nickel-activation, including nickel ion permeases, transporters, and binding proteins. ${ }^{324,336}$ Furthermore, there is an interesting, yet not fully understood, connection between the proteins responsible for biogenesis of the [NiFe]-hydrogenase cofactor 
(HydA and HydB) and the UreG and UreE proteins that is essential for urease activation in $H$. pylori. ${ }^{336-338}$

In addition to the urease enzyme itself, the importance of these accessory proteins in urease activity renders them each unique targets for inhibition of this metabolism. Inhibitors of urease activity have been studied for more than 50 years, ${ }^{339,340}$ but primarily have been applied to combat $H$. pylori gastric and Proteus urinary infections. ${ }^{341}$ More recently, efforts to minimize gut microbial urease activity via microbiota transplant have been directed toward the treatment of hyperammonemia. ${ }^{342}$ Introduction of a model gut community with minimal urease activity into mice promoted development of a more complex microflora with reduced urease activity ${ }^{342,343}$ and was shown to improve phenotypes associated with hyperammonemia. ${ }^{342}$ In a similar fashion, manipulation of the gut microbiota, or specific targeting of urease and its cofactor biosynthetic machinery, could be applied to the treatment of Crohn's disease, which is exacerbated by high urease activity. ${ }^{306}$

\subsection{Hydrogen sulfide production}

The typical gut microbiota in a healthy adult human is dominated by two phyla, Firmicutes and Bacteroides, representing up to $90 \%$ of all microbes. ${ }^{12,13}$ However, environmental factors, such as diet, ${ }^{344}$ can enable blooms of residents that are typically only present in low abundance. For example, the Deltaproteobacterium Bilophila wadsworthia is barely detectable in the average healthy human gut; however, in mice fed a typical highfat Western diet, the population of B. wadsworthia expands. ${ }^{345}$
Importantly, this shift in community composition has been correlated with ulcerative colitis and colon cancer. ${ }^{345-347}$

The genus name of this organism means "bile-loving", hinting at the underlying cause of its expansion. Bile acids are produced exclusively by vertebrates to emulsify dietary lipids and fat-soluble vitamins, which facilitates their absorption in the intestines. ${ }^{348}$ They are also signaling molecules, acting as ligands to nuclear and G-protein coupled receptors that regulate lipid, glucose, and energy metabolism..$^{348,349}$ These biomolecules are synthesized from cholesterol in the liver and conjugated with glycine and taurine to form salts that can then enter the digestive system. ${ }^{350}$ While some microbes are sensitive to the moderate antibacterial activity of bile acids, ${ }^{351}$ other gut microbes and pathogens transform these molecules into secondary bile acids through deconjugation, oxidation, and dehydroxylation reactions. ${ }^{352}$ Some of these secondary bile acids can be reabsorbed through enterohepatic circulation to accumulate in the liver, whereas others are excreted. ${ }^{352}$ High levels of these microbiallyderived molecules in bile, blood, and feces have been correlated with gallstone disease and colon cancer. ${ }^{352}$ Although the purposes of bile acid oxidation and dehydroxylation are not entirely understood, the deconjugation of bile salts liberates free glycine and taurine, which can be sources of carbon, nitrogen, and sulfur, as well as substrates for energy production.

In the case of B. wadsworthia, the released taurine is metabolized to generate sulfite (Fig. 10a), which can be used as an electron acceptor for anaerobic respiration. ${ }^{353}$ Indeed, only taurine-conjugated bile salts induced a bloom of $B$. wadsworthia

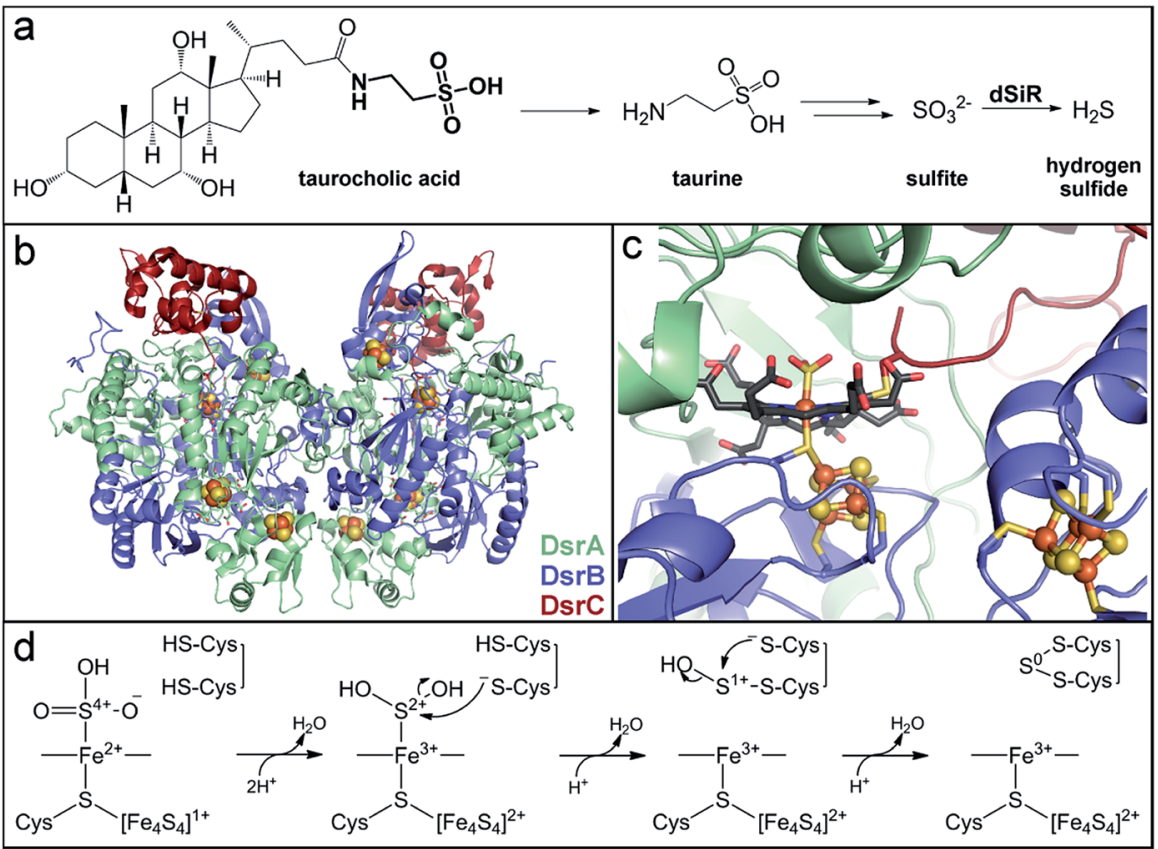

Fig. 10 Microbial taurine metabolism linked to human disease. (a) Deconjugation of taurine-bile salts by microbes releases free taurine, followed by reduction of the downstream metabolite sulfite to hydrogen sulfide as a means of anaerobic respiration. (b) Quaternary structure of the dissimilatory sulfite reductase (PDB accession code: $2 \mathrm{~V} 4 \mathrm{~J}$ ), composed of a dimer of trimeric subunits: DsrA (light green), DsrB (blue), and DsrC (red). Iron-sulfur clusters are depicted as spheres. (c) DsrB active site located at the interface with the DsrA subunit, depicting the siroheme cofactor bridged to one iron-sulfur cluster and a sulfite ligand. The C-terminal tail of the DsrC subunit is shown in red. (d) Proposed mechanism for the first two two-electron reduction steps mediated by the DsrABC complex that yields the protein-based trisulfide substrate for anaerobic respiration. 
in $I L 10^{-1-}$ deficient mice. ${ }^{345}$ This expansion can be recapitulated by a milk, saturated fat-based diet, as it stimulates increased production of taurine-conjugated bile salts. ${ }^{345}$ Notably, this diet and the associated expansion of B. wadsworthia have been connected with development of colitis in IL $10^{-1-}$ deficient mice. ${ }^{345}$ Although genetic susceptibility is essential in this model, the colonization of this pathobiont and its metabolic functions are causative in development of the observed disease phenotypes.

The final product of taurine metabolism and sulfite respiration, hydrogen sulfide (Fig. 10a), has been detected at higher levels in patients with ulcerative colitis. ${ }^{354,355}$ While this observation might suggest a role of this gaseous molecule in inducing the disease, contradictory properties of hydrogen sulfide have complicated efforts to establish its causality in ulcerative colitis. ${ }^{356}$ Hydrogen sulfide is an inhibitor of host $\beta$-oxidation of microbially-produced short-chain fatty acids in colonocytes, ${ }^{357}$ preventing energy acquisition and compromising the epithelial barrier. It has also been shown to stimulate T-cell activation, ${ }^{358}$ which could induce antigen production against commensal microbes. Conversely, various reports have shown hydrogen sulfide to be anti-inflammatory and ameliorate colitis in animal models. ${ }^{359-361}$ Thus, the role of hydrogen sulfide in the development or mediation of inflammatory bowel disease remains to be definitively established.

Hydrogen sulfide is generated from the six-electron reduction of sulfite. In B. wadsworthia, this reaction is catalyzed by the metalloenzyme dissimilatory sulfite reductase (dSiR). ${ }^{362}$ Its structure consists of three subunits with $\alpha_{2} \beta_{2} \gamma_{2}$ stoichiometry (Fig. 10b), encoded by the genes $d s r A$, $d s r B$ and $d s r C$, respectively. The DsrA and DsrB proteins are evolutionarily related as paralogs that likely resulted from gene duplication and divergent evolution to only maintain $\sim 20 \%$ sequence identity in contemporary bacteria. Thus, these two subunits form a structurally symmetric heterodimer, but only the DsrB subunit harbors a functional active site capable of sulfite reduction. ${ }^{363}$ The active site in the DsrB subunit, situated at the interface of the $\alpha \beta$ dimer, contains a siroheme cofactor that is bridged via the axial cysteine ligand to a $[4 \mathrm{Fe}-4 \mathrm{~S}]$ cluster (Fig. 10c). In contrast, the corresponding site in the DsrA subunit contains a demetallated siroheme (termed sirohydrochlorin), lacks critical conserved residues, and has an occluded substrate channel. The role of the third subunit DsrC $(\gamma)$ was contentious for some time; however, recent biochemical characterization of this protein, described below, revealed its essential role in sulfite reduction. ${ }^{364}$

The overall six-electron reduction of sulfite to hydrogen sulfide was originally proposed to occur by three consecutive two-electron reduction steps. ${ }^{365-367}$ However, at present the data suggest that the three steps occur by different mechanisms and with different electron sources. In the current proposal, the siroheme cofactor in DsrB activates the sulfite substrate and mediates the first two-electron reduction (Fig. 10d). This type of cofactor is found in all types of sulfite reductases (assimilatory and dissimilatory), as well as some nitrite reductases, underscoring its ability to mediate multi-electron reduction of inorganic anions. ${ }^{367}$ The two inorganic components, the iron ion of the siroheme and the $[4 \mathrm{Fe}-4 \mathrm{~S}]$ cluster, are electronically coupled through the bridging cysteine ligand, ${ }^{368}$ which enables the cofactor to effectively store two electron equivalents. The two reducing equivalents are provided by an unknown exogenous source and are thought to be transferred via an additional $[4 \mathrm{Fe}-4 \mathrm{~S}]$ cluster that is located close to the protein surface in a ferredoxin-like domain of the DsrB subunit. ${ }^{363}$ In the reduced state, the coupled iron-sulfur cluster is in the 1+ oxidation state and the siroheme has a high-spin $\mathrm{Fe}^{2+}$ ion with an open axial coordination site. The structure of the dSiR complex solved in the presence of substrate demonstrated direct sulfite ligation via the sulfur atom to the open coordination site of the DsrB siroheme with tetrahedral geometry (Fig. 10c). ${ }^{363}$ The substrate oxygen atoms are stabilized in the active site by positivelycharged lysine and arginine residues. Coordination of the $\pi$ acceptor sulfite substrate to the electron-rich siroheme- $\mathrm{Fe}^{2+}$ weakens the S-O bond through $\pi$-backbonding, facilitating its cleavage upon reduction. ${ }^{365,366}$ This bond breaking step is likely also facilitated by protonation of the departing oxygen atom.

The next step in sulfite reduction is primarily mediated by the DsrC subunit. DsrC possesses two conserved cysteine residues at the C-terminal tail that are critical for conversion of sulfite to sulfide with fidelity. ${ }^{364}$ This tail is disordered in solution, but the structure of DsrAB in complex with DsrC showed the C-terminal tail positioned in a crevice between the $\alpha \beta$ dimer in close proximity to the siroheme cofactor (Fig. 10c). ${ }^{363}$ In vitro characterization revealed that this cysteine thiol forms a trisulfide with the sulfur atom derived from sulfite and the other conserved cysteine residue. ${ }^{369}$ This intermediate was rationalized to arise from nucleophilic attack of the deprotonated cysteine thiol on the two-electron reduced sulfite intermediate ligated to the siroheme (Fig. 10d). This step would result in dehydration and reduction of the intermediate to generate sulfur in the 1+ oxidation state, which would weaken the S-Fe $\mathrm{Fe}^{3+}$ bond and induce dissociation. Attack by the other cysteine thiol would eliminate the final hydroxyl group to form the trisulfide intermediate (Fig. 10d).

The elucidation of this intermediate illuminated the key to sulfite respiration. The neutral oxidation state of the sulfitederived sulfur atom in the trisulfide intermediate implies that the dissimilatory sulfite reductase system (DsrABC) only reduces sulfite by four electrons. The final two electrons needed to reduce the trisulfide are predicted to derive from the membrane-bound DsrMKJOP complex ${ }^{369}$ that had been previously implicated in sulfite reduction. ${ }^{364}$ The DsrK subunit is homologous to the heterodisulfide reductase HdrD in methanogens and, like HdrD, possesses a [4Fe-4S] cluster that could reduce the trisulfide intermediate. ${ }^{370,371}$ Involvement of this complex enables coupling of electron transfer and subsequent substrate reduction to the transfer of protons across the membrane, generating a proton motive force to drive energy production. ${ }^{369,371}$ This concept could not be rationalized previously invoking a six-electron reduction by the cytoplasmic DsrABC components alone because no membrane components were involved. In this model, DsrABC are responsible for the four-electron reduction of sulfite to the protein-based trisulfide, 
which then serves as the terminal electron acceptor for anaerobic respiration by the DsrMKJOP complex.

The complexity of this multi-component protein system is interesting in light of the observation that siroheme itself is competent for sulfite reduction to hydrogen sulfide in isolation with exogenous reductants. ${ }^{372,373}$ In this instance, Nature has evolved a mechanism to limit the involvement of the siroheme cofactor in order to generate energy from the final two-electron reduction step. Ultimately, the ability to anaerobically respire on taurine-derived sulfite gives B. wadsworthia a competitive advantage in the gut. However, this microbial adaptation can have inadvertent negative consequences for the host and provides a clear example of the complex interactions between external factors (i.e., diet), host biology, microbial metabolism, and human disease.

\section{Microbial metabolism of xenobiotics}

The human host and gut microbes are continually exposed to foreign substances, or xenobiotics, including pharmaceuticals, dietary bioactive molecules, and environmental chemicals. Transformation of pharmaceuticals by human enzymes is well-established, but the gut microbiota also plays a role in drug metabolism and can affect both drug availability and efficacy. ${ }^{374,375}$ However, in the vast majority of cases these transformations have not been connected to specific microbes and/or enzymes. Human enzymes that process xenobiotics typically catalyze oxidative and conjugative reactions to increase the polarity and molecular weight of these substances, thus facilitating their excretion. ${ }^{375}$ In contrast, microbial transformations of xenobiotics are most often hydrolytic and reductive, allowing the bacteria to access sources of nutrients and energy..$^{374,375}$ The cancer drug irinotecan is a well-studied example of a pharmaceutical small molecule drug that undergoes a hydrolytic transformation by gut microbes to provide a source of carbon and energy. The active form of the drug is detoxified through glucuronidation by human liver enzymes, leading to its inactivation and excretion. ${ }^{376}$ However, as the glucuronide form traverses the GI tract, microbes in the large intestine cleave the sugar appendage through the action of $\beta$-glucuronidases, releasing it for further metabolism. ${ }^{376}$ This reaction reactivates the drug in the gut, causing severe side effects that limit its pharmacological use. ${ }^{376}$ Whereas this transformation is an example of an undesirable gut microbe-drug interaction, in other cases microbial metabolism is required for drug activation. For instance, the rheumatoid arthritis and ulcerative colitis drug sulfasalazine (Fig. 11a) is delivered as a prodrug with an azo moiety that is converted by microbial azoreductases to the biologically active agent. ${ }^{377-380}$ The metabolizing bacteria may be using sulfasalazine and other azo-containing drugs as terminal electron acceptors for anaerobic respiration to increase their energy production. However, the specific azoreductases for many of these prodrugs have not been discovered or characterized.

The nature of reductive chemistry necessitates electron transfer, a common function of metallocofactors. Digoxin is a cardiac drug that is metabolized by strains of the gut microbe Eggerthella lenta, rendering it inactive. ${ }^{381,382}$ The reduction of digoxin to (20R)-dihydrodigoxin (Fig. 11b) is catalyzed by two proteins, termed Cgr1 and Cgr2. ${ }^{381,382}$ Cgr1 shares sequence homology with membrane-associated cytochrome proteins and is predicted to harbor multiple cytochrome c-type hemes. ${ }^{382}$ This protein is postulated to participate in electron delivery to Cgr2, which catalyzes the reduction of the $\alpha, \beta$-unsaturated lactone moiety in digoxin. ${ }^{382}$ Cgr2 shares homology with flavindependent reductases and requires FAD for activity, but also harbors a $[4 \mathrm{Fe}-4 \mathrm{~S}]$ cluster that can potentially mediate electron transfer from the Cgr1 partner to the flavin cofactor for digoxin reduction. ${ }^{383}$ The presence of a [4Fe-4S] cluster in Cgr2 was not predicted bioinformatically from the protein sequence, and thus Cgr2 likely uses a novel fold to accommodate this metallocofactor. Interestingly, the reduction activity of Cgr2 is specific for substrates of the cardenolide structural family, which originate from plant sources. ${ }^{383}$ The lack of enzymatic

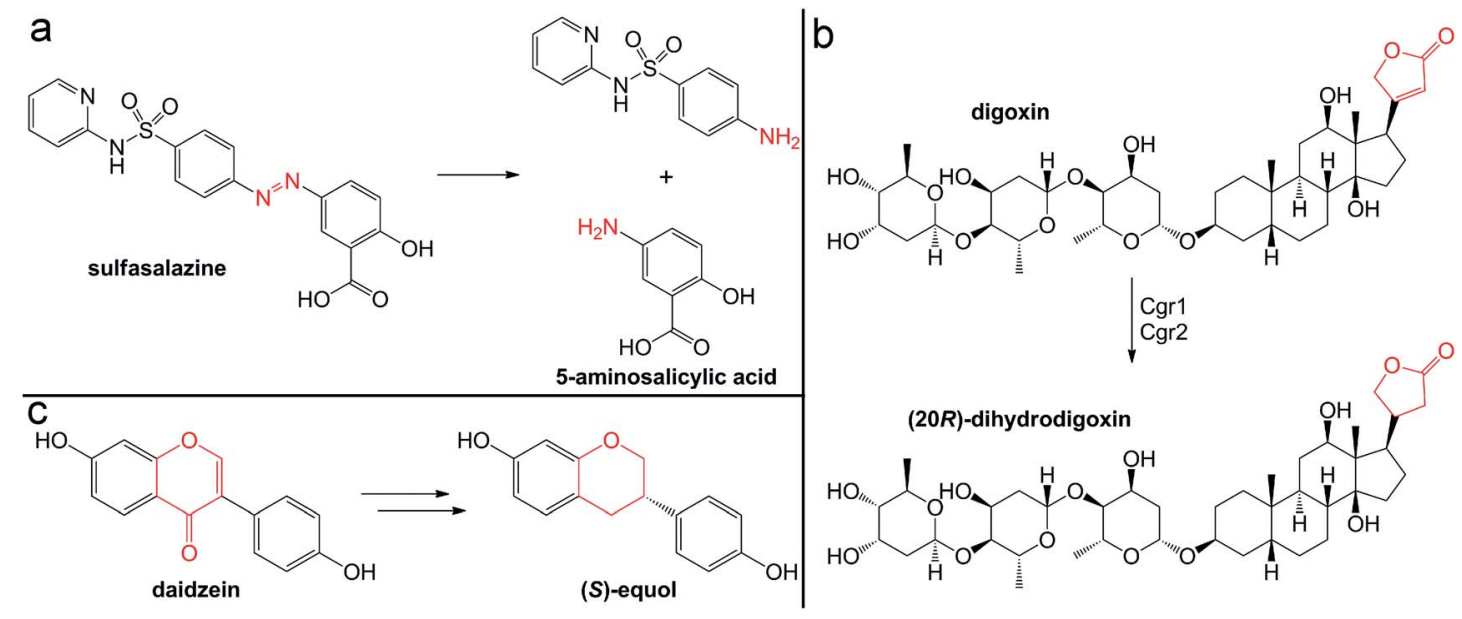

Fig. 11 Reductive transformations of the xenobiotics (a) sulfasalazine, (b) digoxin, and (c) daidzein by gut microbes. 
activity toward additional endogenous host and dietary substrates suggests that this activity may not have arisen from promiscuous enzyme activity. One possible explanation could be that Cgr2 evolved to protect the host from the toxicity of these plant-derived compounds. ${ }^{383}$ This discovery portends that there may be other novel enzymes to uncover from the gut environment that have evolved specifically in response to xenobiotic exposure.

Similar reductive strategies are predicted in the transformation of dietary molecules, such as phytochemicals that are associated with altered disease risk. The soy-derived isoflavonoid, daidzein, is sequentially reduced by gut microbes to the estrogenic molecule, equol (Fig. 11c). ${ }^{384}$ Equol has been linked to reduced risk for breast and prostate cancers, likely due to its ability to act as a ligand for the human estrogen receptor. ${ }^{\mathbf{3 8 4}}$ However, there is substantial variation among individuals in the ability of their gut microbiota to metabolize daidzein to equol. ${ }^{385}$ Equol-producing organisms possess a gene cluster that encodes for three essential enzymes that convert daidzein to equol. ${ }^{386-389}$ The first enzyme, daidzein reductase, catalyzes the initial flavindependent reduction to generate dihydrodaidzein. ${ }^{387}$ In addition, this enzyme is predicted to harbor a $[4 \mathrm{Fe}-4 \mathrm{~S}]$ cluster based on conservation of a cysteine-rich sequence motif. ${ }^{387}$ Although this hypothesis remains to be experimentally confirmed, an electron transfer role for this metallocofactor is easily envisioned in isoflavanoid reduction.

These examples are some of the few enzymes that have been connected to xenobiotic metabolism. Discovery of the organisms and enzymes responsible for other transformations will enable the identification of gene markers for metabolism that could be applied to predict an individual's response to different diets or drug therapies. It could also lead to development of approaches to enhance production of beneficial bioactive compounds and mitigate negative effects that influence drug bioavailability and efficacy. The metabolic capabilities of the gut microbiota, together with the variability in drug-metabolizing enzymes in the human genome, can have dramatic impacts on inter-individual response to medications and on development of precision medicine.

\section{Metalloenzyme abundance in human microbiomes}

Each of the isolated cases discussed in this review demonstrates the relevance of metalloenzymes in human gut microbial metabolism. However, the characterized enzymes from the gut microbiota represent a very small portion of the genetic potential associated with this community. To evaluate the prevalence and distribution of different classes of metalloenzymes in the human gut microbiota, we analyzed the stool metagenomes originating from the first phase of the NIH Human Microbiome Project (HMP), a study of the microbiotas of healthy adult individuals from the United States. ${ }^{13}$ We first categorized the genes identified in the assembled stool metagenomes into functional protein families using criteria from the Pfam protein family database (Fig. 12b). ${ }^{390}$ Only $\sim 40 \%$ of these genes can be assigned to a protein family (Fig. 12b). Table 1 shows the most highly represented families that use a metallocofactor (redox or non-redox) for their function (among proteins with representation greater than 1 out of every 1000 genes). An analogous analysis using criteria from the enzyme
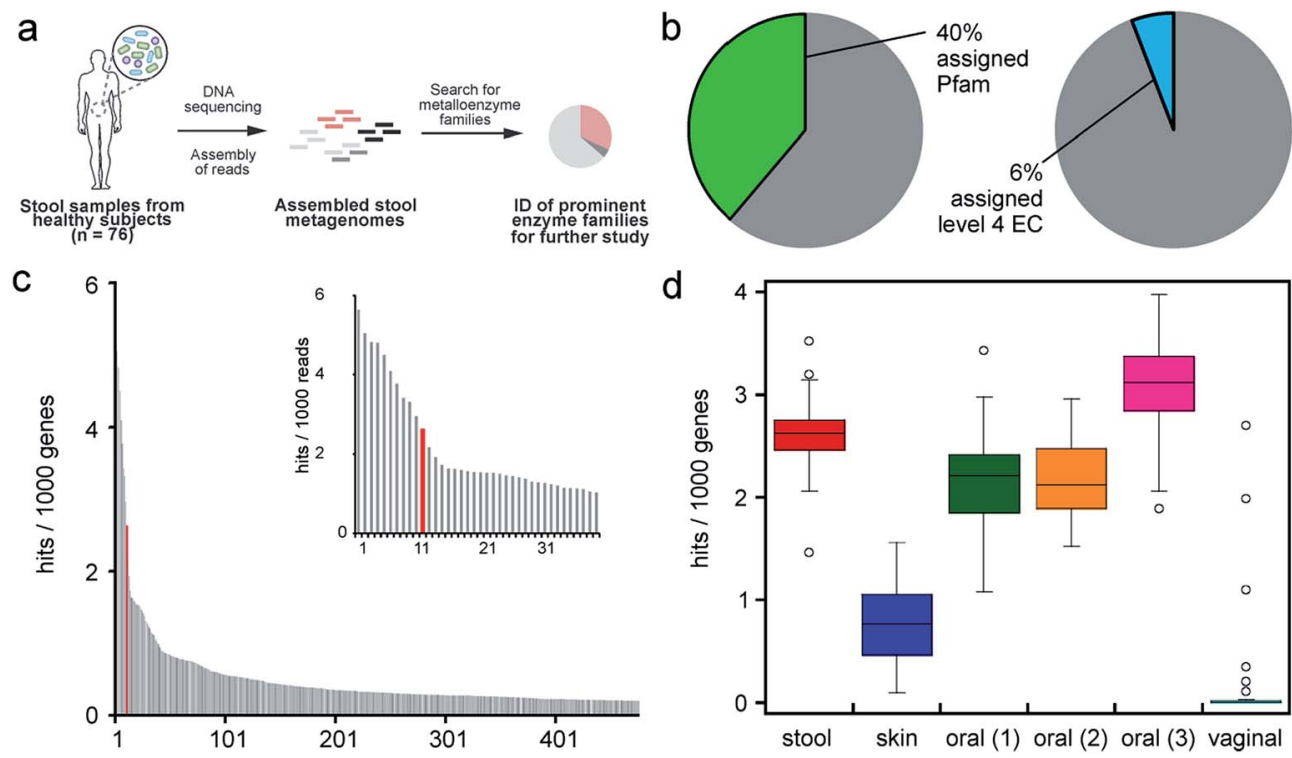

Fig. 12 Analysis of metalloenzyme family prevalence and distribution in HMP metagenomes using the Pfam or EC classification systems. (a) Overview of analysis workflow. (b) Percentage of genes assigned a Pfam or EC number. (c) Pfam classes with representation in HMP stool metagenomes above a threshold of 1 hit/5000 genes and 1 hit/1000 genes (inset). The radical SAM superfamily, highlighted in red, is the eleventh highest represented family overall. (d) Prevalence of radical SAM enzyme encoding genes in the HMP assembled metagenomes from different body sites. Box plots are standard Tukey plots representing the median, $25^{\text {th }}$ and $75^{\text {th }}$ quartile values for radical SAM representation in the metagenomes of various human body sites. [oral (1) = buccal mucosa; oral (2) = supragingival plaque; oral (3) = tongue dorsum]. 
Table 1 Representation of protein families that use a metallocofactor in the HMP assembled stool metagenomes above a mean threshold of 0.5 hits/1000 genes

\begin{tabular}{lll}
\hline Pfam & Pfam description & $\begin{array}{l}\text { Mean representation } \\
\text { in stool metagenomes } \\
\text { (hits/1000 genes) }\end{array}$ \\
\hline PF04055 & Radical SAM superfamily & 2.6 \\
PF00149 & Calcineurin-like phosphoesterase & 1.5 \\
PF01609 & Transposase DDE domain & 1.4 \\
PF00293 & NUDIX domain & 0.76 \\
PF01546 & Peptidase family M20/M25/M40 & 0.66 \\
PF13408 & Recombinase Zn $\beta$-ribbon domain & 0.65 \\
PF00383 & CMP/dCMP deaminase & 0.63 \\
& Zn-binding domain & \\
PF01807 & CHC2-type Zn finger domain & 0.61 \\
PF01966 & HD domain & 0.61 \\
PF00557 & Metallopeptidase family M24 & 0.60
\end{tabular}

commission (EC) classification system, which is substantially more stringent, resulted in fewer annotations. Less than $6 \%$ of the genes in the assembled stool metagenomes could be assigned a level 4 EC function (Fig. 12b), which is the level needed to evaluate the use of a metallocofactor in catalysis. Therefore, this classification system was not suitable for assessing metalloenzyme prevalence and distribution.

Using the Pfam classification analysis, we found that the radical SAM enzyme superfamily is the most prevalent metalloenzyme family in the human gut microbiome. This observation is perhaps unsurprising, as this family is highly represented in anaerobic bacteria, which dominate the healthy human GI tract. Radical SAM enzymes are found in every subject sampled with a mean representation of 2.6 hits per 1000 genes and a range of 1.5-3.5 hits per 1000 genes in metagenome assemblies (Fig. 12c and d). This high representation of radical SAM enzymes is not universal, as similar analyses of additional HMP metagenomes revealed the skin and vaginal microbiotas have a very low prevalence of radical SAM enzymes (Fig. 12d). While this observation might be expected because of the oxygen present in these habitats, the oral cavity, which includes both aerobic and anaerobic sites, has a high representation of radical SAM enzymes. Interestingly, this trend was also noted when assessing the abundance of genes encoding GREs, which are typically co-localized with radical SAM activating enzymes, in these same data sets. ${ }^{125}$ The prevalence of GREs in both the oral and gut cavities led the authors to posit that the oral cavity could be a reservoir for bacteria that can colonize the colon and have unique impacts in that niche. ${ }^{125}$ As demonstrated throughout this review, radical SAM enzymes are already known to play a wide range of roles in gut microbial metabolism. However, our analysis reveals that the majority of the radical SAM genes present in the stool metagenomes remain uncharacterized, as less than $40 \%$ have an assigned EC number. While this likely reflects the overall lack of characterization of this extensive superfamily (>300 000 members), the biological context of this particular analysis could offer leads for uncharacterized enzymes to prioritize for further study.
Inclusive of and beyond metalloenzyme families, the vast amount of genetic data from individual organisms and microbial communities creates a challenge for identifying and prioritizing enzymes for study. With respect to the gut microbiota, the enzymes and metabolic functions that have an impact on human health and disease are obvious candidates of interest. One approach to uncover potentially diseaseassociated activities is to compare metagenomic, metatranscriptomic, metaproteomic, and metabolomic data sets from healthy and patient populations. This type of analysis could identify differentially regulated genes, expressed proteins, and microbial metabolites that may contribute to disease risk or development as well as provide support for proposed associations between gut microbial metabolism and host health and disease. Other experimental approaches such as activity-based functional profiling can be impactful tools for the discovery of novel enzymes by leveraging their chemical properties. Although not widely applied to gut microbial communities as of yet, this technique was used to enhance a comparative metaproteomic study of a mouse model of IBD using a cysteine nucleophile-reactive probe to assess host and microbial peptidase profiles. ${ }^{391}$ The quantification of gene abundance may be a critical component for assessing relevance in the gut microbiota. An approach termed chemically-guided functional profiling, which uses the computational tool ShortBRED ${ }^{392}$ in conjunction with Sequence Similarity Network analysis, ${ }^{393}$ has been applied to assess the abundance of GREs in the HMP metagenomes. ${ }^{\mathbf{1 2 5}}$ This analysis identified a highly abundant, previously uncharacterized enzyme that was found to catalyze the dehydration of 4-hydroxy-L-proline. ${ }^{125}$ Another avenue is to apply well-established computational tools for identifying biosynthetic gene clusters to discover novel secondary metabolites produced by gut microbes. For example, the bioinformatics tool ClusterFinder ${ }^{394}$ has been successfully deployed to analyze the HMP metagenomes for multiple types of biosynthetic gene clusters. ${ }^{149}$ This work identified a diverse set of over 3000 putative biosynthetic gene clusters that are highly represented in the gut and oral microbiotas and are largely uncharacterized. Further studies of these cryptic gene clusters could reveal novel natural products with potential therapeutic applications, as well as improve our fundamental understanding of host-microbe or microbe-microbe interactions.

\section{Conclusions}

Recognition of the complex relationship between the human host and its gut microbial residents has redefined our perception of human health. In order to progress the field beyond the present correlative connections between the microbiota and human health and disease, the specific metabolic functions of these organisms must be uncovered. Integrating diverse and innovative experimental and computational approaches will enable the discovery of microbial chemical transformations and products that influence host biology. Biochemists and chemical biologists are therefore uniquely poised to increase our mechanistic understanding of the 
human gut microbiota and devise approaches for therapeutically targeting these organisms to improve human health.

\section{Conflicts of interest}

There are no conflicts of interest to declare.

\section{Acknowledgements}

The authors would like to acknowledge Abraham Waldman for helpful comments during writing and Eric Franzosa for assistance with the HMP metagenomic analysis. We acknowledge funding from the Bill and Melinda Gates Foundation (OPP1158186) (HMMI-Gates Faculty Scholar Award to E. P. B.). L. J. R. is the recipient of a Helen Hay Whitney postdoctoral research fellowship.

\section{References}

1 C. A. Thaiss, N. Zmora, M. Levy and E. Elinav, Nature, 2016, 535, 65-74.

2 K. Honda and D. R. Littman, Nature, 2016, 535, 75-84.

3 H. K. Biesalski, Ann. N. Y. Acad. Sci., 2016, 1372, 53-64.

4 A. J. Bäumler and V. Sperandio, Nature, 2016, 535, 85-93.

5 J. A. Gilbert, R. A. Quinn, J. Debelius, Z. Z. Xu, J. Morton, N. Garg, J. K. Jansson, P. C. Dorrestein and R. Knight, Nature, 2016, 535, 94-103.

6 C. L. Sears and W. S. Garrett, Cell Host Microbe, 2014, 15, 317-328.

7 A. D. Kostic, R. J. Xavier and D. Gevers, Gastroenterology, 2014, 146, 1489-1499.

8 P. D. Cani and N. M. Delzenne, Curr. Pharm. Des., 2009, 15, 1546-1558.

9 H. Tremlett, K. C. Bauer, S. Appel-Cresswell, B. B. Finlay and E. Waubant, Ann. Neurol., 2017, 81, 369-382.

10 W. H. Tang, T. Kitai and S. L. Hazen, Circ. Res., 2017, 120, 1183-1196.

11 J. W. Arnold, J. Roach and M. A. Azcarate-Peril, Trends Microbiol., 2016, 24, 887-901.

12 P. B. Eckburg, E. M. Bik, C. N. Bernstein, E. Purdom, L. Dethlefsen, M. Sargent, S. R. Gill, K. E. Nelson and D. A. Relman, Science, 2005, 308, 1635-1638.

13 The Human Microbiome Project Consortium, Nature, 2012, 486, 207-214.

14 T. Yatsunenko, F. E. Rey, M. J. Manary, I. Trehan, M. G. Dominguez-Bello, M. Contreras, M. Magris, G. Hidalgo, R. N. Baldassano, A. P. Anokhin, A. C. Heath, B. Warner, J. Reeder, J. Kuczynski, J. G. Caporaso, C. A. Lozupone, C. Lauber, J. C. Clemente, D. Knights, R. Knight and J. I. Gordon, Nature, 2012, 486, 222-227.

15 C. A. Lozupone, J. I. Stombaugh, J. I. Gordon, J. K. Jansson and R. Knight, Nature, 2012, 489, 220-230.

16 A. Heintz-Buschart and P. Wilmes, Trends Microbiol., 2017, 26(7), 563-574.

17 B. Zhu, X. Wang and L. Li, Protein Cell, 2010, 1, 718-725.

18 J. Qin, R. Li, J. Raes, M. Arumugam, K. S. Burgdorf, C. Manichanh, T. Nielsen, N. Pons, F. Levenez, T. Yamada,
D. R. Mende, J. Li, J. Xu, S. Li, D. Li, J. Cao, B. Wang, H. Liang, H. Zheng, Y. Xie, J. Tap, P. Lepage, M. Bertalan, J. M. Batto, T. Hansen, D. Le Paslier, A. Linneberg, H. B. Nielsen, E. Pelletier, P. Renault, T. Sicheritz-Ponten, K. Turner, H. Zhu, C. Yu, S. Li, M. Jian, Y. Zhou, Y. Li, X. Zhang, S. Li, N. Qin, H. Yang, J. Wang, S. Brunak, J. Dore, F. Guarner, K. Kristiansen, O. Pedersen, J. Parkhill, J. Weissenbach, H. I. T. C. Meta, P. Bork, S. D. Ehrlich and J. Wang, Nature, 2010, 464, 59-65.

19 M. S. Donia and M. A. Fischbach, Science, 2015, 349, 1254766. 20 L. K. Ursell, H. J. Haiser, W. Van Treuren, N. Garg, L. Reddivari, J. Vanamala, P. C. Dorrestein, P. J. Turnbaugh and R. Knight, Gastroenterology, 2014, 146, 1470-1476.

21 J. K. Nicholson, E. Holmes, J. Kinross, R. Burcelin, G. R. Gibson, W. Jia and S. Pettersson, Science, 2012, 336, 1262-1267.

22 E. Holmes, J. V. Li, T. Athanasiou, H. Ashrafian and J. K. Nicholson, Trends Microbiol., 2011, 19, 349-359.

23 N. Koppel and E. P. Balskus, Cell Chem Biol, 2016, 23, 18-30. 24 B. D. Wallace, H. Wang, K. T. Lane, J. E. Scott, J. Orans, J. S. Koo, M. Venkatesh, C. Jobin, L. A. Yeh, S. Mani and M. R. Redinbo, Science, 2010, 330, 831-835.

25 R. Joice, K. Yasuda, A. Shafquat, X. C. Morgan and C. Huttenhower, Cell Metab., 2014, 20, 731-741.

26 W. Buckel and B. T. Golding, Annu. Rev. Microbiol., 2006, 60, 27-49.

27 N. M. Koropatkin, E. A. Cameron and E. C. Martens, Nat. Rev. Microbiol., 2012, 10, 323-335.

28 E. C. Martens, E. C. Lowe, H. Chiang, N. A. Pudlo, M. Wu, N. P. McNulty, D. W. Abbott, B. Henrissat, H. J. Gilbert, D. N. Bolam and J. I. Gordon, PLoS Biol., 2011, 9, e1001221.

29 M. E. Johansson, H. Sjovall and G. C. Hansson, Nat. Rev. Gastroenterol. Hepatol., 2013, 10, 352-361.

30 L. E. Tailford, E. H. Crost, D. Kavanaugh and N. Juge, Front. Genet., 2015, 6, 81.

31 D. A. Ravcheev and I. Thiele, Front. Genet., 2017, 8, 111.

32 M. M. Grondin, K. Tamura, G. Déjean, D. W. Abbott and H. Brumer, J. Bacteriol., 2017, 199, e00860-16.

33 M. A. McGuckin, S. K. Linden, P. Sutton and T. H. Florin, Nat. Rev. Microbiol., 2011, 9, 265-278.

34 T. Bhattacharya, T. S. Ghosh and S. S. Mande, PLoS One, 2015, 10, e0142038.

35 W. E. C. Moore and L. V. Holdeman, Appl. Microbiol., 1974, 27, 961-979.

36 A. A. Salyers, J. R. Vercellotti, S. E. H. West and T. D. Wilkins, Appl. Environ. Microbiol., 1977, 33, 319-322.

37 E. C. Martens, H. C. Chiang and J. I. Gordon, Cell Host Microbe, 2008, 4, 447-457.

38 E. C. Martens, N. M. Koropatkin, T. J. Smith and J. I. Gordon, J. Biol. Chem., 2009, 284, 24673-24677.

39 J. L. Sonnenburg, J. Xu, D. D. Leip, C.-H. Chen, B. P. Westover, J. Weatherford, J. D. Buhler and J. I. Gordon, Science, 2005, 307, 1955-1959.

40 D. K. Podolsky, J. Biol. Chem., 1985, 260, 8262-8271.

41 S. Inoue and Z. Yosizawa, Arch. Biochem. Biophys., 1966, 117, 257-265.

42 M. Filipe, Invest. Cell Pathol., 1979, 2, 195-216. 
43 A. Nieuw Amerongen, J. Bolscher, E. Bloemena and E. Veerman, Biol. Chem., 1998, 379, 1-18.

44 N. Mian, C. E. Anderson and P. W. Kent, Biochem. J., 1979, 181, 387-399.

45 A. P. Corfield, S. A. Wagner, L. J. D. O'Donnell, P. Durdey, R. A. Mountford and J. R. Clamp, Glycoconjugate J., 1993, 10, 72-81.

46 H. H. Tsai, D. Sunderland, G. R. Gibson, C. A. Hart and J. M. Rhodes, Clin. Sci., 1992, 82, 447-454.

47 D. P. Wright, C. G. Knight, S. G. Parkar, D. L. Christie and A. M. Roberton, J. Bacteriol., 2000, 182, 3002-3007.

$48 \mathrm{~J} . \mathrm{Xu}, \mathrm{M}$. A. Mahowald, R. E. Ley, C. A. Lozupone, M. Hamady, E. C. Martens, B. Henrissat, P. M. Coutinho, P. Minx, P. Latrelle, H. Cordum, A. V. Brunt, K. Kim, R. S. Fulton, L. A. Fulton, S. W. Clifton, R. K. Wilson, R. D. Knight and J. I. Gordon, PLoS Biol., 2007, 5, e156.

49 J. E. Ulmer, E. M. Vilen, R. B. Namburi, A. Benjdia, J. Beneteau, A. Malleron, D. Bonnaffe, P. A. Driguez, K. Descroix, G. Lassalle, C. Le Narvor, C. Sandstrom, D. Spillmann and O. Berteau, J. Biol. Chem., 2014, 289, 24289-24303.

50 M. Egan, H. Jiang, M. O'Connell Motherway, S. Oscarson and D. van Sinderen, Appl. Environ. Microbiol., 2016, 82, 6611-6623.

51 A. Cartmell, E. C. Lowe, A. Basle, S. J. Firbank, D. A. Ndeh, H. Murray, N. Terrapon, V. Lombard, B. Henrissat, J. E. Turnbull, M. Czjzek, H. J. Gilbert and D. N. Bolam, Proc. Natl. Acad. Sci. U. S. A., 2017, 114, 7037-7042.

52 C. A. Hickey, K. A. Kuhn, D. L. Donermeyer, N. T. Porter, C. Jin, E. A. Cameron, H. Jung, G. E. Kaiko, M. Wegorzewska, N. P. Malvin, R. W. Glowacki, G. C. Hansson, P. M. Allen, E. C. Martens and T. S. Stappenbeck, Cell Host Microbe, 2015, 17, 672-680.

53 H. H. Tsai, A. D. Dwarakanath, C. A. Hart, J. D. Milton and J. M. Rhodes, Gut, 1995, 36, 570-576.

54 T. Barbeyron, L. Brillet-Gueguen, W. Carre, C. Carriere, C. Caron, M. Czjzek, M. Hoebeke and G. Michel, PLoS One, 2016, 11, e0164846.

55 A. Benjdia and O. Berteau, Biochem. Soc. Trans., 2016, 44, 109-115.

56 M. J. Appel and C. R. Bertozzi, ACS Chem. Biol., 2015, 10, 7284.

57 I. Boltes, H. Czapinska, A. Kahner, R. v. Bülow, T. Dierks, B. Schmidt, K. v. Figura, M. A. Kertesz and I. Usón, Structure, 2001, 9, 483-491.

58 R. v. Bülow, B. Schmidt, T. Dierks, K. v. Figura and I. Usón, J. Mol. Biol., 2001, 305, 269-277.

59 C. S. Bond, P. R. Clements, S. J. Ashby, C. A. Collyer, S. J. Harrop, J. J. Hopwood and J. M. Guss, Structure, 1996, 5, 277-289.

60 F. G. Hernandez-Guzman, T. Higashiyama, W. Pangborn, Y. Osawa and D. Ghosh, J. Biol. Chem., 2003, 278, 2298922997.

61 T. Dierks, A. Dickmanns, A. Preusser-Kunze, B. Schmidt, M. Mariappan, K. von Figura, R. Ficner and M. G. Rudolph, Cell, 2005, 121, 541-552.

62 A. Schirmer and R. Kolter, Chem. Biol., 1998, 5, R181-R186.
63 T. Dierks, C. Miech, J. Hummerjohann, B. Schmidt, M. A. Kertesz and K. von Figura, J. Biol. Chem., 1998, 273, 25560-25564.

64 O. Berteau, A. Guillot, A. Benjdia and S. Rabot, J. Biol. Chem., 2006, 281, 22464-22470.

65 C. Miech, T. Dierks, T. Selmer, K. v. Figura and B. Schmidt, J. Biol. Chem., 1998, 273, 4835-4837.

66 C. Marquordt, Q. Fang, E. Will, J. Peng, K. von Figura and T. Dierks, J. Biol. Chem., 2003, 278, 2212-2218.

67 D. Roeser, A. Preusser-Kunze, B. Schmidt, K. Gasow, J. G. Wittmann, T. Dierks, K. von Figura and M. G. Rudolph, Proc. Natl. Acad. Sci. U. S. A., 2006, 103, 81-86.

68 B. L. Carlson, E. R. Ballister, E. Skordalakes, D. S. King, M. A. Breidenbach, S. A. Gilmore, J. M. Berger and C. R. Bertozzi, J. Biol. Chem., 2008, 283, 20117-20125.

69 C. Szameit, C. Miech, M. Balleininger, B. Schmidt, K. von Figura and T. Dierks, J. Biol. Chem., 1999, 274, 15375-15381.

70 A. Benjdia, G. Deho, S. Rabot and O. Berteau, FEBS Lett., 2007, 581, 1009-1014.

71 Q. Fang, J. Peng and T. Dierks, J. Biol. Chem., 2004, 279, 14570-14578.

72 J. B. Broderick, B. R. Duffus, K. S. Duschene and E. M. Shepard, Chem. Rev., 2014, 114, 4229-4317.

73 P. A. Frey, A. D. Hegeman and F. J. Ruzicka, Crit. Rev. Biochem. Mol. Biol., 2008, 43, 63-88.

74 S. C. Wang and P. A. Frey, Trends Biochem. Sci., 2007, 32, 101-110.

75 S. J. Booker and T. L. Grove, F1000 Biology Reports, 2010, 2, 52.

76 A. Benjdia, J. Leprince, C. Sandstrom, H. Vaudry and O. Berteau, J. Am. Chem. Soc., 2009, 131, 8348-8349.

77 T. L. Grove, J. H. Ahlum, R. M. Qin, N. D. Lanz, M. I. Radle, C. Krebs and S. J. Booker, Biochemistry, 2013, 52, 2874-2887.

78 T. A. Grell, P. J. Goldman and C. L. Drennan, J. Biol. Chem., 2015, 290, 3964-3971.

79 T. L. Grove, K.-H. Lee, J. S. Clair, C. Krebs and S. J. Booker, Biochemistry, 2008, 47, 7523-7538.

80 P. J. Goldman, T. L. Grove, L. A. Sites, M. I. McLaughlin, S. J. Booker and C. L. Drennan, Proc. Natl. Acad. Sci. U. S. A., 2013, 110, 8519-8524.

81 T. Dierks, M. R. Lecca, P. Schlotterhose, B. Schmidt and K. von Figura, EMBO J., 1999, 18, 2084-2091.

82 A. Benjdia, E. C. Martens, J. I. Gordon and O. Berteau, J. Biol. Chem., 2011, 286, 25973-25982.

83 P. C. Kashyap, A. Marcobal, L. K. Ursell, S. A. Smits, E. D. Sonnenburg, E. K. Costello, S. K. Higginbottom, S. E. Domino, S. P. Holmes, D. A. Relman, R. Knight, J. I. Gordon and J. L. Sonnenburg, Proc. Natl. Acad. Sci. U. S. A., 2013, 110, 17059-17064.

84 R. J. Kelly, S. Rouquier, D. Giorgi, G. G. Lennon and J. B. Lowe, J. Biol. Chem., 1995, 270, 4640-4649.

85 D. P. McGovern, M. R. Jones, K. D. Taylor, K. Marciante, X. Yan, M. Dubinsky, A. Ippoliti, E. Vasiliauskas, D. Berel, C. Derkowski, D. Dutridge, P. Fleshner, D. Q. Shih, G. Melmed, E. Mengesha, L. King, S. Pressman, T. Haritunians, X. Guo, S. R. Targan, J. I. Rotter and 
I. B. D. G. C. International, Hum. Mol. Genet., 2010, 19, 3468-3476.

86 P. Rausch, A. Rehman, S. Künzel, R. Häsler, S. J. Ott, S. Schreiber, P. Rosenstiel, A. Franke and J. F. Baines, Proc. Natl. Acad. Sci. U. S. A., 2011, 108, 19030-19035.

87 L. Maroni, S. F. van de Graaf, S. D. Hohenester, R. P. Oude Elferink and U. Beuers, Clin. Rev. Allergy Immunol., 2015, 48, 182-191.

88 L. Bry, P. G. Falk, T. Midtvedt and J. I. Gordon, Science, 1996, 273, 1380-1383.

89 L. V. Hooper, J. Xu, P. G. Falk, T. Midtvedt and J. I. Gordon, Proc. Natl. Acad. Sci. U. S. A., 1999, 96, 9833-9838.

90 J. M. Pickard, C. F. Maurice, M. A. Kinnebrew, M. C. Abt, D. Schenten, T. V. Golovkina, S. R. Bogatyrev, R. F. Ismagilov, E. G. Pamer, P. J. Turnbaugh and A. V. Chervonsky, Nature, 2014, 514, 638-641.

91 M. J. Coyne, B. Reinap, M. M. Lee and L. E. Comstock, Science, 2005, 307, 1778-1781.

92 K. M. Ng, J. A. Ferreyra, S. K. Higginbottom, J. B. Lynch, P. C. Kashyap, S. Gopinath, N. Naidu, B. Choudhury, B. C. Weimer, D. M. Monack and J. L. Sonnenburg, Nature, 2013, 502, 96-99.

93 J. Badía, J. Ros and J. Aguilar, J. Bacteriol., 1985, 161, 435437.

94 R. M. Jeter, J. Gen. Microbiol., 1990, 136, 887-896.

95 M. A. Vinolo, H. G. Rodrigues, R. T. Nachbar and R. Curi, Nutrients, 2011, 3, 858-876.

96 J. Tan, C. McKenzie, M. Potamitis, A. N. Thorburn, C. R. Mackay and L. Macia, Adv. Immunol., 2014, 121, 91-119.

97 M. Kasubuchi, S. Hasegawa, T. Hiramatsu, A. Ichimura and I. Kimura, Nutrients, 2015, 7, 2839-2849.

98 D. J. Morrison and T. Preston, Gut Microbes, 2016, 7, 189200.

99 G. den Besten, K. van Eunen, A. K. Groen, K. Venema, D. J. Reijngoud and B. M. Bakker, J. Lipid Res., 2013, 54, 2325-2340.

100 E. Hosseini, C. Grootaert, W. Verstraete and T. Van de Wiele, Nutr. Rev., 2011, 69, 245-258.

101 H. A. Lee, Jr. and R. H. Abeles, J. Biol. Chem., 1963, 238, 2367-2373.

102 H. A. Barker, Annu. Rev. Biochem., 1972, 784, 55-90.

103 R. H. Abeles and D. Dolphin, Acc. Chem. Res., 1975, 9, 114120.

104 T. Toraya, Chem. Rev., 2003, 103, 2095-2127.

105 M. Yamanishi, M. Yunoki, T. Tobimatsu, H. Sato, J. Matsui, A. Dokiya, Y. Iuchi, K. Oe, K. Suto, N. Shibata, Y. Morimoto, N. Yasuoka and T. Toraya, Eur. J. Biochem., 2002, 269, 44844494.

106 D. C. Hodgkin, J. Kamper, M. Mackay and J. Pickworth, Nature, 1956, 178, 64-66.

107 R. Bonnnett, J. R. Cannon, V. M. Clark, A. W. Johnson, L. F. J. Parker, E. L. Smith and S. A. Todd, J. Chem. Soc., 1957, 227, 1158-1168.

$108 \mathrm{~J}$. Pilbrow, EPR of $B_{12}$-dependent enzyme reactions and related systems, John Wiley \& Sons, Inc., New York, 1982.
109 M. Yamanishi, S. Yamada, H. Muguruma, Y. Murakami, T. Tobimatsu, A. Ishida, J. Yamauchi and T. Toraya, Biochemistry, 1998, 37, 4799-4803.

110 A. Abend, R. Nitsche, V. Bandarian, E. Stupperich and J. Rétey, Angew. Chem., Int. Ed., 1998, 37, 625-627.

111 N. Shibata, J. Masuda, T. Tobimatsu, T. Toraya, K. Suto, Y. Morimoto and N. Yasuoka, Structure, 1999, 7, 997-1008.

112 J. Masuda, N. Shibata, Y. Morimoto, T. Toraya and N. Yasuoka, Structure, 2000, 8, 775-788.

113 E. N. G. Marsh and G. D. Melendez, Biochim. Biophys. Acta, 2012, 1824, 1154-1164.

114 T. Toraya, Cell. Mol. Life Sci., 2000, 57, 106-127.

115 P. A. Schwartz and P. A. Frey, Biochemistry, 2007, 46, 72937301.

116 T. Toraya, S. Honda and K. Mori, Biochemistry, 2010, 49, 7210-7217.

117 T. Toraya, K. Yoshizawa, M. Eds and T. Yamabe, J. Biochem., 1999, 126, 650-654.

118 M. Yamanishi, H. Ide, Y. Murakami and T. Toraya, Biochemistry, 2005, 44, 2113-2118.

119 V. B. Pett, M. N. Liebman, P. Murray-Rust, K. Prasad and J. P. Glusker, J. Am. Chem. Soc., 1987, 109, 3207-3215.

120 J. Rétey, A. Umani-Ronchi, J. Seible and D. Arigoni, Experientia, 1966, 22, 502-503.

121 B. J. Levin and E. P. Balskus, Biochemistry, 2018, 57(23), 3222-3226.

122 O. W. Wagner, H. A. Lee, Jr., P. A. Frey and R. H. Abeles, J. Biol. Chem., 1966, 241, 1751-1762.

123 P. A. Frey, M. K. Essenberg and R. H. Abeles, J. Biol. Chem., 1967, 242, 5369-5377.

124 J. W. LaMattina, N. D. Keul, P. Reitzer, S. Kapoor, F. Galzerani, D. J. Koch, I. E. Gouvea and W. N. Lanzilotta, J. Biol. Chem., 2016, 291, 15515-15526.

125 B. J. Levin, Y. Y. Huang, S. C. Peck, Y. Wei, A. Martinez-Del Campo, J. A. Marks, E. A. Franzosa, C. Huttenhower and E. P. Balskus, Science, 2017, 355(6325), eaai8386.

126 K. P. Scott, J. C. Martin, G. Campbell, C. D. Mayer and H. J. Flint, J. Bacteriol., 2006, 188, 4340-4349.

127 T. Selmer, A. J. Pierik and J. Heider, Biol. Chem., 2005, 386, 981-988.

128 K. A. Shisler and J. B. Broderick, Arch. Biochem. Biophys., 2014, 546, 64-71.

129 S. G. Reddy, K. K. Wong, C. V. Parast, J. Peisach, R. S. Magliozzo and J. W. Kozarich, Biochemistry, 1998, 37, 558-563.

130 M. Feliks and G. M. Ullmann, J. Phys. Chem. B, 2012, 116, 7076-7087.

131 B. Kovačević, D. Barić, D. Babić, L. Bilić, M. Hanževački, G. M. Sandala, L. Radom and D. M. Smith, J. Am. Chem. Soc., 2018, 140, 8487-8496.

132 F. Rivera-Chávez, L. F. Zhang, F. Faber, C. A. Lopez, M. X. Byndloss, E. E. Olsan, G. Xu, E. M. Velazquez, C. B. Lebrilla, S. E. Winter and A. J. Bäumler, Cell Host Microbe, 2016, 19, 443-454.

133 C. A. Lopez, B. M. MIller, F. Rivera-Chávez, E. M. Velazquez, M. X. Byndloss, A. Chávez-Arroyo, K. L. Lokken, 
R. M. Tsolis, S. E. Winter and A. J. Bäumler, Science, 2016, 353, 1249-1253.

134 L. Staib and T. M. Fuchs, Front. Microbiol., 2015, 6, 1116.

135 F. Faber, P. Thiennimitr, L. Spiga, M. X. Byndloss, Y. Litvak, S. Lawhon, H. L. Andrews-Polymenis, S. E. Winter and A. J. Baumler, PLoS Pathog., 2017, 13, e1006129.

136 C. G. Buffie and E. G. Pamer, Nat. Rev. Immunol., 2013, 13, 790-801.

137 N. Kamada, G. Y. Chen, N. Inohara and G. Nunez, Nat. Immunol., 2013, 14, 685-690.

138 M. G. Rooks and W. S. Garrett, Nat. Rev. Immunol., 2016, 16, 341-352.

139 A. Agus, J. Denizot, J. Thevenot, M. Martinez-Medina, S. Massier, P. Sauvanet, A. Bernalier-Donadille, S. Denis, P. Hofman, R. Bonnet, E. Billard and N. Barnich, Sci. Rep., 2016, 6, 19032.

140 L. K. Ursell, W. Van Treuren, J. L. Metcalf, M. Pirrung, A. Gewirtz and R. Knight, BioEssays, 2013, 35, 810-817.

141 S. R. Modi, J. J. Collins and D. A. Relman, J. Clin. Invest., 2014, 124, 4212-4218.

142 G. Cammarota, G. Ianiro and A. Gasbarrini, J. Clin. Gastroenterol., 2014, 48, 693-702.

143 T. J. Borody and A. Khoruts, Nat. Rev. Gastroenterol. Hepatol., 2011, 9, 88-96.

144 P. G. Arnison, M. J. Bibb, G. Bierbaum, A. A. Bowers, T. S. Bugni, G. Bulaj, J. A. Camarero, D. J. Campopiano, G. L. Challis, J. Clardy, P. D. Cotter, D. J. Craik, M. Dawson, E. Dittmann, S. Donadio, P. C. Dorrestein, K. D. Entian, M. A. Fischbach, J. S. Garavelli, U. Goransson, C. W. Gruber, D. H. Haft, T. K. Hemscheidt, C. Hertweck, C. Hill, A. R. Horswill, M. Jaspars, W. L. Kelly, J. P. Klinman, O. P. Kuipers, A. J. Link, W. Liu, M. A. Marahiel, D. A. Mitchell, G. N. Moll, B. S. Moore, R. Muller, S. K. Nair, I. F. Nes, G. E. Norris, B. M. Olivera, H. Onaka, M. L. Patchett, J. Piel, M. J. Reaney, S. Rebuffat, R. P. Ross, H. G. Sahl, E. W. Schmidt, M. E. Selsted, K. Severinov, B. Shen, K. Sivonen, L. Smith, T. Stein, R. D. Sussmuth, J. R. Tagg, G. L. Tang, A. W. Truman, J. C. Vederas, C. T. Walsh, J. D. Walton, S. C. Wenzel, J. M. Willey and W. A. van der Donk, Nat. Prod. Rep., 2013, 30, 108-160.

145 S. Kommineni, D. J. Bretl, V. Lam, R. Chakraborty, M. Hayward, P. Simpson, Y. Cao, P. Bousounis, C. J. Kristich and N. H. Salzman, Nature, 2015, 526, 719722.

146 M. A. Ortega and W. A. van der Donk, Cell Chem. Biol., 2016, 23, 31-44.

147 K. J. Hetrick and W. A. van der Donk, Curr. Opin. Chem. Biol., 2017, 38, 36-44.

148 A. J. Marsh, O. O'Sullivan, R. R. Paul, P. D. Cotter and C. Hill, BMC Genomics, 2010, 11, 679.

149 M. S. Donia, P. Cimermancic, C. J. Schulze, L. C. Wieland Brown, J. Martin, M. Mitreva, J. Clardy, R. G. Linington and M. A. Fischbach, Cell, 2014, 158, 1402-1414.

150 A.-C. Letzel, S. J. Pidot and C. Hertweck, BMC Genomics, 2014, 15, 983.

151 C. J. Walsh, C. M. Guinane, C. Hill, R. P. Ross, P. W. O'Toole and P. D. Cotter, BMC Microbiol., 2015, 15, 183.
152 J. Zheng, M. G. Ganzle, X. B. Lin, L. Ruan and M. Sun, Environ. Microbiol., 2015, 17, 2133-2143.

153 S. van Kuijk, K. S. Noll and M. L. Chikindas, Lett. Appl. Microbiol., 2012, 54, 52-58.

154 H. Mathur, V. Fallico, P. M. O'Connor, M. C. Rea, P. D. Cotter, C. Hill and R. P. Ross, Front. Microbiol., 2017, 8, 696.

155 K. Babasaki, T. Takao, Y. Shimonishi and K. Kurahashi, J. Biochem., 1985, 98, 585-603.

156 K. Kawulka, T. Sprules, R. T. McKay, P. Mercier, C. M. Diaper, P. Zuber and J. C. Vederas, J. Am. Chem. Soc., 2003, 125, 4726-4727.

157 K. Kawulka, T. Sprules, C. M. Diaper, R. M. Whittal, R. T. McKay, P. Mercier, P. Zuber and J. C. Vederas, Biochemistry, 2004, 43, 3385-3395.

158 C. E. Shelburne, F. Y. An, V. Dholpe, A. Ramamoorthy, D. E. Lopatin and M. S. Lantz, J. Antimicrob. Chemother., 2007, 59, 297-300.

159 K. S. Noll, P. J. Sinko and M. L. Chikindas, Probiotics Antimicrob. Proteins, 2011, 3, 41-47.

160 M. C. Rea, C. S. Sit, E. Clayton, P. M. O'Connor, R. M. Whittal, J. Zheng, J. C. Vederas, R. P. Ross and C. Hill, Proc. Natl. Acad. Sci. U. S. A., 2010, 107, 9852-9857.

161 M. C. Rea, A. Dobson, O. O'Sullivan, F. Crispie, F. Fouhy, P. D. Cotter, F. Shanahan, B. Kiely, C. Hill and R. P. Ross, Proc. Natl. Acad. Sci. U. S. A., 2011, 108(Suppl. 1), 4639-4644.

162 C. S. Sit, R. T. McKay, C. Hill, R. P. Ross and J. C. Vederas, J. Am. Chem. Soc., 2011, 133, 7680-7683.

163 C. S. Sit, M. J. van Belkum, R. T. McKay, R. W. Worobo and J. C. Vederas, Angew. Chem., Int. Ed. Engl., 2011, 50, 87188721.

164 G. Wang, G. Feng, A. B. Snyder, D. C. Manns, J. J. Churey and R. W. Worobo, FEMS Microbiol. Lett., 2014, 357, 69-76.

165 J. Dabard, C. Bridonneau, C. Phillipe, P. Anglade, D. Molle, M. Nardi, M. Ladire, H. Girardin, F. Marcille, A. Gomez and M. Fons, Appl. Environ. Microbiol., 2001, 67, 4111-4118.

166 A. Gomez, M. Ladire, F. Marcille and M. Fons, J. Bacteriol., 2002, 184, 18-28.

167 F. Marcille, A. Gomez, P. Joubert, M. Ladire, G. Veau, A. Clara, F. Gavini, A. Willems and M. Fons, Appl. Environ. Microbiol., 2002, 68, 3424-3431.

168 A. Pujol, E. H. Crost, G. Simon, V. Barbe, D. Vallenet, A. Gomez and M. Fons, FEMS Microbiol. Ecol., 2011, 78, 405-415.

169 L. Flühe and M. A. Marahiel, Curr. Opin. Chem. Biol., 2013, 17, 605-612.

170 L. Flühe, T. A. Knappe, M. J. Gattner, A. Schäfer, O. Burghaus, U. Linne and M. A. Marahiel, Nat. Chem. Biol., 2012, 8, 350-357.

171 N. A. Bruender, J. Wilcoxen, R. D. Britt and V. Bandarian, Biochemistry, 2016, 55, 2122-2134.

172 T. L. Grove, P. M. Himes, S. Hwang, H. Yumerefendi, J. B. Bonanno, B. Kuhlman, S. C. Almo and A. A. Bowers, J. Am. Chem. Soc., 2017, 139, 11734-11744.

173 N. I. Burzlaff, P. J. Rutledge, I. J. Clifton, C. M. H. Hensgens, M. Pcikford, R. M. Adlington, P. L. Roach and J. E. Baldwin, Nature, 1999, 401, 721-724. 
174 E. Tamanaha, B. Zhang, Y. Guo, W. C. Chang, E. W. Barr, G. Xing, J. St Clair, S. Ye, F. Neese, J. M. Bollinger, Jr. and C. Krebs, J. Am. Chem. Soc., 2016, 138, 8862-8874.

175 A. M. Taylor, S. Stoll, R. D. Britt and J. T. Jarrett, Biochemistry, 2011, 50, 7953-7963.

176 C. J. Fugate, T. A. Stich, E. G. Kim, W. K. Myers, R. D. Britt and J. T. Jarrett, J. Am. Chem. Soc., 2012, 134, 9042-9045.

177 A. Benjdia, A. Guillot, P. Ruffié, J. Leprince and O. Berteau, Nat. Chem., 2017, 9, 698-707.

178 P. R. Burkholder and I. McVeigh, Proc. Natl. Acad. Sci. U. S. A., 1942, 28, 285-289.

179 V. A. Najjar and R. Barrett, The Synthesis of B Vitamins by Intestinal Bacteria, Vitamins \& Hormones, ed. R. S. Harris and K. V. Thimann, Academic Press, 1945, vol. 3, pp. 23-48.

180 M. E. Coates, Proc. Nutr. Soc., 1973, 32, 53-58.

181 M. J. Albert, V. I. Mathan and S. J. Baker, Nature, 1980, 283, 781-782.

182 B. S. Wostmann, Annu. Rev. Nutr., 1981, 1, 257-279.

183 M. J. Hill, Eur. J. Cancer Prev., 1997, 6, S43-S45.

184 S. M. Nabokina, K. Inoue, V. S. Subramanian, J. E. Valle, H. Yuasa and H. M. Said, J. Biol. Chem., 2014, 289, 44054416.

185 A. Qiu, M. Jansen, A. Sakaris, S. H. Min, S. Chattopadhyay, E. Tsai, C. Sandoval, R. Zhao, M. H. Akabas and I. D. Goldman, Cell, 2006, 127, 917-928.

186 P. H. Degnan, N. A. Barry, K. C. Mok, M. E. Taga and A. L. Goodman, Cell Host Microbe, 2014, 15, 47-57.

187 P. H. Degnan, M. E. Taga and A. L. Goodman, Cell Metab., 2014, 20, 769-778.

188 A. P. Mehta, S. H. Abdelwahed, N. Mahanta, D. Fedoseyenko, B. Philmus, L. E. Cooper, Y. Liu, I. Jhulki, S. E. Ealick and T. P. Begley, J. Biol. Chem., 2015, 290, 3980-3986.

189 K. Yokoyama and E. A. Lilla, Nat. Prod. Rep., 2018, 35, 660694.

190 M. R. Challand, F. T. Martins and P. L. Roach, J. Biol. Chem., 2010, 285, 5240-5248.

191 M. Kriek, F. Martins, M. R. Challand, A. Croft and P. L. Roach, Angew. Chem., Int. Ed. Engl., 2007, 46, 92239226.

192 M. Kriek, F. Martins, R. Leonardi, S. A. Fairhurst, D. J. Lowe and P. L. Roach, J. Biol. Chem., 2007, 282, 17413-17423.

193 G. Mkrtchyan, V. Aleshin, Y. Parkhomenko, T. Kaehne, M. L. Di Salvo, A. Parroni, R. Contestabile, A. Vovk, L. Bettendorff and V. Bunik, Sci. Rep., 2015, 5, 12583.

194 L. Hiffler, B. Rakotoambinina, N. Lafferty and D. Martinez Garcia, Front. Nutr., 2016, 3, 16.

195 D. R. Sannino, A. J. Dobson, K. Edwards, E. R. Angert and N. Buchon, mBio, 2018, 9.

196 V. A. Najjar and L. E. Holt, Jr., JAMA, J. Am. Med. Assoc., 1943, 123, 683-684.

197 S. M. Nabokina, M. B. Ramos, J. E. Valle and H. M. Said, Am. J. Physiol.: Cell Physiol., 2015, 308, C750-C757.

198 S. M. Nabokina, V. S. Subramanian and H. M. Said, Biochim. Biophys. Acta, 2016, 1858, 866-871.

199 S. M. Nabokina, M. B. Ramos and H. M. Said, PLoS One, 2016, 11, e0149255.
200 G. Juyal, S. Negi, A. Sood, A. Gupta, P. Prasad, S. Senapati, J. Zaneveld, S. Singh, V. Midha, S. van Sommeren, R. K. Weersma, J. Ott, S. Jain, R. C. Juyal and B. K. Thelma, Gut, 2015, 64, 571-579.

201 A. Gupta and B. K. Thelma, Genes Immun., 2016, 17, 105109.

202 S. J. Booker, R. M. Cicchillo and T. L. Grove, Curr. Opin. Chem. Biol., 2007, 11, 543-552.

203 N. D. Lanz and S. J. Booker, Biochim. Biophys. Acta, 2015, 1853, 1316-1334.

204 M. M. Cosper, G. N. L. Jameson, H. L. Hernández, C. Krebs, B. H. Huynh and M. K. Johnson, Biochemistry, 2004, 43, 2007-2021.

205 G. N. L. Jameson, M. M. Cosper, H. L. Hernández, M. K. Johnson and B. H. Huynh, Biochemistry, 2004, 43, 2022-2031.

206 F. Berkovitch, Y. Nicolet, J. T. Wan, J. T. Jarrett and C. L. Drennan, Science, 2004, 303, 76-79.

207 F. Escalettes, D. Florentin, B. Tse Sum Bui, D. Lesage and A. Marquet, J. Am. Chem. Soc., 1999, 121, 3571-3578.

208 A. M. Taylor, C. E. Farrar and J. T. Jarrett, Biochemistry, 2008, 47, 9309-9317.

209 N. B. Ugulava, C. J. Sacanell and J. T. Jarrett, Biochemistry, 2001, 40, 8352-8358.

210 M. R. Reyda, R. Dippold, M. E. Dotson and J. T. Jarrett, Arch. Biochem. Biophys., 2008, 471, 32-41.

211 M. R. Reyda, C. J. Fugate and J. T. Jarrett, Biochemistry, 2009, 48, 10782-10792.

212 E. L. McCarthy and S. J. Booker, Science, 2017, 358, 373-377.

213 L. Tong, Cell. Mol. Life Sci., 2013, 70, 863-891.

214 D. Mock, Seminars in Dermatology, 1991, 10, 296-302.

215 A. Hayashi, Y. Mikami, K. Miyamoto, N. Kamada, T. Sato, S. Mizuno, M. Naganuma, T. Teratani, R. Aoki, S. Fukuda, W. Suda, M. Hattori, M. Amagai, M. Ohyama and T. Kanai, Cell Rep., 2017, 20, 1513-1524.

216 C. Fergus, D. Barnes, M. A. Alqasem and V. P. Kelly, Nutrients, 2015, 7, 2897-2929.

217 H. Kasai, Y. Kuchino, K. Nihei and S. Nishimura, Nucleic Acids Res., 1975, 2, 1931-1939.

218 F. Harada and S. Nishimura, Biochemistry, 1972, 11, 301308.

219 J. R. Katze, B. Basile and J. A. McCloskey, Science, 1982, 216, 55-56.

220 M. Vinayak and C. Pathak, Biosci. Rep., 2009, 30, 135-148.

221 T. Marks and W. R. Farkas, Biochem. Biophys. Res. Commun., 1997, 230, 233-237.

222 C. Pathak, Y. K. Jaiswal and M. Vinayak, BioFactors, 2007, 29, 159-173.

223 D. Iwata-Reuyl, Bioorg. Chem., 2003, 31, 24-43.

224 J. R. Katze, U. Gündüz, D. L. Smith, C. S. Cheng and J. A. McCloskey, Biochemistry, 1984, 23, 1171-1176.

225 U. Gündüz and J. R. Katze, J. Biol. Chem., 1984, 259, 11101113.

226 W. R. Farkas, J. Biol. Chem., 1980, 255, 6832-6835.

227 J. P. Reyniers, J. R. Pleasants, B. S. Wostmann, J. R. Katze and W. R. Farkas, J. Biol. Chem., 1981, 256, 11591-11594. 
228 S. Yokoyama, T. Miyazawa, Y. Iitaka, Z. Yamaizuma, H. Kasai and S. Nishimura, Nature, 1975, 282, 107-109.

229 H. Kasai, Z. Ohashi, F. Harada, S. Nishimura, N. J. Oppenheimer, P. F. Crain, J. G. Liehr, D. L. von Minden and J. A. McCloskey, Biochemistry, 1975, 14, 4198-4208.

230 R. M. McCarty and V. Bandarian, Bioorg. Chem., 2012, 43, 15-25.

231 Z. D. Miles, R. M. McCarty, G. Molnar and V. Bandarian, Proc. Natl. Acad. Sci. U. S. A., 2011, 108, 7368-7372.

232 J. Bridwell-Rabb and C. L. Drennan, Curr. Opin. Chem. Biol., 2017, 37, 63-70.

233 Z. D. Miles, W. K. Myers, W. M. Kincannon, R. D. Britt and V. Bandarian, Biochemistry, 2015, 54, 4927-4935.

234 K. A. Payne, K. Fisher, H. Sjuts, M. S. Dunstan, B. Bellina, L. Johannissen, P. Barran, S. Hay, S. E. Rigby and D. Leys, J. Biol. Chem., 2015, 290, 27572-27581.

235 D. P. Dowling, Z. D. Miles, C. Kohrer, S. J. Maiocco, S. J. Elliott, V. Bandarian and C. L. Drennan, Nucleic Acids Res., 2016, 44, 9965-9976.

236 R. Banerjee and S. W. Ragsdale, Annu. Rev. Biochem., 2003, 72, 209-247.

237 V. Bandarian and C. L. Drennan, Curr. Opin. Struct. Biol., 2015, 35, 116-124.

238 D. P. Dowling, N. A. Bruender, A. P. Young, R. M. McCarty, V. Bandarian and C. L. Drennan, Nat. Chem. Biol., 2013, 10, 106-112.

239 R. M. McCarty, C. Krebs and V. Bandarian, Biochemistry, 2013, 52, 188-198.

240 W. Zhu and Y. Liu, ACS Catal., 2015, 5, 3953-3965.

241 P. Close, D. Bose, A. Chariot and S. A. Leidel, in Cancer and Noncoding RNAs, ed. D. S. Mitra, Academic Press, Boston, 2018, vol. 1.

242 C. Pathak, Y. K. Jaiswal and M. Vinayak, Mol. Biol. Rep., 2008, 35, 369-374.

243 C. Pathak, Y. K. Jaiswal and M. Vinayak, RNA Biol., 2005, 2, 143-148.

244 B. Lamas, M. L. Richard, V. Leducq, H. P. Pham, M. L. Michel, G. Da Costa, C. Bridonneau, S. Jegou, T. W. Hoffmann, J. M. Natividad, L. Brot, S. Taleb, A. Couturier-Maillard, I. Nion-Larmurier, F. Merabtene, P. Seksik, A. Bourrier, J. Cosnes, B. Ryffel, L. Beaugerie, J. M. Launay, P. Langella, R. J. Xavier and H. Sokol, Nat. Med., 2016, 22, 598-605.

245 T. Zelante, R. G. Iannitti, C. Cunha, A. De Luca, G. Giovannini, G. Pieraccini, R. Zecchi, C. D'Angelo, C. Massi-Benedetti, F. Fallarino, A. Carvalho, P. Puccetti and L. Romani, Immunity, 2013, 39, 372-385.

246 M. Venkatesh, S. Mukherjee, H. Wang, H. Li, K. Sun, A. P. Benechet, Z. Qiu, L. Maher, M. R. Redinbo, R. S. Phillips, J. C. Fleet, S. Kortagere, P. Mukherjee, A. Fasano, J. Le Ven, J. K. Nicholson, M. E. Dumas, K. M. Khanna and S. Mani, Immunity, 2014, 41, 296-310.

247 L. Cervantes-Barragan, J. N. Chai, M. D. Tianero, B. Di Luccia, P. P. Ahern, J. Merriman, V. S. Cortez, M. G. Caparon, M. S. Donia, S. Gilfillan, M. Cella,
J. I. Gordon, C.-S. Hsieh and M. Colonna, Science, 2017, 357, 806-810.

248 M. Wlodarska, C. Luo, R. Kolde, E. d'Hennezel, J. W. Annand, C. E. Heim, P. Krastel, E. K. Schmitt, A. S. Omar, E. A. Creasey, A. L. Garner, S. Mohammadi, D. J. O'Connell, S. Abubucker, T. D. Arthur, E. A. Franzosa, C. Huttenhower, L. O. Murphy, H. J. Haiser, H. Vlamakis, J. A. Porter and R. J. Xavier, Cell Host Microbe, 2017, 22, 25-37.

249 S. Dickert, A. J. Pierik and W. Buckel, Mol. Microbiol., 2002, 44, 49-60.

250 S. Dickert, A. J. Pierik, D. Linder and W. Buckel, Eur. J. Biochem., 2000, 267, 3874-3884.

$251 \mathrm{~W}$. Buckel, B. M. Martins, A. Messerschmidt and B. T. Golding, Biol. Chem., 2005, 386, 951-959.

252 W. Buckel, J. Zhang, P. Friedrich, A. Parthasarathy, H. Li, I. Djurdjevic, H. Dobbek and B. M. Martins, Biochim. Biophys. Acta, 2012, 1824, 1278-1290.

253 D. M. Smith, W. Buckel and H. Zipse, Angew. Chem., Int. Ed. Engl., 2003, 42, 1867-1870.

254 W. Buckel, M. Hetzel and J. Kim, Curr. Opin. Chem. Biol., 2004, 8, 462-467.

255 K. P. Locher, M. Hans, A. P. Yeh, B. Schmidt, W. Buckel and D. C. Rees, J. Mol. Biol., 2001, 307, 297-308.

256 S. H. Knauer, W. Buckel and H. Dobbek, Biochemistry, 2012, 51, 6609-6622.

257 J. Kim, Y. Lu and W. Buckel, C. R. Chim., 2007, 10, 742-747.

258 J. Kim, M. Hetzel, C. D. Boiangiu and W. Buckel, FEMS Microbiol. Rev., 2004, 28, 455-468.

259 H. Schindelin, C. Kisker, J. L. Schlessman, J. B. Howard and D. C. Rees, Nature, 1997, 387(6631), 370-376.

260 M. Hans, W. Buckel and E. Bill, J. Biol. Inorg Chem., 2008, 13, 563-574.

261 J. Kim, D. Darley and W. Buckel, FEBS J., 2005, 272, 550561.

262 S. H. Knauer, W. Buckel and H. Dobbek, J. Am. Chem. Soc., 2011, 133, 4342-4347.

263 M. Hans, W. Buckel and E. Bill, Eur. J. Biochem., 2000, 267, 7082-7093.

264 H. R. Hayward and T. C. Stadtman, J. Bacteriol., 1959, 78, 557-561.

265 C. Bradbeer, J. Biol. Chem., 1965, 240, 4669-4674.

266 D. H. Lang, C. K. Yeung, R. M. Peter, C. Ibarra, R. Gasser, K. Itagaki, R. M. Philpot and A. E. Rettie, Biochem. Pharmacol., 1998, 56, 1005-1012.

267 Z. Wang, E. Klipfell, B. J. Bennett, R. Koeth, B. S. Levison, B. Dugar, A. E. Feldstein, E. B. Britt, X. Fu, Y. M. Chung, Y. Wu, P. Schauer, J. D. Smith, H. Allayee, W. H. Tang, J. A. DiDonato, A. J. Lusis and S. L. Hazen, Nature, 2011, 472, 57-63.

268 W. H. Tang, Z. Wang, B. S. Levison, R. A. Koeth, E. B. Britt, X. Fu, Y. Wu and S. L. Hazen, N. Engl. J. Med., 2013, 368, 1575-1584.

269 Z. Wang, W. H. Tang, J. A. Buffa, X. Fu, E. B. Britt, R. A. Koeth, B. S. Levison, Y. Fan, Y. Wu and S. L. Hazen, Eur. Heart J., 2014, 35, 904-910. 
270 M. Dambrova, G. Latkovskis, J. Kuka, I. Strele, I. Konrade, S. Grinberga, D. Hartmane, O. Pugovics, A. Erglis and E. Liepinsh, Exp. Clin. Endocrinol. Diabetes, 2016, 124, 251-256.

271 S. H. Zeisel and M. Warrier, Annu. Rev. Nutr., 2017, 37, 157181.

272 Y. M. Chen, Y. Liu, R. F. Zhou, X. L. Chen, C. Wang, X. Y. Tan, L. J. Wang, R. D. Zheng, H. W. Zhang, W. H. Ling and H. L. Zhu, Sci. Rep., 2016, 6, 19076.

273 S. C. Mitchell and R. L. Smith, Drug Metab. Dispos., 2001, 29, 517-521.

274 K. A. Romano, A. Martinez-Del Campo, K. Kasahara, C. L. Chittim, E. I. Vivas, D. Amador-Noguez, E. P. Balskus and F. E. Rey, Cell Host Microbe, 2017, 22, 279-290.

275 S. Craciun and E. P. Balskus, Proc. Natl. Acad. Sci. U. S. A., 2012, 109, 21307-21312.

276 S. Craciun, J. A. Marks and E. P. Balskus, ACS Chem. Biol., 2014, 9, 1408-1413.

277 A. Martinez-del Campo, S. Bodea, H. A. Hamer, J. A. Marks, H. J. Haiser, P. J. Turnbaugh and E. P. Balskus, mBio, 2015, 6(2), e00042-15.

278 S. Bodea, M. A. Funk, E. P. Balskus and C. L. Drennan, Cell Chem. Biol., 2016, 23, 1206-1216.

279 J. A. Krzycki, Curr. Opin. Chem. Biol., 2004, 8, 484-491.

280 L. Paul, D. J. Ferguson and J. A. Krzycki, J. Bacteriol., 2000, 182, 2520-2529.

281 J. F. Brugère, G. Borrel, N. Gaci, W. Tottey, P. W. O'Toole and C. Malpuech-Brugère, Gut Microbes, 2014, 5, 5-10.

282 J. F. Brugère, G. Borrel, P. W. O'Toole, C. Malpuech-Brugère and M. Alric, US Pat., US20160074440A1, 2016.

283 S. Hafiz and C. L. Oakley, J. Med. Microbiol., 1976, 9, 129136.

284 L. D'Ari and H. A. Barker, Arch. Microbiol., 1985, 143, 311312.

285 L. F. Dawson, R. A. Stabler and B. W. Wren, J. Med. Microbiol., 2008, 57, 745-749.

286 L. F. Dawson, E. H. Donahue, S. T. Cartman, R. H. Barton, J. Bundy, R. McNerney, N. P. Mintn and B. W. Wren, BMC Microbiol., 2011, 11, 86.

287 R. A. Stabler, M. He, L. Dawson, M. Martin, E. Valiente, C. Corton, T. D. Lawley, M. Sebaihia, M. A. Quail, G. Rose, D. N. Gerding, M. Gibert, M. R. Popoff, J. Parkhill, G. Dougan and B. W. Wren, Genome Biol., 2009, 10, R102.

288 B. Bammens, P. Evenepoel, H. Keuleers, K. Verbeke and Y. Vanrenterghem, Kidney Int., 2006, 69, 1081-1087.

289 J. Poveda, M. D. Sanchez-Nino, G. Glorieux, A. B. Sanz, J. Egido, R. Vanholder and A. Ortiz, Nephrol., Dial., Transplant., 2014, 29, 56-64.

290 T. Selmer and P. I. Andrei, Eur. J. Biochem., 2001, 268, 13631372.

291 L. Yu, M. Blaser, P. I. Andrei, A. J. Pierik and T. Selmer, Biochemistry, 2006, 45, 9584-9592.

292 B. M. Martins, M. Blaser, M. Feliks, G. M. Ullmann, W. Buckel and T. Selmer, J. Am. Chem. Soc., 2011, 133, 14666-14674.
293 M. Blaser, Activation and Regulation of the 4hydroxyphenylacetate decarboxylase system from Clostridium difficile, Ph.D. thesis, Philipps-Universit at Marburg, Marburg, Germany, 2006.

294 P. I. Andrei, A. J. Pierik, S. Zauner, L. C. Andrei-Selmer and T. Selmer, Eur. J. Biochem., 2004, 271, 2225-2230.

295 B. Selvaraj, A. J. Pierik, E. Bill and B. M. Martins, J. Biol. Inorg Chem., 2014, 19, 1317-1326.

296 M. Feliks, B. M. Martins and G. M. Ullmann, J. Am. Chem. Soc., 2013, 135, 14574-14585.

297 L. Altieri, C. Neri, R. Sacco, P. Curatolo, A. Benvenuto, F. Muratori, E. Santocchi, C. Bravaccio, C. Lenti, M. Saccani, R. Rigardetto, M. Gandione, A. Urbani and A. M. Persico, Biomarkers, 2011, 16, 252-260.

298 A. M. Persico and V. Napolioni, Neurotoxicol. Teratol., 2012, 36, 82-90.

299 E. Bone, A. Tamm and M. Hill, Am. J. Clin. Nutr., 1976, 29, 1448-1454.

300 M. T. Yokoyama and J. R. Carslon, Appl. Environ. Microbiol., 1981, 41, 71-76.

301 E. Y. Hsiao, S. W. McBride, S. Hsien, G. Sharon, E. R. Hyde, T. McCue, J. A. Codelli, J. Chow, S. E. Reisman, J. F. Petrosino, P. H. Patterson and S. K. Mazmanian, Cell, 2013, 155, 1451-1463.

302 H. A. Krebs and K. Henseleit, Hoppe-Seyler's Z. Physiol. Chem., 1932, 210, 33-66.

303 I. D. Weiner, W. E. Mitch and J. M. Sands, Clin. J. Am. Soc. Nephrol., 2014, 10, 1444-1458.

304 W. J. Visek, Fed. Proc., 1972, 31, 1178-1193.

305 M. J. Maroney and S. Ciurli, Chem. Rev., 2014, 114, 42064228.

306 J. Ni, T.-C. D. Shen, E. Z. Chen, K. Bittinger, A. Bailey, M. Roggiani, A. Sirota-Madi, E. S. Friedman, L. Chau, A. Lin, I. Nissim, J. Scott, A. Lauder, C. Hoffman, G. Rivas, L. Albenberg, R. N. Baldassano, J. Braun, R. J. Xavier, C. B. Clish, M. Yudkoff, H. Li, M. Goulian, F. D. Bushman, J. D. Lewis and G. D. Wu, Sci. Transl. Med., 2017, 9, eaah6888.

307 M. Romero-Gomez, M. Jover, J. J. Galan and A. Ruiz, Metab. Brain Dis., 2009, 24, 147-157.

308 D. J. Kang, N. S. Betrapally, S. A. Ghosh, R. B. Sartor, P. B. Hylemon, P. M. Gillvet, A. J. Sanyal, D. M. Heuman, D. Carl, H. Zhou, R. Liu, X. Wang, J. Yang, C. Jiao, J. Herzog, H. R. Lippman, M. Sikaroodi, R. R. Brown and J. S. Bajaj, Hepatology, 2016, 64, 1232-1248.

309 R. A. Burne and Y.-Y. M. CHen, Microbes Infect., 2000, 2, 533-542.

310 D. T. Smoot, H. L. T. Mobley, G. R. Chippendale, J. F. Lewison and J. H. Resau, Infect. Immun., 1990, 58, 1992-1994.

311 I. Konieczna, P. Zarnowiec, M. Kwinkowski, B. Kolesińska, J. Frączyk, Z. Kamiński and W. Kaca, Curr. Protein Pept. Sci., 2012, 13, 789-806.

312 R. L. Blakeley, J. A. Hinds, H. E. Kunze, E. C. Webb and B. Zerner, Biochemistry, 1969, 8, 1991-2000.

313 E. Jabri, M. B. Carr, R. P. Hausinger and P. A. Karplus, Science, 1995, 268, 998-1004. 
314 S. Benini, W. R. Rypniewski, K. S. Wilson, S. Miletti, S. Ciurli and S. Mangani, Structure, 1999, 7, 205-216.

315 M. A. Pearson, R. A. Schaller, L. O. Michel, P. A. Karplus and R. P. Hausinger, Biochemistry, 1998, 37, 6214-6220.

316 S. Benini, W. R. Rypniewski, K. S. Wilson, S. Miletti, S. Ciurli and S. Mangani, J. Biol. Inorg Chem., 2000, 5, 110-118.

317 S. Benini, W. R. Rypniewski, K. S. Wilson, S. Mangani and S. Ciurli, J. Am. Chem. Soc., 2004, 126, 3714-3715.

318 J. L. Boer, S. B. Mulrooney and R. P. Hausinger, Arch. Biochem. Biophys., 2014, 544, 142-152.

319 N. E. Dixon, C. Gazzola, R. L. Blakeley and B. Zerner, J. Am. Chem. Soc., 1975, 97, 4131-4133.

320 G. J. King and B. Zerner, Inorg. Chim. Acta, 1997, 255, 381388.

321 I.-S. Park and R. P. Hausinger, Biochemistry, 1996, 35, 53455352.

322 B. Zambelli, F. Musiani, S. Benini and S. Ciurli, Acc. Chem. Res., 2011, 44, 520-530.

323 M. A. Farrugia, L. Macomber and R. P. Hausinger, J. Biol. Chem., 2013, 288, 13178-13185.

324 E. L. Carter, N. Flugga, J. L. Boer, S. B. Mulrooney and R. P. Hausinger, Metallomics, 2009, 1, 207-221.

325 Z. Chang, J. Kuchar and R. P. Hausinger, J. Biol. Chem., 2004, 279, 15305-15313.

326 M. A. Farrugia, L. Han, Y. Zhong, J. L. Boer, B. T. Ruotolo and R. P. Hausinger, J. Am. Soc. Mass Spectrom., 2013, 24, 1328-1337.

327 Y. H. Fong, H. C. Wong, M. H. Yuen, P. H. Lau, Y. W. Chen and K. B. Wong, PLoS Biol., 2013, 11, e1001678.

328 Y. H. Fong, H. C. Wong, C. P. Chuck, Y. W. Chen, H. Sun and K. B. Wong, J. Biol. Chem., 2011, 286, 43241-43249.

329 X. Yang, H. Li, T. P. Lai and H. Sun, J. Biol. Chem., 2015, 290, 12474-12485.

330 R. Shi, C. Munger, A. Asinas, S. L. Benoit, E. Miller, A. Matte, R. J. Maier and M. Cygler, Biochemistry, 2010, 49, 7080-7088.

331 M. Stola, F. Musiani, S. Marngani, P. Turano, N. Safarov, B. Zambelli and S. Ciurli, Biochemistry, 2006, 45, 6495-6509.

332 K. Banaszak, V. Martin-Diaconescu, M. Bellucci, B. Zambelli, W. Rypniewski, M. J. Maroney and S. Ciurli, Biochem. J., 2012, 441, 1017-1026.

333 B. Zambelli, A. Berardi, V. Martin-Diaconescu, L. Mazzei, F. Musiani, M. J. Maroney and S. Ciurli, J. Biol. Inorg Chem., 2014, 19, 319-334.

334 V. Martin-Diaconescu, C. A. Joseph, J. L. Boer, S. B. Mulrooney, R. P. Hausinger and M. J. Maroney, J. Biol. Inorg Chem., 2017, 22, 497-503.

335 L.-T. Hu and H. L. T. Mobley, Infect. Immun., 1993, 61, 25632569.

336 K. A. Higgins, C. E. Carr and M. J. Maroney, Biochemistry, 2012, 51, 7816-7832.

337 H. de Reuse, D. Vinella and C. Cavazza, Front. Cell. Infect. Microbiol., 2013, 3, 94.

338 H. Q. Hu, R. C. Johnson, D. S. Merrell and M. J. Maroney, Biochemistry, 2017, 56, 1105-1116.
339 W. N. Fishbein and P. P. Carbone, J. Biol. Chem., 1965, 240, 2407-2414.

340 Z. Amtul, A. Rahman, R. A. Siddiqui and M. I. Choudhary, Curr. Med. Chem., 2002, 9, 1323-1348.

341 C. Follmer, J. Clin. Pathol., 2010, 63, 424-430.

342 T.-C. D. Shen, L. Albenberg, K. Bittinger, C. Chehoud, Y.-Y. Chen, C. A. Judge, L. Chau, J. Ni, M. Sheng, A. Lin, B. J. Wilkins, E. L. Buza, J. D. Lewis, Y. Daikhin, I. Nissim, M. Yudkoff, F. D. Bushman and G. D. Wu, J. Clin. Invest., 2015, 125, 2841-2850.

343 T.-C. D. Shen, C. Chehoud, J. Ni, E. Hsu, Y.-Y. Chen, A. Bailey, A. Laughlin, K. Bittinger, F. D. Bushman and G. D. Wu, PLoS One, 2016, 11, e0155620.

344 L. A. David, C. F. Maurice, R. N. Carmody, D. B. Gootenberg, J. E. Button, B. E. Wolfe, A. V. Ling, A. S. Devlin, Y. Varma, M. A. Fischbach, S. B. Biddinger, R. J. Dutton and P. J. Turnbaugh, Nature, 2014, 505, 559-563.

345 S. Devkota, Y. Wang, M. W. Musch, V. Leone, H. FehlnerPeach, A. Nadimpalli, D. A. Antonopoulos, B. Jabri and E. B. Chang, Nature, 2012, 487, 104-108.

346 S. Devkota and E. B. Chang, Digestive diseases, 2015, 33, 351-356.

347 J. M. Ridlon, P. G. Wolf and H. R. Gaskins, Gut Microbes, 2016, 7, 201-215.

348 S. M. Houten, M. Watanabe and J. Auwerx, EMBO J., 2006, 25, 1419-1425.

349 P. B. Hylemon, H. Zhou, W. M. Pandak, S. Ren, G. Gil and P. Dent, J. Lipid Res., 2009, 50, 1509-1520.

350 S. Mukhopadhyay and U. Maitra, Curr. Sci., 2004, 87, 16661683.

351 M. Begley, C. G. Gahan and C. Hill, FEMS Microbiol. Rev., 2005, 29, 625-651.

352 J. M. Ridlon, D. J. Kang and P. B. Hylemon, J. Lipid Res., 2006, 47, 241-259.

353 H. Laue, K. Denger and A. M. Cook, Appl. Environ. Microbiol., 1997, 63, 2016-2021.

354 J. Levine, C. J. Ellis, J. K. Furne, J. Springfield and M. D. Levitt, Am. J. Gastroenterol., 1998, 93, 83-87.

355 G. R. Gibson, J. H. Cummings and G. T. Macfarlane, FEMS Microbiol. Ecol., 1991, 86, 103-132.

356 M. C. L. Pitcher and J. H. Cummings, Gut, 1996, 39, 1-4.

357 W. Babidge, S. Millard and W. Roediger, Mol. Cell. Biochem., 1998, 118, 117-124.

358 T. W. Miller, E. A. Wang, S. Gould, E. V. Stein, S. Kaur, L. Lim, S. Amarnath, D. H. Fowler and D. D. Roberts, J. Biol. Chem., 2012, 287, 4211-4221.

359 J. L. Wallace, L. Vong, W. McKnight, M. Dicay and G. R. Martin, Gastroenterology, 2009, 137, 569-578.

360 I. Fasolino, A. A. Izzo, T. Clavel, B. Romano, D. Haller and F. Borrelli, Mol. Nutr. Food Res., 2015, 59, 434-442.

361 J. P. Motta, K. L. Flannigan, T. A. Agbor, J. K. Beatty, R. W. Blackler, M. L. Workentine, G. J. Da Silva, R. Wang, A. G. Buret and J. L. Wallace, Inflammatory Bowel Dis., 2015, 21, 1006-1017.

362 H. Laue, M. Friedrich, J. Ruff and A. M. Cook, J. Bacteriol., 2001, 183, 1727-1733. 
363 T. F. Oliveira, C. Vonrhein, P. M. Matias, S. S. Venceslau, I. A. Pereira and M. Archer, J. Biol. Chem., 2008, 283, 34141-34149.

364 S. S. Venceslau, Y. Stockdreher, C. Dahl and I. A. Pereira, Biochim. Biophys. Acta, 2014, 1837, 1148-1164.

365 S. M. Lui, A. Soriano and J. A. Cowan, J. Am. Chem. Soc., 1993, 115, 10483-10486.

366 S. M. Lui, W. Liang, A. Soriano and J. A. Cowan, J. Am. Chem. Soc., 1994, 116, 4531-4536.

367 B. R. Crane and E. D. Getzoff, Curr. Opin. Struct. Biol., 1996, 6, 744-756.

368 I. Moura, J. LeGall, A. R. Lino, J. H. D. Peck, G. Fauque, A. V. Xavier, D. V. DerVartanian, J. J. G. Moura and B. H. Huynh, J. Am. Chem. Soc., 1988, 110, 1075-1082.

369 A. A. Santos, S. S. Venceslau, F. Grein, W. D. Leavitt, C. Dahl, D. T. Johnston and I. A. C. Pereira, Science, 2015, 350, 1541-1545.

370 F. Grein, I. A. Pereira and C. Dahl, J. Bacteriol., 2010, 192, 6369-6377.

371 F. Grein, A. R. Ramos, S. S. Venceslau and I. A. Pereira, Biochim. Biophys. Acta, 2013, 1827, 145-160.

372 Y. Seki and M. Ishimoto, J. Biochem., 1979, 86, 273-276.

373 Y. Seki, N. Sogawa and M. Ishimoto, J. Biochem., 1981, 90, 1487-1492.

374 P. Spanogiannopoulos, E. N. Bess, R. N. Carmody and P. J. Turnbaugh, Nat. Rev. Microbiol., 2016, 14, 273-287.

375 N. Koppel, V. Maini Rekdal and E. P. Balskus, Science, 2017, 356(6344), eaag2770.

376 M. K. Ma and H. K. McLeod, Curr. Med. Chem., 2003, 10, 4149.

377 E. M. Cooke, Gut, 1969, 10, 565-568.

378 M. A. Peppercorn, Ann. Intern. Med., 1984, 3, 377-386.

379 G. L. Plosker and K. F. Croom, Drugs, 2005, 65, 1825-1849.

380 H. Zheng, M. Chen, Y. Li, Y. Wang, L. Wei, Z. Liao, M. Wang, F. Ma, Q. Liao and Z. Xie, Front. Microbiol., 2017, 8, 1703.
381 H. J. Haiser, D. B. Gootenberg, K. Chatman, G. Sirasani, E. P. Balskus and P. J. Turnbaugh, Science, 2013, 341, 295-298.

382 H. J. Haiser, K. L. Seim, E. P. Balskus and P. J. Turnbaugh, Gut Microbes, 2014, 5, 233-238.

383 N. Koppel, J. E. Bisanz, M.-E. Pandelia, P. J. Turnbaugh and E. P. Balskus, eLife, 2018, 7, e33953.

384 J. P. Yuan, J. H. Wang and X. Liu, Mol. Nutr. Food Res., 2007, 51, 765-781.

385 I. R. Rowland, H. Wiseman, T. A. Sanders, H. Adlercreutz and E. A. Bowey, Nutr. Cancer, 2000, 36, 27-32.

386 Y. Shimada, M. Takahashi, N. Miyazawa, T. Ohtani, Y. Abiru, S. Uchiyama and H. Hishigaki, J. Mol. Microbiol. Biotechnol., 2011, 21, 160-172.

387 H. Tsuji, K. Moriyama, K. Nomoto and H. Akaza, Appl. Environ. Microbiol., 2012, 78, 1228-1236.

388 C. Schröder, A. Matthies, W. Engst, M. Blaut and A. Braune, Appl. Environ. Microbiol., 2013, 79, 3494-3502.

389 Y. Kawada, S. Yokoyama, E. Yanase, T. Niwa and T. Suzuki, Biosci. Microbiota, Food Health, 2016, 35, 113-121.

390 R. D. Finn, P. Coggill, R. Y. Eberhardt, S. R. Eddy, J. Mistry, A. L. Mitchell, S. C. Potter, M. Punta, M. Qureshi, A. Sangrador-Vegas, G. A. Salazar, J. Tate and A. Bateman, Nucleic Acids Res., 2016, 44, D279-D285.

391 M. D. Mayers, C. Moon, G. S. Stupp, A. I. Su and D. W. Wolan, J. Proteome Res., 2017, 16, 1014-1026.

392 J. Kaminski, M. K. Gibson, E. A. Franzosa, N. Segata, G. Dantas and C. Huttenhower, PLoS Comput. Biol., 2015, 11, e1004557.

393 J. A. Gerlt, J. T. Bouvier, D. B. Davidson, H. J. Imker, B. Sadkhin, D. R. Slater and K. L. Whalen, Biochim. Biophys. Acta, 2015, 1854, 1019-1037.

394 P. Cimermancic, M. H. Medema, J. Claesen, K. Kurita, L. C. Wieland Brown, K. Mavrommatis, A. Pati, P. A. Godfrey, M. Koehrsen, J. Clardy, B. W. Birren, E. Takano, A. Sali, R. G. Linington and M. A. Fischbach, Cell, 2014, 158, 412-421. 